\title{
All Rodents Are Not the Same: A Modern Synthesis of Cortical Organization
}

\author{
Leah Krubitzera, ${ }^{a}$ Katharine L. Campi ${ }^{a, b}$ Dylan F. Cooke \\ ${ }^{a}$ Center for Neuroscience and ${ }^{b}$ Department of Psychology, University of California, Davis, Calif., USA
}

\section{Key Words}

Rats $\cdot$ Mice $\cdot$ Somatosensory cortex $\cdot$ Visual cortex .

Auditory cortex $\cdot$ Motor cortex $\cdot$ Evolution

\begin{abstract}
Rodents are a major order of mammals that is highly diverse in distribution and lifestyle. Five suborders, 34 families, and 2,277 species within this order occupy a number of different niches and vary along several lifestyle dimensions such as diel pattern (diurnal vs. nocturnal), terrain niche, and diet. For example, the terrain niche of rodents includes arboreal, aerial, terrestrial, semi-aquatic, burrowing, and rock dwelling. Not surprisingly, the behaviors associated with particular lifestyles are also highly variable and thus the neocortex, which generates these behaviors, has undergone corresponding alterations across species. Studies of cortical organization in species that vary along several dimensions such as terrain niche, diel pattern, and rearing conditions demonstrate that the size and number of cortical fields can be highly variable within this order. The internal organization of a cortical field also reflects lifestyle differences between species and exaggerates behaviorally relevant effectors such as vibrissae, teeth, or lips. Finally, at a cellular level, neuronal number and density varies for the same cortical field in different species and is even different for the same species reared in different conditions (laboratory vs. wild-caught).
\end{abstract}

These very large differences across and within rodent species indicate that there is no generic rodent model. Rather, there are rodent models suited for specific questions regarding the development, function, and evolution of the neocortex.

Copyright $\odot 2011$ S. Karger AG, Basel

\section{Introduction}

Rodents are the most widely used animal models for studies of brain organization, function, development, and evolution. Experiments on mice and rats account for over $40 \%$ of all studies of the brain and neural function [Manger et al., 2008]. Thus, it is not surprising that, from an experimental standpoint, when we refer to rodent models we almost inevitably think of mice or rats. In many cases, at least with the current technologies, experiments could not be done except in a species such as the mouse with well-explored genetics and available knockouts. In other experiments, however, mice and rats may be poor choices or not the appropriate model. This extreme bias in animal selection, especially for under-

\section{K.L. Campi and D.F. Cooke contributed equally to this work.}

\section{KARGER}

() 2011 S. Karger AG, Basel

Fax +4161306 1234

E-Mail karger@karger.ch

www.karger.com
Accessible online at: www.karger.com/bbe
Leah Krubitzer

Center for Neuroscience, University of California, Davis

1544 Newton Ct.

Davis, CA 95618 (USA)

Tel. +1 530757 8868, E-Mail lakrubitzer@ucdavis.edu 


\section{Visual areas}

$\mathrm{AL} \quad$ anterolateral area; part of $18 \mathrm{a}$, see V2 (rat; fig. 8b)

AM anteromedial area; part of $18 \mathrm{~b}$ (rat; fig. $8 \mathrm{~b}$ )

L lateral area; lateral to V3 and ML; with ML, possibly homologous to primate middle temporal area, MT (squirrel; fig. 8d)

LI laterointermediate area; perhaps homologous to part of V3 (rat; fig. 8b)

LL laterolateral area; perhaps homologous to part of V3 (rat; fig. 8b)

LM lateromedial area; encompasses part or all of 18a, homologous to V2 (rat; fig. 8b)

ML middle lateral area; lateral to V3; with L, possibly homologous to primate middle temporal area, MT (squirrel; fig. 8d)

Oc1 area occipitalis 1; Zilles' term for area 17 (rat, mouse; fig. 4)

Oc2.1 area occipitalis 2.1; Zilles' term for area 18a (rat, mouse; fig. 4)

OTc occipital temporal caudal area or V3 (squirrel; fig. 4, 10)

OTr occipital temporal rostral area or V3 (squirrel; fig. 4, 10)

PM posteromedial area; part of $18 \mathrm{~b}$ (rat; fig. $8 \mathrm{~b}$ )

RM1-4 rostromedial areas 1-4; part of $18 \mathrm{~b}$ (mouse)

Te2 area temporalis 2; Zilles' term, similar to TP (fig. 4)

$\mathrm{Tm} \quad$ temporal mediodorsal region (squirrel; fig. 4)

TP temporal posterior area; similar to Te2 (fig. 10)

V1 primary visual area; coextensive with area 17 (fig. 8, 10)

V2 second visual area; coextensive with area $18 \mathrm{a}$ (fig. 8,10 )

V2M medial secondary visual area; part of $18 \mathrm{~b}$ (mouse)

V3 third visual area (mice, squirrels; fig. 8a, d)

Vm medial visual area; coextensive with 18/18b (hamster; fig. 8c)

Vmc medial visual area; caudal subdivision, part of $18 \mathrm{~b}$ (mouse; fig. 8a)

$\mathrm{Vmr} \quad$ medial visual area; rostral subdivision, part of $18 \mathrm{~b}$ (mouse; fig. 8a)

\section{Auditory areas}

A1 primary auditory area; with $\mathrm{AAF} / \mathrm{R}$, part of auditory core (fig. 12)

A2/AII second auditory area (mouse, guinea pig; fig. 12a)

AAF anterior auditory field, also termed R; with A1, part of auditory core (mouse, rat, gerbil; fig. 12a, c, d)

AV anteroventral field (gerbil; fig. 12d)

D dorsal field (gerbil; fig. 12d)

DC dorsocaudal auditory area (guinea pig; fig. 12b)

DCB dorsocaudal belt (guinea pig; fig. 12b)

DP dorsoposterior field (gerbil, mouse; fig. 12a, d)

DRB dorsorostral belt (guinea pig; fig. 12b)

PAF posterior auditory field (rat; fig. 12c)

$\mathrm{R} \quad$ rostral field; rostral to A1, also termed AAF; with A1, part of auditory core (squirrel; fig. 12f)

SRAF suprarhinal auditory field (rat; fig. 12c)

TA temporal anterior area (fig. 12f)

Tai temporal anterior intermediate area (squirrel; fig. 12f)

Tav temporal anterior ventral area (squirrel; fig. 12f)

Te1 area temporalis 1; Zilles' term for area 41 and A1+AAF (fig. 4)

TI temporal intermediate area (squirrel; fig. 4)

$\begin{array}{ll}\text { UF } & \text { ultrasonic field (mouse; fig. 12a) } \\ \text { V } & \text { ventral field (gerbil; fig. 12d) } \\ \text { VAF } & \text { ventral auditory field (rat; fig. 12c) } \\ \text { VCB } & \text { ventrocaudal belt (guinea pig; fig. 12b) } \\ \text { VP } & \text { ventroposterior field (gerbil; fig. 12d) } \\ \text { VRB } & \text { ventrorostral belt (guinea pig; fig. 12b) }\end{array}$

Somatosensory areas

DZ dysgranular zone of S1; with TZ, possibly homologous to 3a (rat; fig. 16a)

GZ granular zone; could be considered 'S1 proper' (rat;

PGZ fig. 16a)

Pm parietal medial area (fig. 19)

PV parietal ventral area (fig. 18)

$\mathrm{R} \quad$ rostral field; rostral to S1; later termed 3a (squirrel, fig. 19)

S1/SmI/SI primary somatosensory area (fig. 17)

S2/SmII/SII second somatosensory area (fig. 18)

TZ transitional zone of S1; with DZ, perhaps homologous to 3a (rat; fig. 16a)

UZ unresponsive zone in S1; perhaps homologous to or part of 3a (rat, squirrel; fig. 17)

\section{Motor areas}

AGl lateral agranular cortex (rat, mouse; fig. 22)

AGm medial agranular cortex (rat, mouse; fig. 22)

M1/MsI primary motor cortex (fig. 22)

M2 second motor area; possibly homologous/coextensive

with AGm; see also SMA

Prc1 area praecentralis 1; with Prc 2, equivalent to AGl (fig. 4)

$\operatorname{Prc} 2$ area praecentralis 2; with $\operatorname{Prc} 1$, equivalent to AGl (fig. 4)

Prc3 area praecentralis 3; with Prcm, equivalent to AGm (fig. 4)

Prcm area praecentralis, medial; with Prc3, equivalent to AGm (fig. 4)

RFA rostral forelimb area

SMA supplementary motor area; perhaps homologous with rodent AGm (primates)

Other cortical areas

F frontal area; rostral to M1 (squirrel; fig. 4)

L limbic area; rostromedial to 17 (squirrel; fig. 4)

MM multimodal cortex (squirrel; fig. 10, 13, 21, 23)

$\mathrm{Pl} \quad$ parietal lateral area (squirrel; fig. 4)

PPC posterior parietal cortex, may be homologous to Pm in squirrels (rat; fig. 10, 13, 21, 23)

Thalamic nuclei

LD lateral dorsal nucleus

LGN lateral geniculate nucleus

LP lateral posterior nucleus

Po posterior nucleus

Pom medial division of the posterior nucleus

VP ventral posterior nucleus

Other terms

ENQ encephalic neuronal quotient

M medial

$\mathrm{R} \quad$ rostral

SNQ somatic neuronal quotient 
Fig. 1. Evolutionary tree depicting the phylogenetic relationship of major orders of mammals and the cortical organization of some of the sensory fields that have been described in particular species. A comparative analysis of the neocortex using a combination of electrophysiological, anatomical, and histochemical techniques allows one to infer the organization of an unknown mammal, such as the common ancestor. If a number of species are compared, one can be fairly confident when assigning features of cortical organization, even in the absence of direct data. Certain cortical regions, such as S1, S2, A1, V1, and $\mathrm{V} 2$, are common to all mammals and most likely are homologous areas that arose from a common ancestor. All brains are oriented so that rostral is left and medial is up.

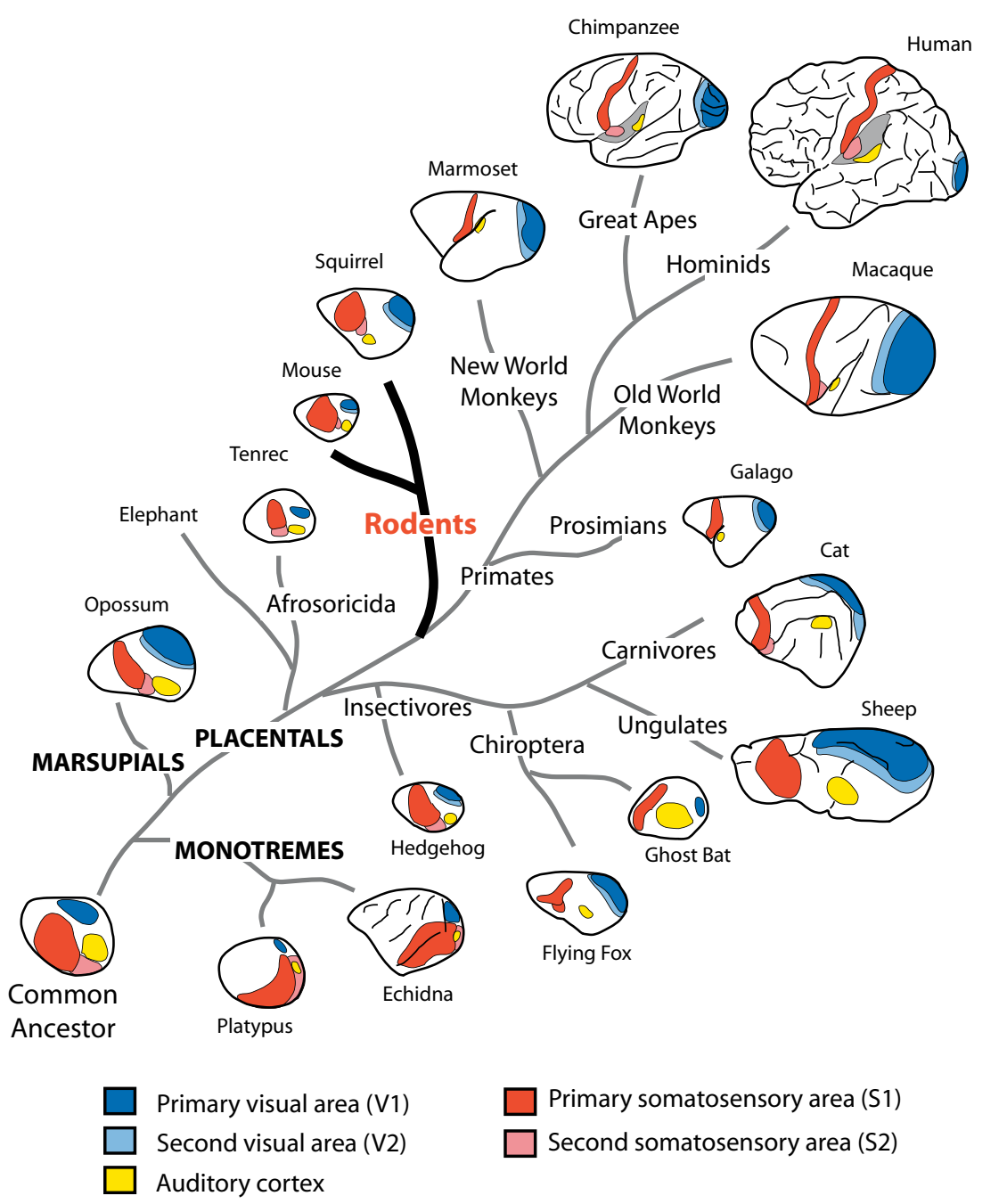

Auditory cortex standing fundamental concepts in evolution, is problematic when one is trying to infer homologous or generalized features of organization versus derived features of organization. For example, characteristics such as sensory map organization or development of neural connections that have been gleaned from these commonly used rodent models may in fact be derived features of murine rodents and of little use for understanding other species. This is complicated by the fact that the rodents that are used as experimental models are normally reared in laboratory conditions, a highly deprived environment which has been demonstrated in environmental enrichment studies to affect neurogenesis, gliogenesis, synapse number, and recovery from cortical injury [Mohammed et al.,
2002; Faherty et al., 2003; Kolb et al., 2003; Komitova et al., 2005; Steiner et al., 2006; Gelfo et al., 2009]. These developmental differences in environment could drastically affect the characteristic of interest.

Despite the lack of diversity of our experimental models, rodents are arguably the most diverse order of mammals and diverged from the lineage leading to primates some 80 million years ago (fig. 1). They are phylogenetically closer to primates than other eutherian orders such as carnivores, Chiroptera (bats), and Eulipotyphla (comprising most of what was formerly known as 'Insectivora'). The rodent order is composed of 5 suborders, 34 families, and 2,277 species, or $40 \%$ of all mammalian species. These species vary along a variety of dimensions includ- 
Fig. 2. Line drawings of representative rodent species depicting the extraordinary diversity in physical morphology in the order Rodentia. Although not drawn to scale, it should be noted that the pygmy jerboa weighs only a few grams while the beaver weighs between 18 and $27 \mathrm{~kg}$. Specialized morphologies of note are the patagium (furry membrane stretching between fore limb and hind limb) in the flying squirrel, the elongated hind limbs in the springhare and pygmy jerboa, the broad fleshy tail and webbed hind feet of the beaver, and the elongated ears of the springhare and tufted ears of the red squirrel. In addition, the characteristics of fur vary, with different adaptations for semiaquatic environments such as that of the beaver and for desert conditions that are home to the jerboa.

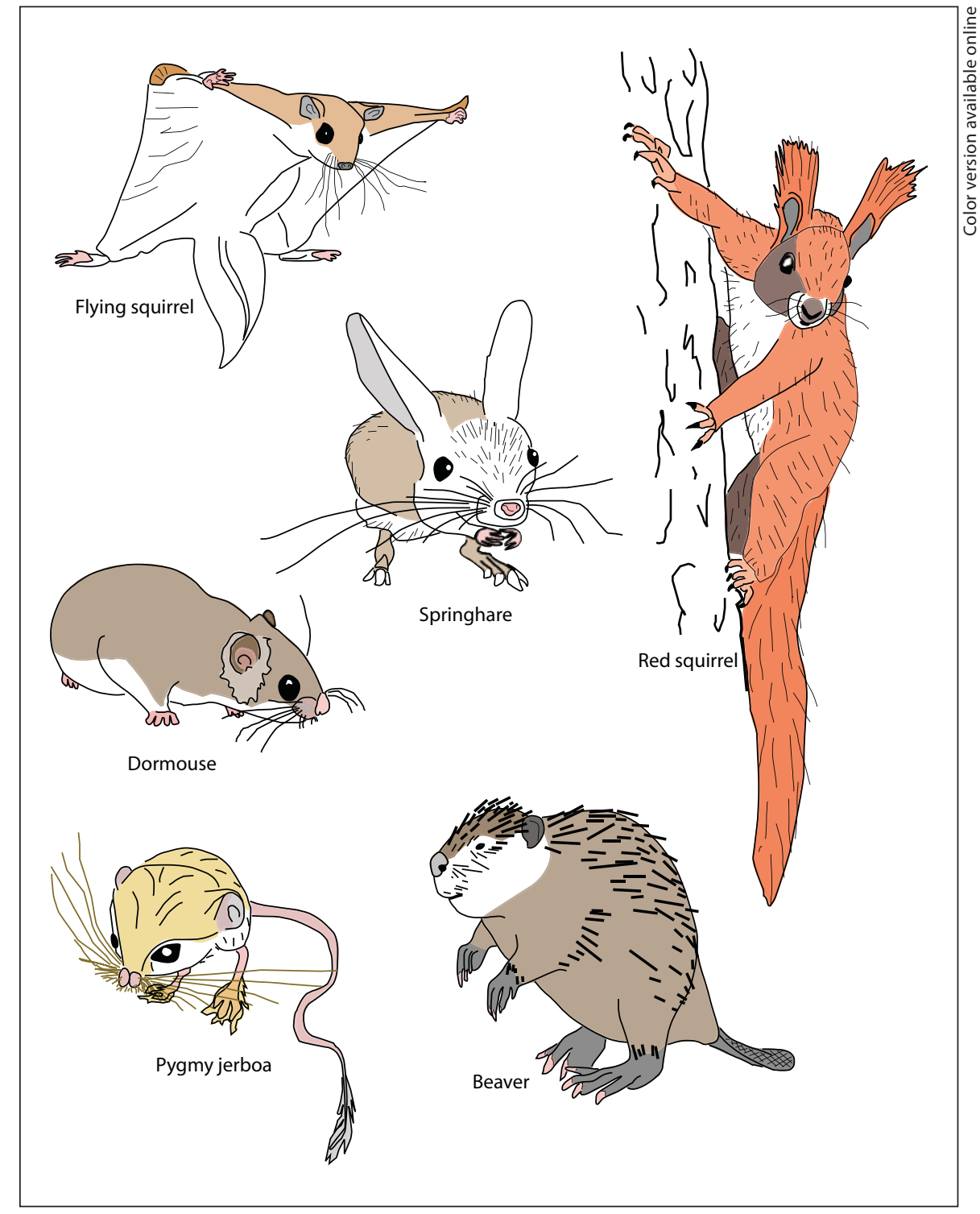

ing body size, peripheral morphology, relative brain size, diel pattern, terrain niche, diet, and sociality (fig. 2, 3). Body size ranges from a few grams for the pygmy jerboa to $65 \mathrm{~kg}$ for the capybara, rivaling differences in primates. Terrain niche varies from the subterranean Argentine tuco-tuco (Ctenomys talarum) to the aerial flying squirrels of the genus Glaucomys. Because of these extraordinary variations, rodents provide a wonderful opportunity to compare very specific aspects of neural organization as they relate to alterations in peripheral morphology, sensory specialization, and behavior.

The common ancestor of all rodents was present approximately 80 million years ago [Huchon et al., 2002,
2007; Steppan et al., 2004], and since that time rodents have diverged to occupy a variety of niches. The variation in several dimensions of lifestyle, such as diel pattern, often evolved independently in several different suborders and even families (fig. 3a). For example, starting with a nocturnal common ancestor, diurnality evolved independently in the family Sciuridae and in some species in Muridae, Cavidae, Ctenodactylidae, and Chinchillidae. Comparisons of sensory morphology, behavior, and visual system organization in tree squirrels, Nile grass rats, and guinea pigs, for example, could reveal if and how the ancestral organization shared by all rodents is modified for diurnal vision. In fact, differences in retinal morphol- 


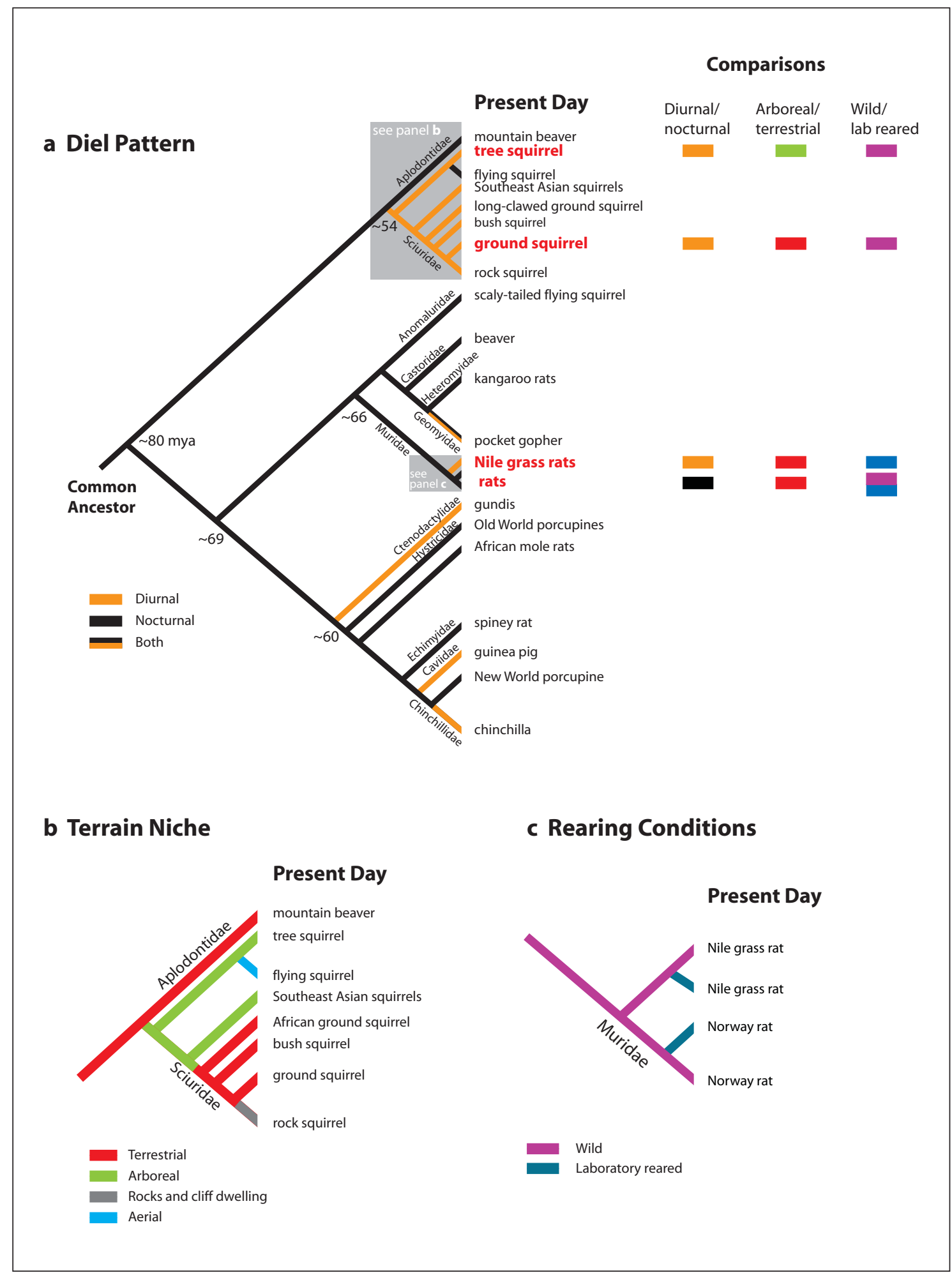

Fig. 3. Phylogenetic tree of the order Rodentia with representative individuals of different families listed with specific comparisons of diel pattern across the entire order (a), terrain niche of Sciuridae (b), and rearing condition of Muridae (c). Specific comparisons made in this review are listed on the right of $\mathbf{a}$ and color-coded for diel pattern, terrain niche, and rearing condition. Numbers at branch points in the tree are reference time in millions of years ago from the present [modified from Huchon et al., 2002, 2007; Steppan et al., 2004]. 
ogy, lateral geniculate nucleus organization, and visual cortex have been identified and related to diurnal lifestyles [e.g. Van Hooser and Nelson, 2006; Gaillard et al., 2008, 2009; Rocha et al., 2009; for review see Solovei et al., 2009]. Interestingly, relatively closely related species in the Sciuridae family, while sharing a common diurnal lifestyle, can differ dramatically in other dimensions such as terrain niche (fig. 3b), and these differences further influence brain organization. For example, squirrels are terrestrial (California ground squirrel and African ground squirrel), arboreal (tree squirrel), rock and cliff dwelling (rock squirrel), and even aerial (flying squirrel). Thus, one would expect modifications in motor cortex due to the physical demands of flight versus climbing, in auditory cortex due to the acoustic context of a subterranean versus high-altitude environment, and in visual cortex due to selection for depth perception for navigation through trees in arboreal versus terrestrial habitats.

Given their diversity and range of specializations, several important comparisons are possible within and across rodent groups. These can illuminate the basic brain organization, constraints imposed on evolving systems, and the types of modifications that have been made to the nervous system that relate to a particular lifestyle and subserve unique behaviors. For example, one can compare the brain organization of species from different suborders and families of rodents to determine which features of organization are common to all rodents due to inheritance from their common ancestor (homology). One can also compare distantly related species that have independently evolved some sensory/lifestyle specializations such as diel pattern (fig. 3a) to determine if and how this basic plan has been modified and if modifications take a similar form (homoplasy) despite independent evolution. This could help reveal what constraints are imposed on evolving systems, possibly due to latent homologies. Comparisons could also be made between relatively closely related species that have divergent lifestyles, such as terrain niche, and the sensory specializations associated with the demands of that niche (fig. 3b). This type of comparison would reveal how rapidly the brain can be altered within a lineage, the type and amplitude of change that generates phenotypic differences, and the level of organization at which the change takes place. Finally, one can compare the same species that have been exposed to radically different rearing conditions, such as wild-caught versus laboratory rodents (fig. 3c), to determine the extent to which the sensory environment present during development contributes to aspects of the cortical phenotype.
In the following review we focus on rodent neocortex, making the types of comparisons described above, and discuss differences in cortical organization in the context of lifestyle. First, we compare global features of cortical organization such as the size of sensory areas in several species of rodents. Second, we compare the organization and cellular composition of visual cortex in rodents. Third, we compare auditory cortex in relation to acoustic demands of particular physical and social environments, and finally we describe the organization of somatosensory and motor cortex in a variety of rodents. This review focuses on the architectonic and functional organization of cortical fields in normal (non-experimental) animals as revealed by cyto- and myeloarchitecture and other histological preparations as well as electrophysiological recording or intracortical microstimulation techniques. A comprehensive description of cortical and thalamic connections in rodents is well beyond the scope of this review, but some studies of connections will be described because they reveal aspects of cortical organization that are contentious in rodents. While we describe data from multiple laboratories and have tried to capture different schemes of rodent cortical organization, our review is not exhaustive. We spend more time on what we consider the strongest data, which is the foundation for our proposals of how cortex is organized within and across different rodent species.

\section{A Note on Terminology}

One of the most difficult aspects of writing a cumulative review on rodent neocortex is not only how one defines a cortical field but also how the field is named. A cortical field is defined using a variety of criteria including architectonic appearance, functional organization, and connectivity. Defining a cortical field is best done when multiple criteria are used, but frequently only a single criterion, such as cortical architecture, is utilized. Delineating cortical fields necessarily involves naming them to distinguish them from other fields and allows for communication regarding a very specific piece of cortical tissue across laboratories, animals, and time. Early studies of rodent cortex, such as those of Brodmann [1909], used cytoarchitecture to define regions within the cortex, and thus cortical areas have architectonic names such as Brodmann's area 17, 18, and 3. Subsequent studies used electrophysiological recording techniques to explore the neocortex and found that there were a number of maps of 
the sensory epithelium. These functional fields were given names such as the primary somatosensory area, SI, or primary visual area, VI. In a number of instances, architectonically defined cortical areas were found to be coextensive with functional areas and, consequently, the terminology is often used interchangeably (the primary visual area is V1 or area 17). This is complicated by the fact that sometimes the same field is termed differently in the same animals even though the same technique may have been used to identify the same architectonic area, e.g. Ocl, striate cortex, or area 17, or the same functional area, e.g. SI, SmI, or S1. Unfortunately, this makes comparisons between the same species, between different species, between laboratories, and over time very complicated. Throughout this review we have re-illustrated the primary data of a number of investigators and have used the terminology that they have coined. However, there are a number of summary diagrams throughout this review. For these figures we have consolidated the data and use consistent terminology.

\section{Gross Organization of the Sensory Neocortex in Rodents}

All behavior is generated by the nervous system, and in mammals complex behavior such as volitional motor control, perception, and cognition is subserved by the neocortex. Thus, the neocortex has been altered in different lineages to generate these complex behaviors. While some argue that these differences in the neocortex could be mainly a factor of differences in neuron number [Herculano-Houzel, 2007] in animals with different sized brains and varying degrees of behavioral complexity, other alterations such as changes in the types of neurons and glia present, connectivity, and the addition of new cortical fields are postulated to play a role as well [for review see Krubitzer, 2009]. While differences in neuron number across species with different sized neocortices has been demonstrated [Herculano-Houzel et al., 2006; Herculano-Houzel, 2011], the types of alterations that have occurred at a higher level of organization are described mainly for the changes in functional organization that have occurred within a cortical field. For example, cortical magnification of behaviorally relevant sensory morphology has been well established within primary sensory areas (see below). In contrast, studies whose purpose was to carefully prepare brains to measure differences in brain parts or cortical field size either within or across species (rather than gleaned from exist- ing data) are less common [Karlen and Krubitzer, 2006; Campi and Krubitzer, 2010].

There have been several studies in which architectonic distinctions were used to delineate cortical fields for the entire neocortex in species such as mice [Caviness, 1975; Wree et al., 1983], rats [Zilles, 1980; Campi and Krubitzer, 2010], guinea pigs [Wree et al., 1981], and squirrels [Brodmann, 1909; Wong and Kaas, 2008; Campi and Krubitzer, 2010 (fig. 4)], and a number of these architectonically defined fields have been directly related to functional boundaries using electrophysiological recording techniques (see below). While there are differences in nomenclature, the findings across laboratories and species show a number of similarities. All species have a granular, heavily myelinated primary somatosensory area ( $\mathrm{S} 1, \mathrm{Sm} 1$, or 3$)$, a clearly defined primary visual cortex (V1, area 17, or Oc1), and a granular, densely myelinated auditory core $\mathrm{A} 1+\mathrm{AAF}(\mathrm{A} 1+\mathrm{R}, \mathrm{Te} 1$, or 41$)$. The location and architecture of a second somatosensory region (S2+PV, SmII, or 40) and a second visual area (V2, 18/18a, or Oc2) have also been distinguished. Motor cortex has been divided into a lateral region termed the lateral agranular cortex (AGl, M1, Prc1+Prc2, or 4) and a medial division (Agm, Prcm+Prc3, or SMA). Additional auditory, somatosensory, and visual areas were also defined and will be described in subsequent sections. These subdivisions conform to similar subdivisions in other mammals (fig. 1) and form a basic plan of cortical organization of rodents in particular and mammals in general. Because of the ubiquity of these fields, they were likely to be present in the ancestor of all rodents and all mammals.

In recent comparative studies of myeloarchitecture in our laboratory, we measured the area of a number of welldefined cortical fields in several species of rodents [Campi et al., 2007, 2011; Campi and Krubitzer, 2010] including tree squirrels (Sciurus carolinensis), ground squirrels (Spermophilus beecheyi), wild-caught rats and laboratory rats (Rattus norvegicus), and Nile grass rats (Arvicanthis niloticus; fig. 5). These studies provided an opportunity to make several interesting comparisons within the order Rodentia (fig. 3). First, we compared diurnal rodents (both species of squirrels as well as Nile grass rats) with nocturnal (Norway rats) rodents. Second, we compared arboreal (tree squirrel) and terrestrial (ground squirrel) squirrels. Finally, we compared wild-caught animals (squirrels and $R$. norvegicus) with laboratory animals ( $R$. norvegicus and Nile grass rat). Measures of the brain, the body, the dorsolateral cortical sheet, and individual cortical fields revealed several interesting findings. First, wild-caught rats had a relatively larger brain (as a fraction 


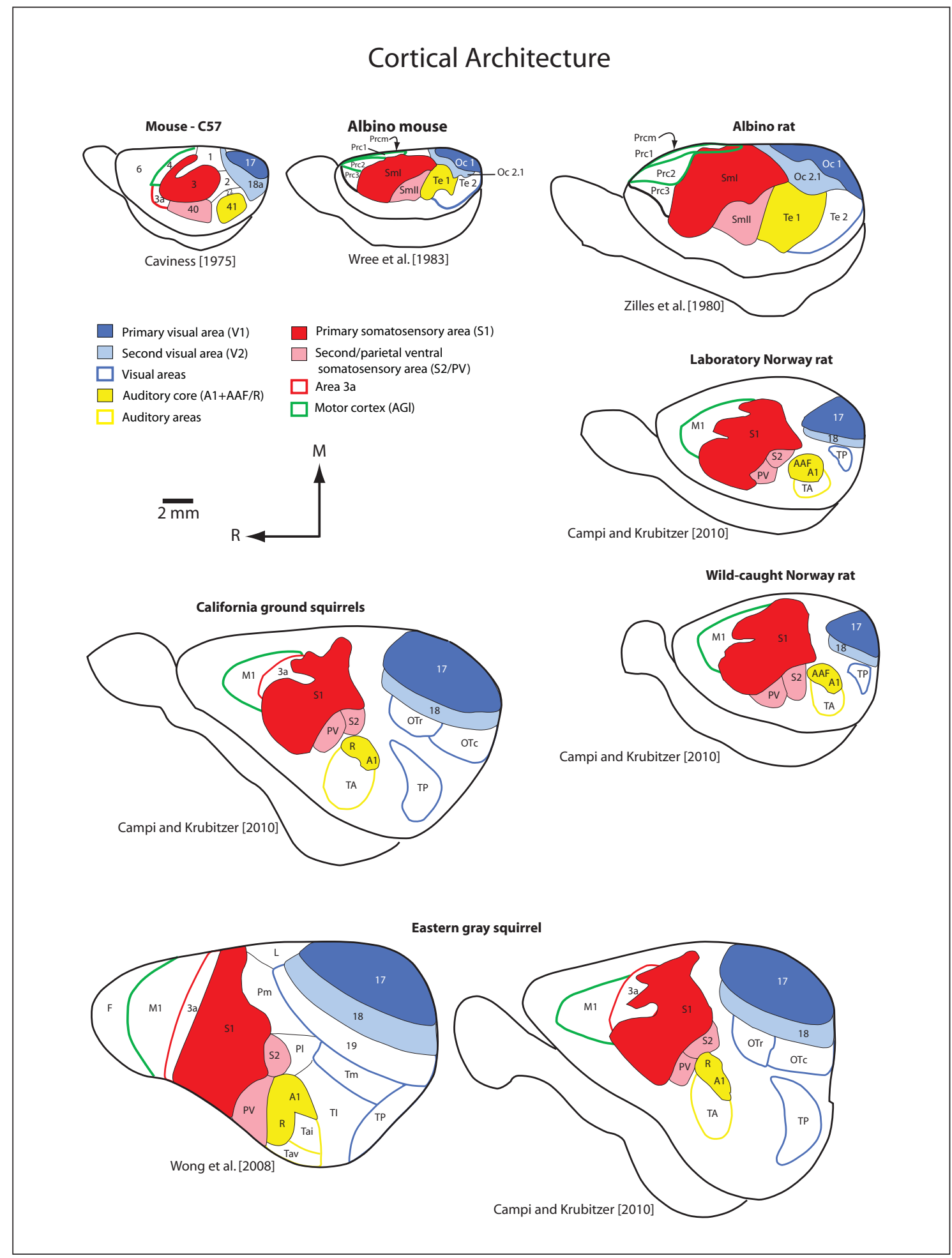

Fig. 4. Schematic representations of cortical architecture from selected studies in mice, rats, and squirrels depicting architectonic subdivisions of sensory cortex. Although nomenclature varies (it is that of the original authors), putative homologous areas have been color-coded for ease of comparison. Rostral is left; medial is up. All drawings are to scale. 


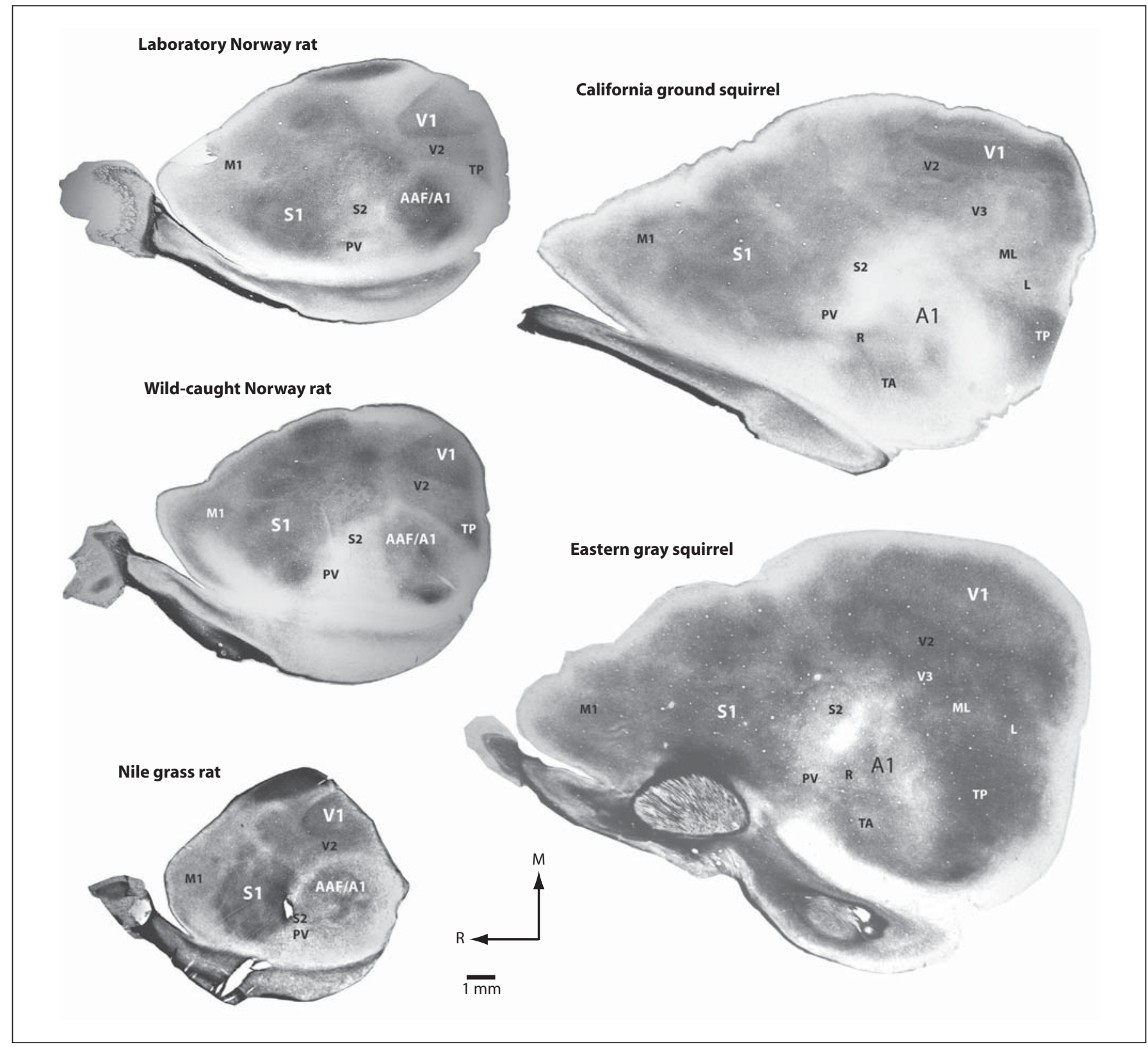

Fig. 5. Myeloarchitecture in flattened cortical sections from 5 rodent species. Photomicrographs of 1 section from each species are shown; any individual section does not show all cortical field boundaries. In all of these sections S1 and V1 can be readily identified. The auditory core is most clearly observed in the sections representing rats but can be identified in the other species when other sections from a series are examined. Conventions are as in previous figures [taken from Campi and Krubitzer, 2010; Campi et al., 2011]. of body weight) than did the laboratory rats, and tree squirrels had a relatively larger brain than did all rodents (as a fraction of body weight; fig. 6a). Squirrels had a larger encephalization quotient (EQ; the measured brain mass compared to the predicted brain mass based on body mass) than did rat groups, and tree squirrels had a higher EQ than did ground squirrels (fig. 6b). For measures of individual cortical fields, both species of squirrels had a larger percentage of cortex devoted to area 17 (V1) as well as other visual areas including area 18, OT 
a Percent Brain to Body

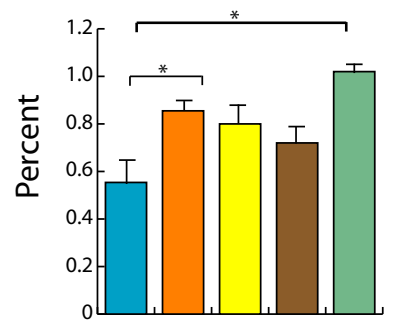

b Encephalization Quotient

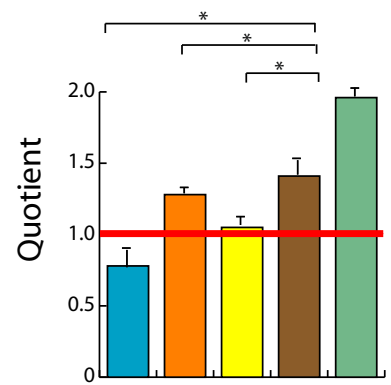

c Auditory Areas

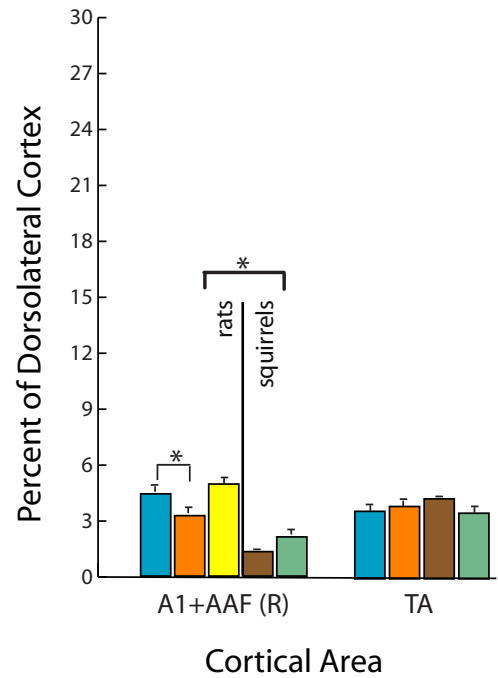

Laboratory Rat

Wild-caught Rat d Somatosensory/Motor Areas

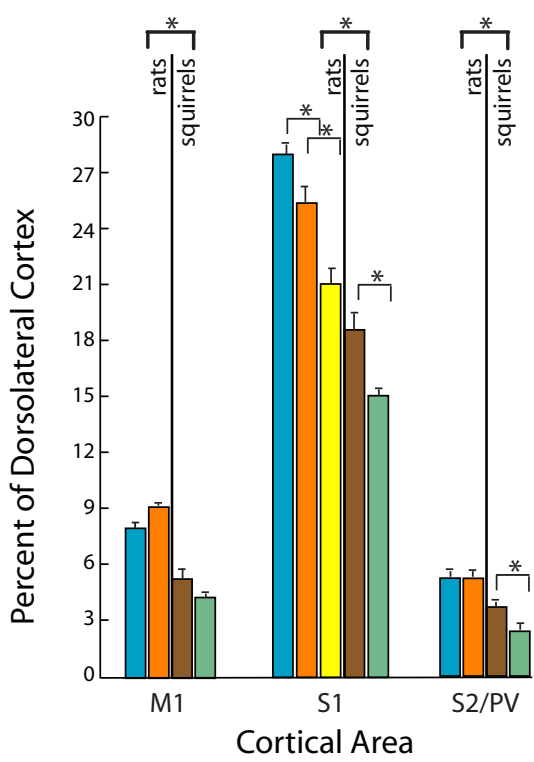

e Visual Areas

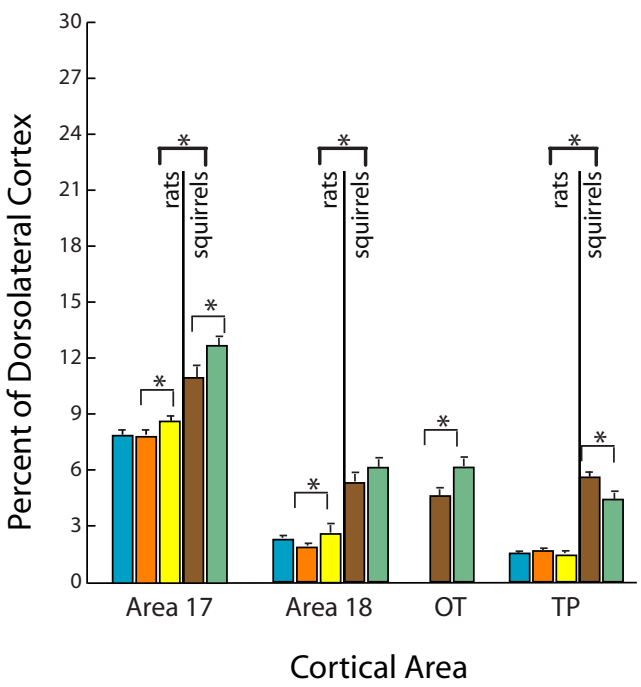

Nile Grass Rat

Eastern Gray Squirrel

California Ground

Squirrel

Fig. 6. Cross-species comparison of relative brain and cortical field size. Bar graphs of mean brain-to-body mass ratios (a), encephalization quotient (b), and percentage of dorsolateral cortex devoted to auditory areas (c), somatosensory/motor areas (d), and visual areas (e). Each colored bar represents a different rodent. In $\mathbf{a}$, the $y$-axis is brain weight as a percentage of body weight. In $\mathbf{b}$, the $y$-axis is the measured brain mass compared to the predicted brain mass based on body mass. In c-e, each colored bar repre- sents a different rodent for a specific area of cortex, and the yaxis shows the percentage of dorsolateral cortex area that individual areas occupy. There are large differences within and across rodent groups associated with lifestyle and rearing conditions. Error bars represent the standard error of the mean. The asterisk indicates a significant difference $(\mathrm{p}<0.05)$ [taken from Campi and Krubitzer, 2010; Campi et al., 2011]. 
(occipitotemporal area or V3), and TP (temporal posterior area) (fig. 6e), and the diurnal rats had proportionately more cortex devoted to areas 17 and 18 compared to the nocturnal rats. Within the squirrel group more cortex was devoted to visual areas in the arboreal tree squirrel while more cortex was devoted to somatosensory areas S1, S2, and PV in the terrestrial (and burrowing) ground squirrel. All rats had a larger percentage of cortex devoted to the auditory core areas S1, S2/PV, and M1 compared to squirrels (fig. $6 \mathrm{c}, \mathrm{d}$ ); nocturnal rats had a larger percentage of cortex devoted to S1 than did diurnal rats [for complete review see Campi and Krubitzer, 2010; Campi et al., 2011].

An interesting and important observation was that differences in cortical field size emerged in the same species of rat ( $R$. norvegicus) that were reared in the wild versus laboratory conditions (fig. 6c, d). Laboratory rats had a larger auditory core (A1+AAF) and S1 compared to wild-caught rats, and wild-caught rats had a larger M1. Additional differences were also noted at a cellular level between these groups, and the significance of this finding will be discussed at the end of the section on the visual system.

Our comparisons [Campi and Krubitzer, 2010; Campi et al., 2011] were based on the fraction of the cortical sheet that any given area would occupy, therefore removing the effects of overall brain size. However, the differences in cortical field size between species may also arise due to simple allometry (or a linear scaling of cortical fields with brain size). In fact, meta-analyses of data from several orders of mammals demonstrate that differences in the size of visual areas between species are due to allometry and that primary fields co-vary with brain size and not with niche specialization [e.g. Kaskan et al., 2005]. This is surprising because, along a number of dimensions, the neocortex relates strongly to sensory specializations and lifestyle (see comparisons of sensory cortex in this review). Such discrepancies between conclusions reached from allometric studies and other studies may be methodological. For example, in previous allometric analyses, the data were collected by multiple laboratories using a variety of techniques. Many critical measures necessary to perform an accurate allometric analysis, such as the size of the cortical sheet (area or volume), brain (weight or volume), and individual cortical fields (area or volume), were not provided in some of the studies that formed the backbone of the meta-analysis [Jones and Burton, 1976; Krubitzer and Kaas, 1990; Felleman and Van Essen, 1991; Krubitzer et al., 1995; Huffman et al., 1999]. In addition, conclusions regarding specific changes in cortical area

A Modern Synthesis of Cortical

Organization in Rodents allocation were based on regression slopes derived from data that combined several mammalian orders, thereby obscuring specializations in lineage, and were skewed by including more data from highly visual lineages such as primates. Finally, species that showed extreme specialization such as platypuses and echidnas were eliminated from the analysis.

To resolve this issue, we performed our own analysis using the rodent species in which sizes of cortical fields were compared (tree squirrels, ground squirrels, laboratory rats, wild-caught rats, and Nile grass rats) and examined the relationship between cortical sheet size and cortical field size to see if changes in brain size alone could account for the differences in cortical field size that we observe in these rodents [Campi et al., 2011]. This analysis controls for potential lineage differences because all species are rodents, and it controls for other confounds mentioned above because the same histological methods and criteria were used to define a cortical field. We calculated the regression line for our data (log transformed) and found that, across rat groups, all 3 primary sensory fields had different positive slopes, meaning that as rat brains increase in size all of these fields increase in size but at different rates. The steepest slope is observed for S1 (fig. 7a). That is, $\mathrm{S} 1$ increases in size at a faster rate than $\mathrm{V} 1$ and $\mathrm{A} 1$ as brains get larger. On the other hand, in wild-caught diurnal ground and tree squirrels, V1 has the steepest slope [Campi and Krubitzer, 2010 (fig. 7b)], indicating different rates of change for different fields in the 2 lineages. These results point to a conclusion similar to that obtained from our more straightforward percentage measurements in squirrel and rat groups that primary sensory areas differentially change size. Thus, in addition to scaling of cortical fields with brain size, the general organization of the neocortex in terms of sensory domain allocation (the amount of cortex devoted to a particular sensory system) and cortical field size reflects the types of sensory and behavioral specializations associated with the lifestyle of a particular rodent. Our review on the organization of cortical fields and the cellular composition of cortical fields substantiates this idea by demonstrating large species differences within the rodent order at all levels of organization.

\section{Organization of Visual Cortex}

Visual cortex organization has been described in several species of rodents using a variety of techniques including electrophysiological recordings and optical im- 
aging [Hall et al., 1971; Kaas et al., 1972, 1989; Montero, 1973; Drager, 1975; Tiao and Blakemore, 1976; Wagor et al., 1980; Espinoza and Thomas, 1983; Schuett et al., 2002; Cang et al., 2005; Van Hooser et al., 2005; Husson et al., 2007; Wang and Burkhalter, 2007]. In all rodents examined, V1, which is coextensive with architectonic area 17 , contains a complete representation of the contralateral visual hemifield, with the upper quadrant represented caudolaterally and the lower quadrant represented rostromedially. The horizontal meridian is represented midway between these 2 poles of $\mathrm{V} 1$, and the vertical meridian is located at the rostral boundary and forms the border with architectonically defined area 18/18a (fig. 8).

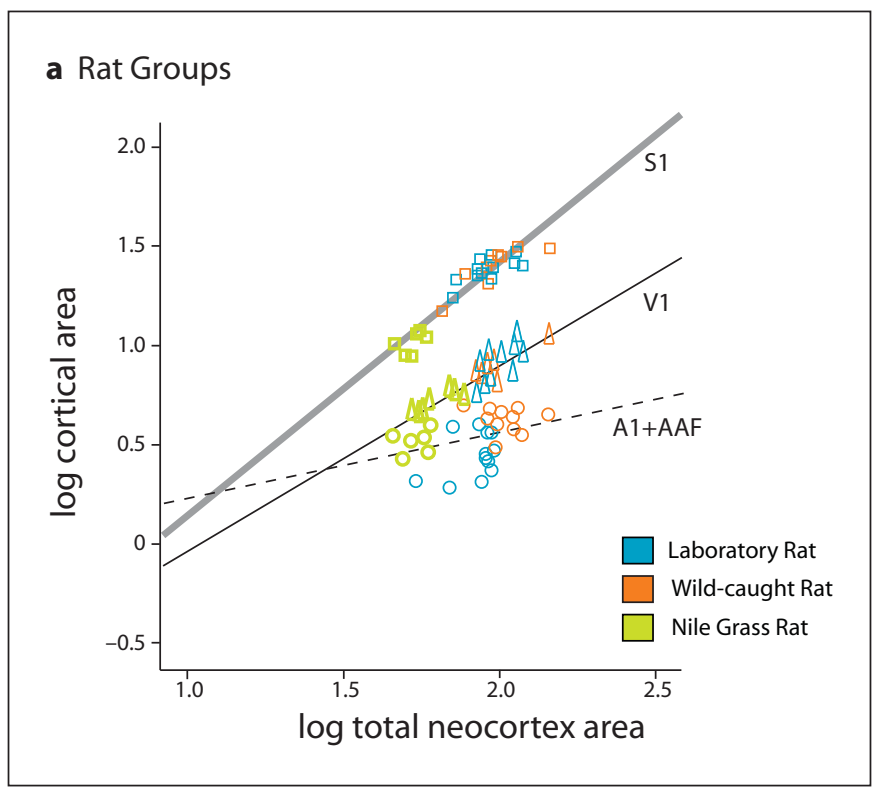

Fig. 7. Cortical area scaling in Norway and Nile rat groups (a) and California ground and eastern gray squirrels (b) shown as log primary areas [V1, S1, and A1+AAF (rats) and A1+R (squirrels)] regressed on log neocortex size. It should be noted that, in the rat group, $\mathrm{S} 1$ has the steepest slope compared with the squirrel groups in which V1 has the steepest slope. The equations and $\mathrm{r}^{2}$ values are as follows: $\mathbf{a} \mathrm{V} 1=0.969 \mathrm{x}-1.043, \mathrm{r}^{2}=0.827 ; \mathrm{S} 1=1.274 \mathrm{x}-1.130$, $\mathrm{r}^{2}=0.0860 ; \mathrm{A} 1=0.332 \mathrm{x}-0.107, \mathrm{r}^{2}=0.096 . \mathbf{b} \mathrm{V} 1=1.447 \mathrm{x}-2.003$, $\mathrm{r}^{2}=0.823 ; \mathrm{S} 1=0.698 \mathrm{x}-0.089, \mathrm{r}^{2}=0.453 ; \mathrm{A} 1=0.194 \mathrm{x}-0.085$, $\mathrm{r}^{2}=-0.036 . \mathrm{V} 1$ individual animal points are depicted by triangles and the slope is a solid black line; S1 individual animal points are depicted by squares and the slope is a solid gray line, and A1 individual animal points are depicted by circles and the slope is a dashed line. Symbols are colored by species.

Fig. 8. Line drawings of the visuotopic organization in striate and extrastriate cortex in the mouse, hamster, rat, and squirrel obtained utilizing electrophysiological recording techniques. The location of V1 is indicated in blue in the small brains at the top of
While the general location and retinotopic organization of V1 is similar across rodents and across all mammals [Van Hooser, 2007; Kaas, 2008], important interspecies differences exist and are often correlated with aspects of lifestyle. For example, the relative size of V1 varies in different species, with arboreal diurnal squirrels having a larger proportion of the cortical sheet devoted to $\mathrm{V} 1$ and other visual fields (see above) compared to terrestrial squirrels and nocturnal rats. There are also clear differences in the extent of cortex representing the overlap of the visual fields of both eyes (fig. 9), or the binocular segment, even within closely related species. For example, the binocular segment of V1 is much larger in

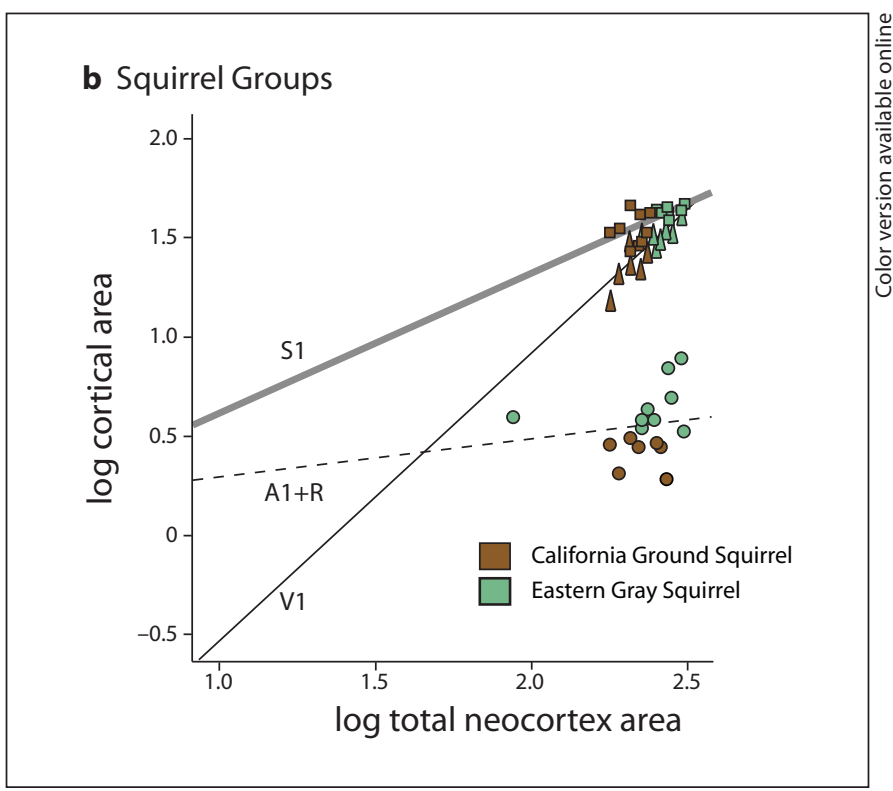

each figure. V1 organization is similar in all rodents depicted; the upper visual field is represented caudally and the lower visual field is represented rostrally. Just lateral to V1 is a mirror representation, i.e. V2, in the mouse, rat, squirrel, and hamster. In rats this region contains 2 fields, i.e. AL and LM. Medial to V1 is 1 or 2 separate visual areas in mice, rats, and hamsters. Central vision is highlighted by gray shading. The horizontal meridian is represented by a blue line. The vertical meridian is represented by a pink line. Arrows in ML and $\mathrm{L}$ of the squirrel indicate that neurons in these regions are direction selective. Rostral is to the left; medial is up. In a-c maps are to the same scale. The squirrel (d) is shown at one half the scale of $\mathbf{a}-\mathbf{c}$. The relative brain-to-map scale is consistent across species, so brains in $\mathbf{a}-\mathbf{c}$ are presented at the same scale. For this and the following illustrations, the maps may be redrawn for either a single case within a study or 2 cases combined; some of these are summary maps provided by the authors of a paper, and some of these are summary maps generated from more than 1 study. Individual studies are listed around all summarized maps. 


\section{The Organization of Visual Cortex in Rodents}

a Mouse<smiles>C1=CCCCC2C=CC(=C1)C2</smiles>

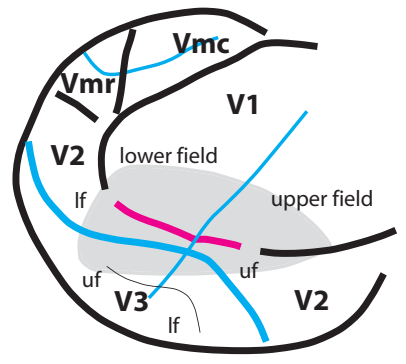

c Hamster

Drager [1975]

Wagor et al. [1980]

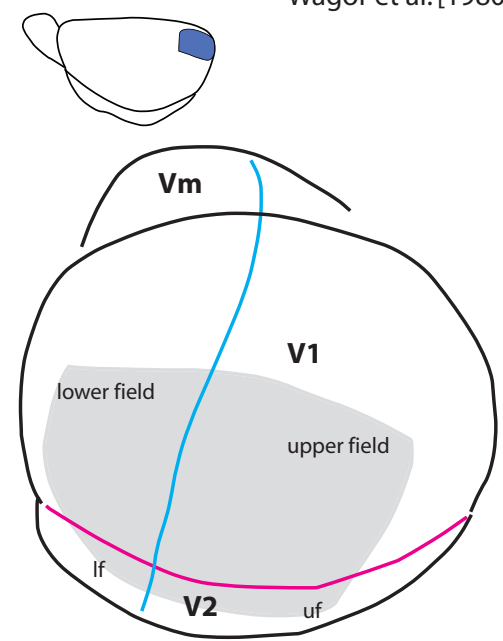

Tiao and Blakemore [1976]

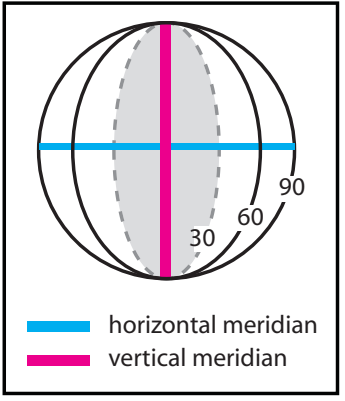

b Rat
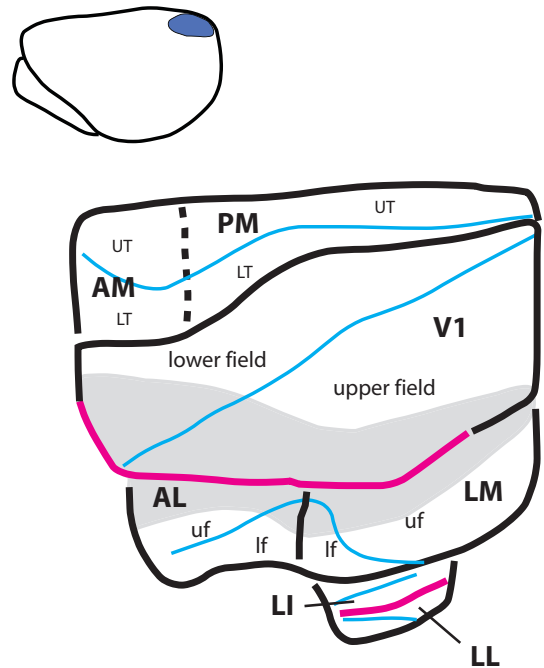

Espinoza and Thomas [1983]

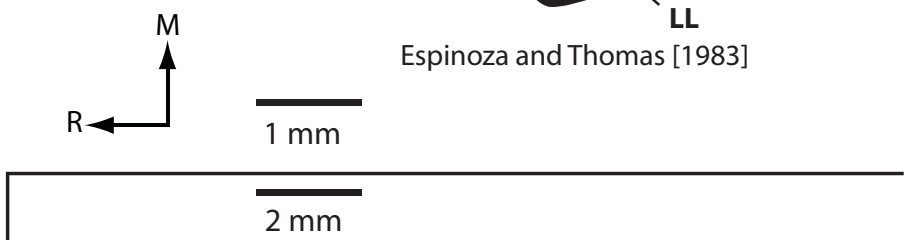

d Squirrel

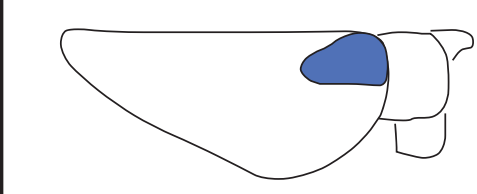

Hall et al. [1971]

Kaas et al. [1989]

Sereno et al. [1991]

Paolini and Sereno [1998]

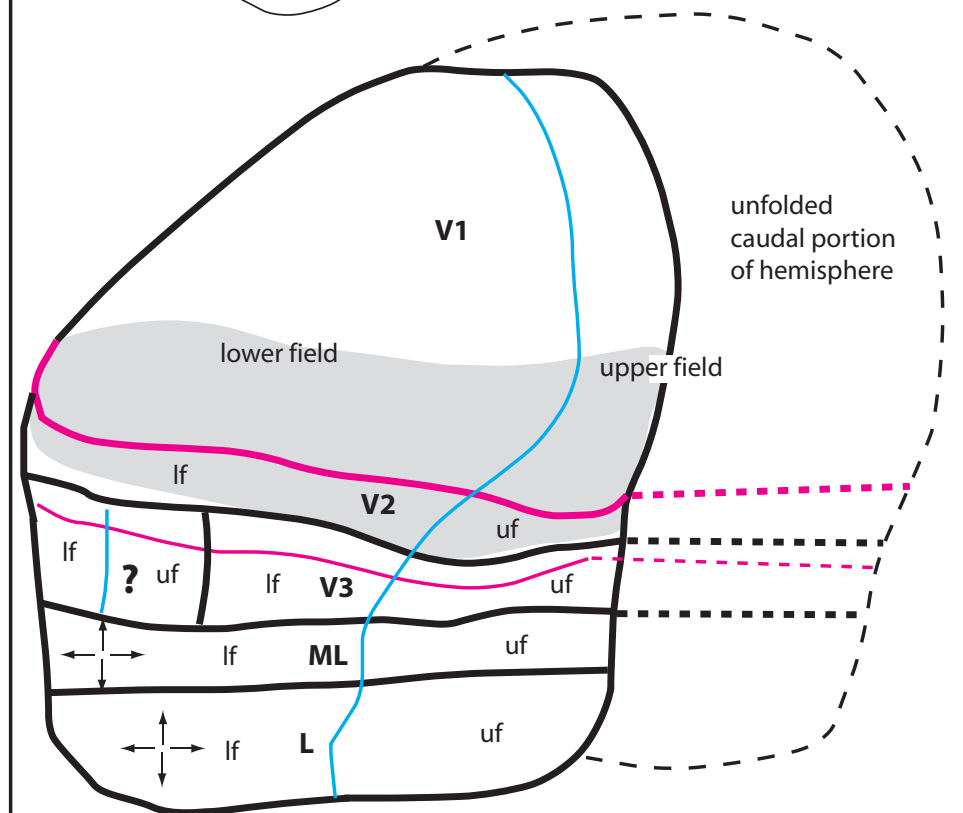


squirrels than in murine rodents and is larger in the tree squirrel than in the ground squirrel. It is possible that the degree of binocular overlap and its corresponding representation is associated more directly with terrain niche than with diel pattern due to visual adaptations such as enhanced depth perception, which would be helpful for rapid navigation and branch-to-branch leaps associated with the habits of the tree squirrel [Koprowski, 1994]. Studies of single units in V1 in squirrels and murine rodents demonstrate that receptive fields for neurons in V1 in mice are larger than in squirrels [Hall et al., 1971; Drager, 1975; Metin et al., 1988; Niell and Stryker, 2008]. While neurons in V1 in rats, mice, and squirrels contain cells that are orientation and direction selective, there are differences in the proportions of these cells [for comparisons between rodents see table 2 in Heimel et al., 2005]. Rats have more direction- and orientation-selective cells than either squirrels or mice, and squirrels have more orientation-selective cells than mice. Neurons in V1 in squirrels show color opponency and have higher spatial and temporal tuning than in mice and rats. These differences have been suggested to optimize aspects of vision in diurnal versus nocturnal visual environments. A similar pattern of $\mathrm{V} 1$ response properties is also seen in other nocturnal and diurnal mammals, particularly in primates [for review see Heimel et al., 2005]. Despite the presence of orientation-selective cells in V1, an orderly orientation map like that observed in primates has not been observed in any rodent [Van Hooser et al., 2005].

While all studies are in agreement on the relative location and organization of the primary visual area, there are dramatic differences in how cortex lateral and medial to V1 is organized both within and across species. Only a few studies generated electrophysiological maps of visual cortex with many densely spaced electrode penetrations in each animal. Such high-quality maps which are necessary for appreciating cortical organization, particularly in small fields, exist for mice [Drager, 1975; Wagor et al., 1980], squirrels [Hall et al., 1971; Kaas et al., 1989], hamsters [Tiao and Blakemore, 1976], and rats [Espinoza and Thomas, 1983] (fig. 8).

Most studies agree that cortex in the architectonically defined area $18 \mathrm{~b}$, just medial to V1, is devoted to visual processing. However, different studies report different numbers and names of areas. Electrophysiological studies indicate that 1-2 retinotopically organized fields are present in this region and have been termed $\mathrm{Vmr}$ and Vmc in mice, VM in hamsters, and AM and PM in rats (fig. 8; see list of abbreviations). Recent architectonic studies in the mouse have further divided this medial cortex into a V2M caudally and 4 rostromedial fields (RM1-4) using nonphosphorylated neurofilament protein [Van der Gucht et al., 2007].

The status of cortex immediately lateral to V1 in rodents is contentious, with investigators differing over whether there is a single functional field, V2, coextensive with the architectonically defined area 18a or several functional fields, only 1 of which is V2. The story is complicated because, even in the same species (mice), different laboratories have different schemes of organization [Wagor et al., 1980; Olavarria et al., 1982; Olavarria and Montero, 1989; Schuett et al., 2002; Kalatsky and Stryker, 2003; Wang and Burkhalter, 2007; Wang et al., 2011]. In rats, studies in which a substantial number of densely spaced recording sites were obtained in individual animals, areas AL and LM are proposed to be coextensive with area 18a and to border V1 [Espinoza and Thomas, 1983]. These investigators and others propose that LM is homologous to V2 in other rodents and other mammals, and $\mathrm{AL}$ is an additional field not described in other rodents or other mammals. A subsequent reanalysis of these data by Rosa and Krubitzer [1999] suggests that recording site progression demonstrates only a single functionally defined field, V2, in area $18 \mathrm{a}$ in rats. More detailed maps in rats of cortex lateral to V1 would help resolve this issue. While other studies in rats [Montero et al., 1973a, b; Olavarria and Montero, 1984; Thomas and Espinoza, 1987; Rumberger et al., 2001] and mice [Olavarria et al., 1982; Olavarria and Montero, 1989; Wang and Burkhalter, 2007; Wang et al., 2011] have used electrophysiological recording and/or connectional data to support multiple areas in this region, these data are difficult to interpret because only a few recording sites were obtained in any given animal for any given field (sometimes only 1-3 recording sites per field) [see fig. 6A, 7A, and $8 \mathrm{~A}$ of Wang and Burkhalter, 2007], and often the data from several animals were combined onto a single composite map [see fig. 1 of Montero et al., 1973a]. Thus, even with electrophysiological recording techniques, the resolution provided by few recordings in a single animal in very small fields (in some instances less than $1 \mathrm{~mm}^{2}$ ) is insufficient to delineate the topography of fields or to determine their borders. Optical imaging studies also provide conflicting parcellation schemes of this region of visual cortex in mice but, again, the resolution of this technique for very small areas (with less precise topography than V1) makes it difficult to reach any firm conclusions about the organization of extrastriate visual areas [see fig. 5 of Schuett et al., 2002; Kalatsky and Stryker, 


\section{a Binocular segment in V1 of squirrels}

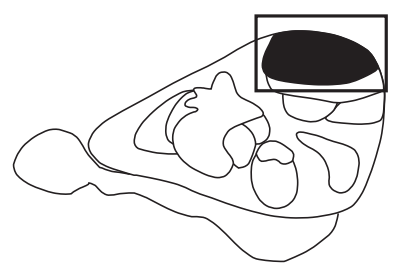

Fig. 9. Myeloarchitecture of the binocular and monocular segments of V1 in the eastern gray squirrel (b) and the California ground squirrel (c). The black box in a shows the area of magnification for $\mathbf{b}$ and $\mathbf{c}$. The monocular (mono) and binocular (bino) segments are labeled. In both animals, the binocular segment is more darkly myelinated and located laterally. Images in $\mathbf{b}$ and $\mathbf{c}$ are presented at the same scale. Caudal is to the right; medial is up [modified from Campi et al., 2010].

2003]. As noted above, connectional data from rats and mice [e.g. Olavarria and Montero, 1981, 1984, 1989; Wang and Burkhalter, 2007] or connectional data alone in hamsters and several Chilean rodents [Bravo et al., 1990; Olavarria and Montero, 1990] have been used to support the presence of multiple fields in area 18a because callosal connections to this region are heterogeneous and projections from V1 are patchy. Each separate patch of label is proposed to indicate the presence of a separate field. However, heterogeneous connections from $\mathrm{V} 1$ to area 18 in rats have also been interpreted to support a single field lateral to V1 and V2, with local discontinuities [Malach, 1989]. Support for the idea of Malach [1989] comes from other species such as squirrels, tree shrews, and cats and multiple species of monkeys in which heterogeneous callosal connections and patchy connections from V1 and other visual areas to area 18 have been observed [Innocenti and Fiore, 1976; Lin et al., 1982; Segraves and Rosenquist, 1982; Gould, 1984; Sesma et al., 1984; Kennedy et al., 1986; Kaas et al., 1989; Krubitzer and Kaas, 1989, 1990; Lyon and Kaas, 2002].

\section{b Eastern Gray Squirrel}

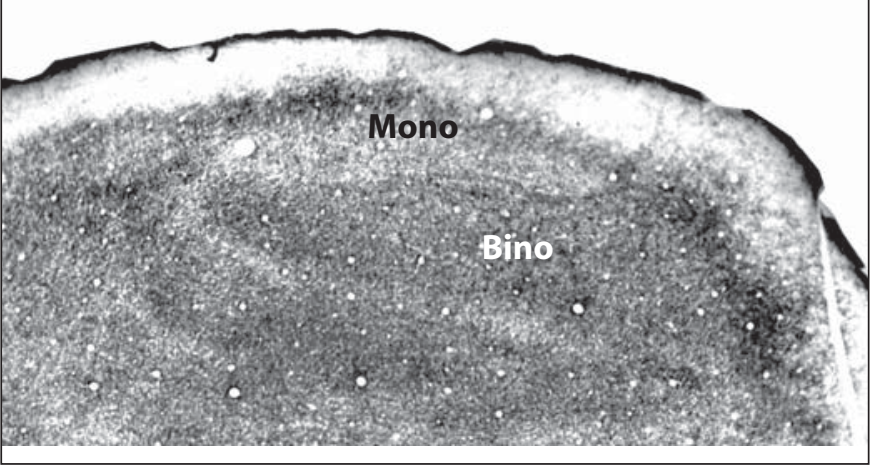

c California Ground Squirrel

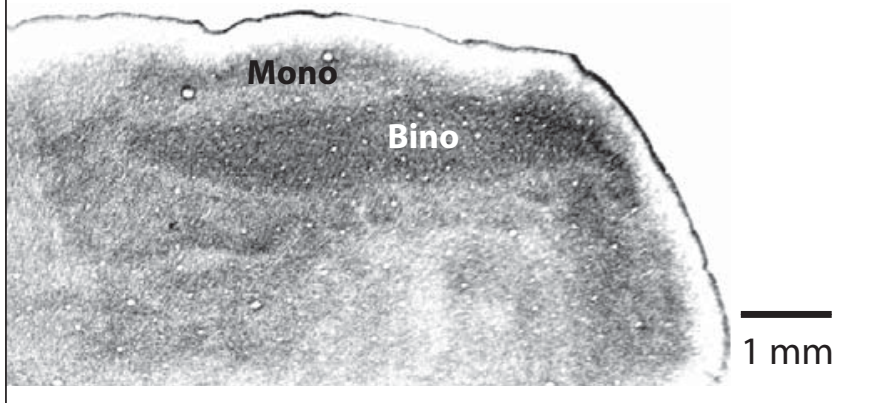

In these previous studies such connections have been interpreted as marking a modularly organized V2 rather than the presence of multiple fields. Electrophysiological recording results in these species provide support for this interpretation.

In squirrels, hamsters, and some studies of mice, a single representation of the contralateral hemifield, V2, coextensive with area $18 / 18 \mathrm{a}$ is proposed to border the lateral edge of V1 [Hall et al., 1971; Tiao and Blakemore, 1976; Wagor et al., 1980; Kaas et al., 1989]. V2 adjoins V1 at the representation of the vertical meridian resulting in a mirror representation with the lower field represented rostrally and the upper field represented caudally, just as in V1 (fig. 8). These data are derived from dense electrophysiological recordings in the same animals and are thus considered very robust.

The remarkable difference in number of extrastriate fields in some studies of mice and rats compared to squirrels is surprising because rats and mice are nocturnal and have an otherwise reduced visual system from the level of the rod-dominated, single-color cone retina (the other 
cone is sensitive to ultraviolet wavelengths in murine rodents) to the 3-layered LGN. Squirrels, on the other hand, have a 2-color cone retina and 5-layered LGN [for review see Van Hooser and Nelson, 2006]. Further, squirrel acuity, and other types of discrimination, exceeds that of mice and rats [Jacobs et al., 1982; Girman et al., 1999; Keller et al., 2000; Prusky et al., 2004; for review see Heimel et al., 2005]. Thus, aspects of visual system organization in squirrels at earlier levels of processing are much more like those of highly visual animals such as tree shrews and primates than like those of nocturnal rodents like mice or rats.

There are 2 possible explanations for the reported differences in the organization of extrastriate cortex in squirrels versus mice and rats. The first is that methodological differences have resulted in different reported organizations. As noted above, a paucity of recording sites in any given area, the very small size of several of the proposed areas, and the combining of sparse data from individuals into composite maps is potentially problematic. Another possible explanation for these differences is that the organization of area 18a in murine rodents, and mice and rats in particular, is highly derived compared to other rodents and all other mammals. If this is the case, these rodents may not be the best rodent models for understanding the general organization of extrastriate visual cortex and aspects of visual processing. Thus, the data, while interesting, cannot be generalized to other species such as tree shrews, cats, ferrets, monkeys, or humans.

Cortex lateral to area $18 \mathrm{a}$ has been explored in mice, hamsters, rats, and squirrels and, except for rats, most studies propose that a third visual area, V3 (or OT), exists in the region that adjoins area 18a [Kaas et al., 1989; Van Hooser and Nelson, 2006] (fig. 8). This area receives direct projections from V1 [Kaas et al., 1989], and studies in mice [Wagor et al., 1980] and squirrels [Sereno, pers. commun.] demonstrate that V3 has a retinotopic representation that mirrors that of V2. In rats, Espinoza and Thomas [1983] propose that 2 areas, i.e. LL and LI (fig. 8b), adjoin area 18a, but these areas are extremely small $(<1$ $\times 0.3 \mathrm{~mm}$ ) and it seems unlikely that the density of mapping in this study was sufficient to distinguish such small cortical fields [see fig. 1 and 2 of Espinoza and Thomas, 1983].

Electrophysiological, architectonic and connectional studies indicate that cortex just lateral to V3 in squirrels contains additional cortical areas, the middle lateral (ML) and lateral (L) visual areas in which neurons are directionally selective [Paolini and Sereno, 1998]. Both ML and $\mathrm{L}$ appear to form mirror images of V3 [Sereno et al., 1991; Sereno, pers. commun.], but more data are needed to define the detailed organization of these fields. V3 in mice and other rodents such as rats and hamsters is bordered laterally by the auditory core areas (fig. 10, 13).

Finally, architectonic studies indicate that at the caudal occipitotemporal junction a field that is similar in appearance is present in all rodents examined. This field is termed Te2 or TP (fig. 4). In squirrels, thalamocortical connections from divisions of the pulvinar [Wong et al., 2008] indicate that this region is involved in processing visual inputs, similar to the temporal pole regions in primates. TP also receives inputs from divisions of the medial geniculate nucleus, suggesting that it may have a role in multisensory processing. Further electrophysiological and anatomical studies of this region in squirrels will help reveal the details of its organization and function. Regardless of interpretation, there is a large difference in the relative size of the temporal pole in squirrels compared to other rodents examined (fig. 10). In mice, rats, hamsters, voles, and other rodents, this temporal region contains a small Te2 or TP area that adjoins the caudolateral boundary of area 18a or V2 and adjoins the caudal boundary of a very small V3. Immediately lateral to this is the auditory cortex, with no additional space available for other cortical fields. In squirrels, TP does not share a boundary with either V2 or V3 (OT) but does share one with ML and L [Paolini and Sereno, 1998; Campi and Krubitzer, 2010]. Thus, there is an expansion of cortex between V3 and TP in squirrels as well as an enormous expansion of TP and cortex lateral and anterior to TP. This is particularly distinct in the eastern gray squirrel (fig. 10).

\section{Cellular Composition of V1 in Diurnal versus Nocturnal Animals and Laboratory versus Wild-Caught Animals}

Both gross brain measures of cortical field size and fine-grain electrophysiological mapping indicate that the organization of visual cortex in rodents differs and these differences go beyond what would be expected by allometry. Recently, using the isotropic fractionator method we examined the cellular composition in nocturnal, wildcaught, and laboratory Norway rats and diurnal, laboratory Nile grass rats [Campi et al., 2011]. The latter rodents are a close sister group to rats and mice. We observed some interesting differences in the number and density of neurons and non-neuronal cells in these 3 groups of 


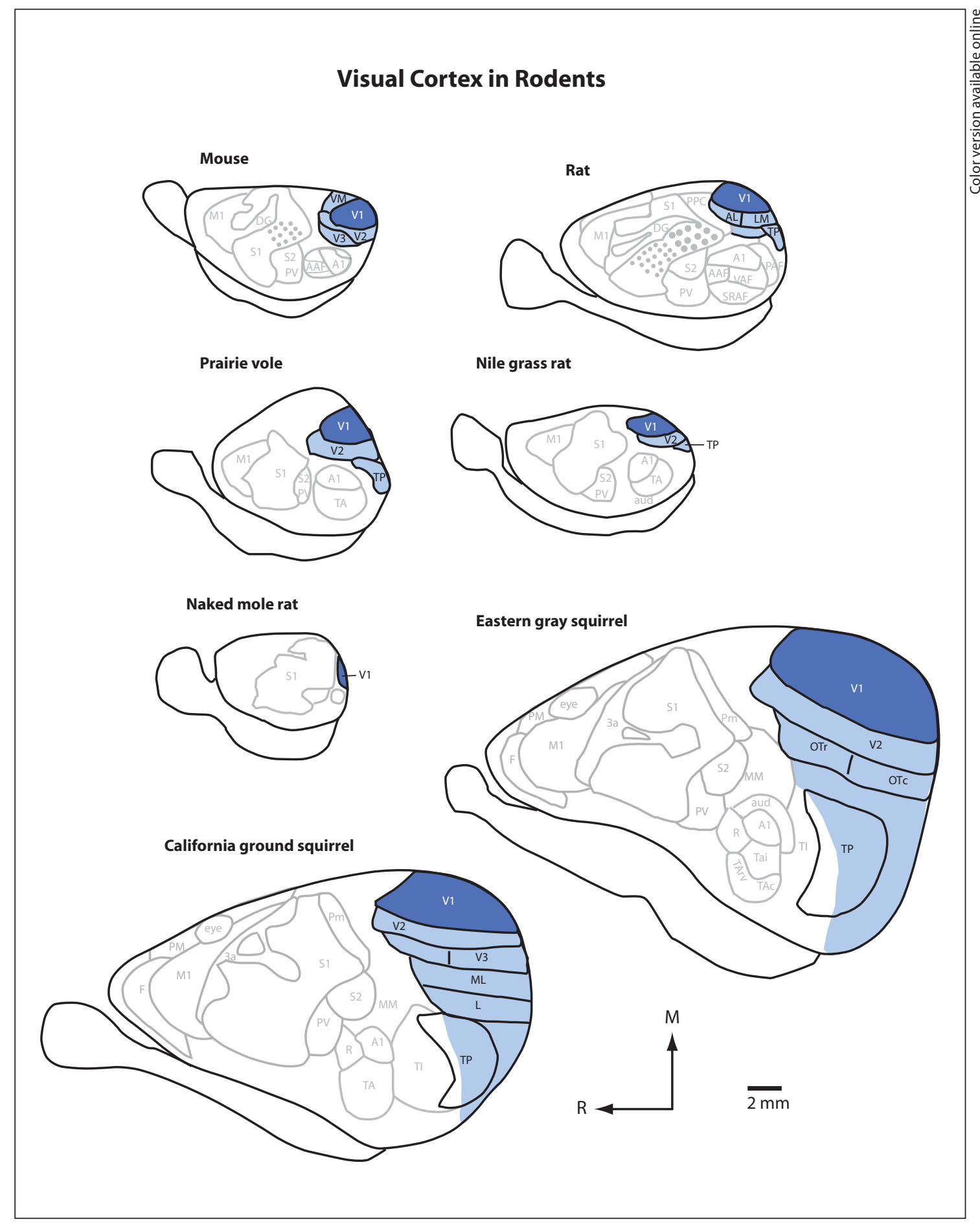

Fig. 10. Line drawings of flattened cortical hemispheres depicting the location of the primary visual area and the extent of visual cortex in the mouse, rat, California ground squirrel, eastern gray squirrel, prairie vole, Nile grass rat, and naked mole rat. Differences in the relative amount of cortex devoted to V1, and in the amount of cortex devoted to visual processing, are readily observed when comparing diurnal squirrels to other rodents, particularly the subterranean naked mole rat. V1: Primary visual area (dark blue), all other proposed visual areas (light blue). All drawings are to scale. The overall brain organization in rats, mice, and squirrels is taken from the studies described in this review. The organization of the prairie vole comes from Campi et al. [2007], the naked mole rat from Henry et al. [2006], and the Nile grass rat from Campi et al. [2011]. In the printed version, colors appear as shades of gray. 


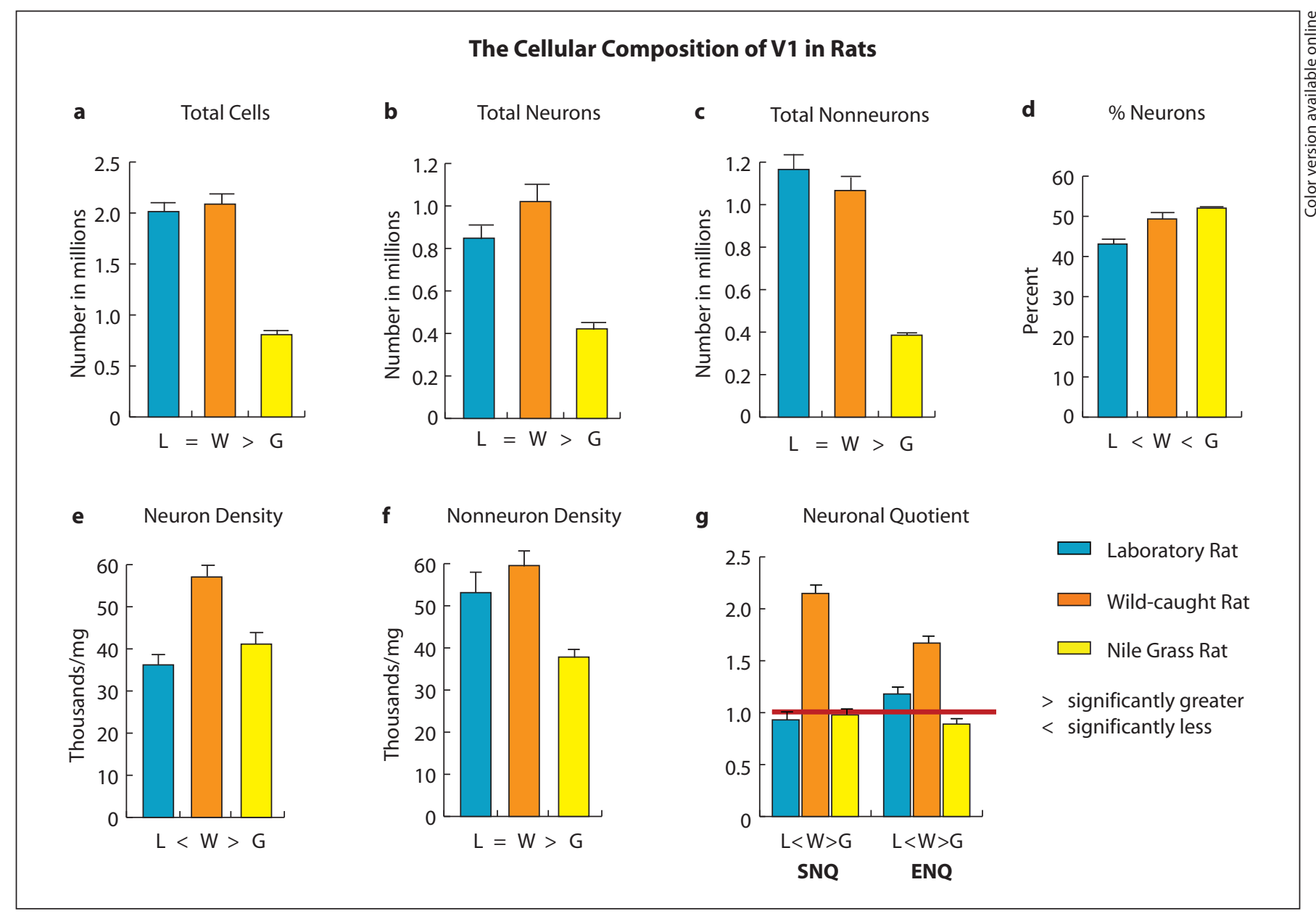

Fig. 11. Cellular composition of V1 in rats. The estimated total cells (a), total neurons (b), total non-neurons (c), percent of neurons (d), the neuron density (e), non-neuron density (f) and neuronal quotient $(\mathbf{g})$ are depicted for $\mathrm{V} 1$ in each group of rodents. Colored bars represent different rat groups, and the $y$-axis for a-c shows the estimated numbers of cells in millions, for $\mathbf{d}$, neurons as a percentage of all cells, for $\mathbf{e}, \mathbf{f}$, thousands of neurons per milligram of tissue, and for $\mathbf{g}$, the ratio of the expected number of neurons to the observed number of neurons calculated based on body (SNQ) and brain (ENQ) weight. Error bars represent the standard error of the mean. Significant differences between groups are indicated by the $>$ or $<$ symbol with abbreviations for each group beneath each panel: $\mathrm{L}=$ laboratory Norway rat, $\mathrm{W}=$ wild-caught Norway rat, $G=$ Nile grass rat. The horizontal line in g represents a ratio of 1 . See table for abbreviations. Taken from Campi et al., 2011. rodents. Both groups of Norway rats (wild-caught and laboratory reared) had more cells, neurons, and non-neurons in area 17 than Nile grass rats (fig. 11a-c). However, Nile grass rats had a greater percentage of neurons in V1 than both nocturnal species, and wild-caught rats had a greater percentage of neurons in V1 than did laboratory rats. Perhaps the most interesting results are that wildcaught rats had the greatest density of neurons in V1 compared to the 2 laboratory rat groups (fig. 11d-f). The results of neuronal density are in good agreement with previous studies on laboratory rats [Peters et al., 1985;
Turner and Greenough, 1985]. To our knowledge, this is the first study of the cellular composition of V1 in wildcaught Norway rats and laboratory Nile grass rats. Finally, wild-caught rats had the largest somatic and encephalic neuronal quotients [SNQ and ENQ; fig. 11g; see Herculano-Houzel, 2007]. These metrics provide estimates of the expected number of neurons for a given body or brain size, respectively. Thus, wild-caught rodents have a higher density and number of neurons in V1 than would be expected for their body or brain size compared to the 2 laboratory rodents. Information processing capacity is 


\section{The Organization of Auditory Cortex in Rodents}

a Mouse
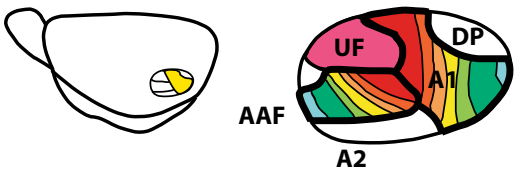

Stiebler [1987]

Stiebler et al. [1997]

\section{b Guinea Pig}

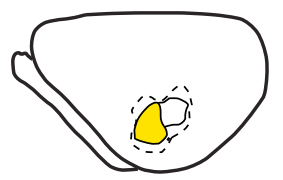

C Rat

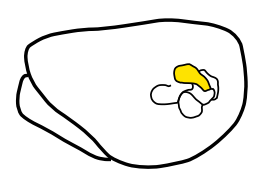

d Gerbil

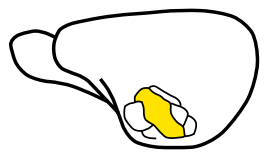

Doron et al. [2002]

Tanaguchi et al. [1992]

Polley et al. [2007]

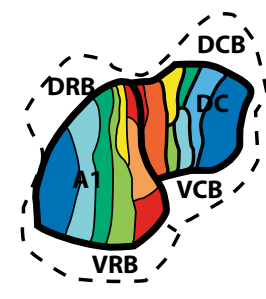

Wallace et al. [2000]

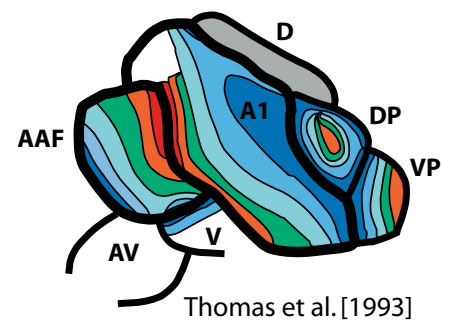

f Squirrel
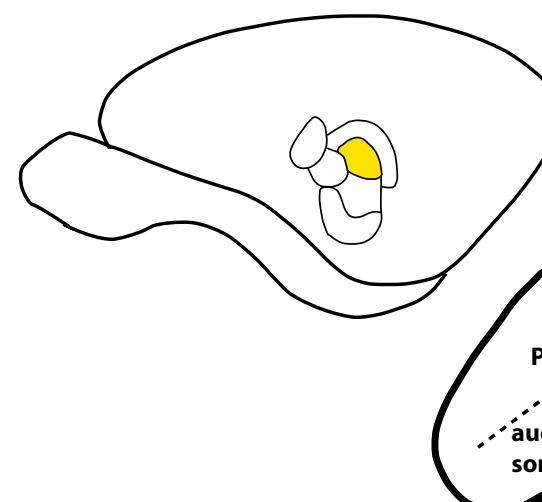

Merzenich et al. [1976] Luethke et al. [1988] Wong et al. [2008]

Thomas et al. [1993]

Harrison et al. [1996]
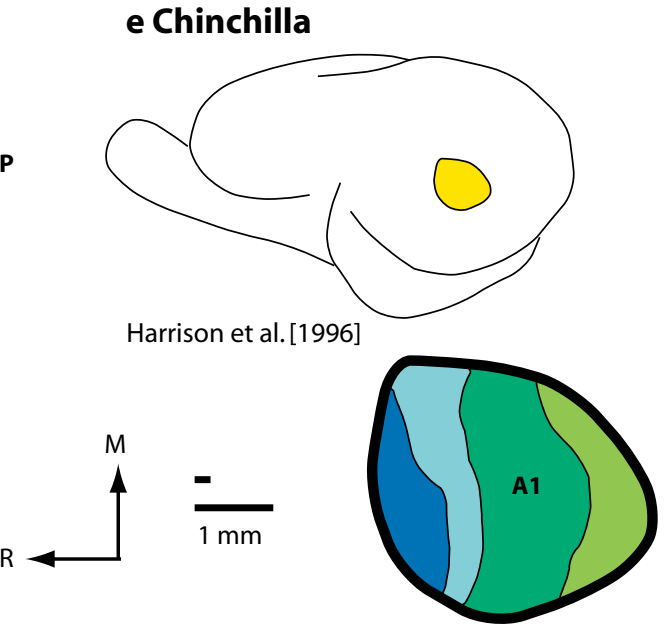

Frequency in $\mathrm{kHz}$

$\square<1$

$\square \quad \begin{array}{ll}\square \\ \square\end{array}$

$\square \quad 5-10$

$\square \quad 10-15$

$\square \quad 15-20$

$\square \quad 20-25$

प 25-30

$\square \quad 30-45$

$\square \quad 50-70$

$\square$ Wideband

Fig. 12. Rodent auditory cortex organization in the mouse (a), guinea pig (b), rat (c), gerbil (d), chinchilla (e), and squirrel (f). Small line drawings are dorsolateral cortex, with auditory areas outlined and A1 in yellow. Expanded views of auditory areas show the location and relative amount of space given to the representation of each frequency range for each rodent. All maps are to scale. The small scale bar $(1 \mathrm{~mm})$ at the top is for the whole brains and the scale bar at the bottom is for the enlarged maps. 
influenced by several parameters including the diameter of myelinated fibers (which we did not measure) and the distance between neurons or neuronal density [Ringo, 1991; Ringo et al., 1994; Zhang and Sejnowski, 2000; Changizi, 2001]. Presumably, these differences in neuronal packing in combination with spine density differences demonstrated in environmental enrichment studies and cellular composition differences between laboratory and wild-caught rodents with similarly sized brains would affect information processing capacity [Kolb et al., 2003; Faherty et al., 2003; Gelfo et al., 2009]. Although we have not examined information processing differences between the groups, neuronal density differences have been demonstrated to be one of the factors in differential intelligence measurements within humans [Anderson and Harvey, 1996] and across mammals [Roth and Dicke, 2005].

The differences in cell density in V1 in laboratory versus wild-caught rats that we described above may be due to differences in the rate of apoptosis during the critical period of development. Previous studies have demonstrated that rats reared in the dark have greater apoptosis in areas 17, 18, and 18a at postnatal day 21 [Papadopoulos and Michaloudi, 1999] and significantly lower neuronal density in the lateral geniculate nucleus (LGN) compared with standard light-reared groups [Jameie et al., 2010]. Rearing in the impoverished standard laboratory environment may result in greater apoptosis and therefore lower neuronal densities in adulthood compared with wild-caught rats that developed in natural and diverse visual environments. Thus, laboratory rodents must be considered highly altered neural models of their wild counterparts. Environmental conditions alter the molecular, cellular, and functional operation of the network in sometimes unexpected ways. The alterations to the network generated through natural or enriched rearing conditions may result in emergent properties that would not exist in the simplified network of the laboratory animal.

\section{Summary of Visual Cortex}

Taken together, the data indicate that visual cortex in most rodents examined has both general aspects of organization like the presence of a topographically organized $\mathrm{V} 1, \mathrm{~V} 2$, and V3 and a small wedge of cortex medial to V1 as well as species-specific aspects of organization that appear to be related to the sensory demands of the environment. Some rodents such as the naked mole rat appear to have a highly reduced visual cortex and may only have a primary visual area (fig. 10). Most notable are changes in the relative size and number of visual cortical areas lateral to V2 and V3, differences in the types and proportions of neurons in V1, and the greater binocular overlap in V1 in diurnal rodents. Further, much like primates, squirrels have independently evolved an expanded temporal lobe with dense input from the pulvinar, suggesting a specialization for object recognition. Interestingly, in wild-caught and laboratory Norway rats, we found differences at both gross and cellular levels of organization. Wild-caught rats have access to more varied visual stimuli than do the classic 'enriched' laboratory rats, and they certainly have a richer visual environment than do standard laboratory rats. This is true for all of the senses. Further, the types and complexity of movements necessary for survival are different in a natural environment versus a laboratory environment, and such differences may contribute to differences in the size of motor cortex. On the other hand, the expansion of somatosensory and auditory cortex in laboratory rats indicates that these senses are less impoverished and may be overutilized compared to the visual system.

\section{Auditory Cortex}

Functional maps and architectonic divisions of auditory cortex have been described in detail in a number of rodents including mice [Stiebler, 1987; Stiebler et al., 1997], rats [Doron et al., 2002; Kalatsky et al., 2005; Polley et al., 2007], gerbils [Thomas et al., 1993; Budinger et al., 2000], guinea pigs [Taniguchi et al., 1992; Wallace et al., 2000; Horikawa et al., 2001; Hosokawa et al., 2004], chinchillas [Harrison et al., 1996; Harel et al., 2000], squirrels [Merzenich et al., 1976; Luethke et al., 1988], and Octodon degus [Thomas and Tillein, 1997] (fig. 12). These studies utilized multiunit recording or optical imaging techniques and provide detailed information on the relative location and tonotopic organization of multiple auditory fields in these rodents. The rodents examined belong to the suborders Sciuromorpha (squirrels), Myomorpha (mice, rats, and gerbils), and Hystricomorpha (chinchillas, guinea pigs, and O. degus; infraorder Caviomorpha) and thus compose a good representation of rodents in general. There are 3 features of auditory organization that all rodents share, as well as species specializations within and across fields that appear to be related to environmental factors and morphological specializations. Similar features include the presence of a core auditory region 


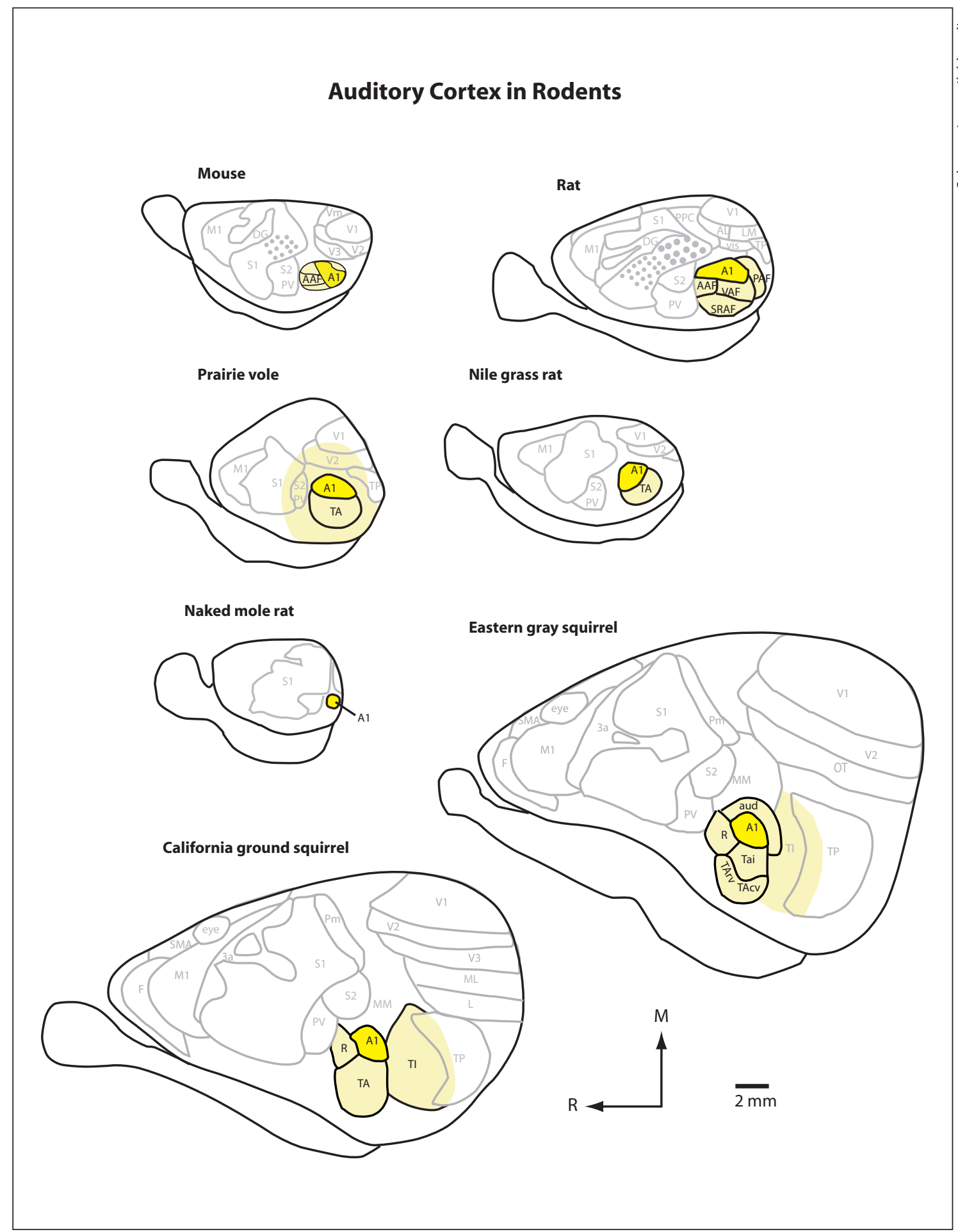

Fig. 13. Line drawings of flattened cortical hemispheres depicting the location of A1 and the extent of auditory cortex in mouse, rat, prairie vole, Nile grass rat, naked mole rat, California ground squirrel, and eastern gray squirrel. A1: Primary auditory area (dark yellow), all other delineated auditory areas and auditory responsive cortex (light yellow). All drawings are to scale. Rostral is to the left; medial is up. In the printed version, colors appear as shades of gray. 
containing 2 topographically organized fields, 1 or more areas of the cortex containing a representation of ultrasonic frequencies (when examined), and cortical magnification of acoustically relevant frequencies.

All species examined appear to have 2 core auditory fields termed the primary auditory area (A1) and an anterior auditory field (AAF) or rostral field (R), surrounded by a belt of auditory cortex composed of few to many fields (fig. 12). The core areas are coextensive with a darkly myelinated area in the temporal cortex (fig. 5) and are tonotopically organized such that similar frequencies are represented in oriented (often dorsoventral) bands that span the field. The ubiquity of this 2 -field core region strongly suggests that the common ancestor or all rodents shared this pattern of organization. Indeed this pattern is found in all mammals, indicating that this core region was present in our common ancestor [for review see Kaas, 2010]. While there is general agreement on the core/belt organization of auditory cortex in rodents, there is some discrepancy on the layout of tonotopic representation, which may be due to true species differences or methodological problems associated with subdividing the neocortex. Most notably, in all but 2 rodents examined (squirrels and guinea pigs, not closely related; fig. 3), low frequencies are represented in the caudal portion of A1 and high frequencies are represented in the rostral portion of A1, with the organization of AAF a mirror reversal of this (compare fig. 12a, c, d, e with fig. 12b, f). A similar pattern is observed in all other mammals that have been examined, except for primates [Kaas, 2010]. Why do squirrels and guinea pigs differ from all other rodents? In primates, the altered organization of A1 is thought to be due to the expansion of the temporal lobe and the rotation of the long axis of A1 [Kaas, 2010]. Thus, one possibility is that the common ancestor of all rodents had 2 core fields that were represented from low to high for A1 and from high to low for AAF or R and that squirrels and guinea pigs independently evolved a reverse organization of these fields. While squirrels clearly have an expansion of the temporal lobe, although not of the same magnitude as primates, guinea pigs do not. Another possibility, and one that we favor, is that the auditory fields have been misidentified in these species [including in our own study; Luethke et al., 1988].

For example, in squirrels, what has been identified previously as the rostral field (R) could instead be the primary auditory area, and cortex rostral to this, in which neurons respond to auditory stimulation, could be AAF. Another possibility is that the field termed A1 could be AAF, and cortex caudal to this would contain the pri- mary auditory area. Although the tonotopic organization of cortex surrounding A1 and R in squirrels has not been explored, neurons in this location are responsive to auditory stimulation, and connections of cortex caudal to A1 indicate that it is involved in unimodal auditory processing [Wong et al., 2008]. In guinea pigs, 2 different laboratories have generated 2 different schemes for the organization of auditory cortex, but in both schemes frequencies in A1 are represented from low to high rostrocaudally and in the opposite layout in a caudal field termed DC [Wallace et al., 2000] or AII [Horikawa et al., 2001]. It is possible that $A 1$ in both schemes of organization is actually AAF and the caudal field is A1 [for review see Kaas, 2010, specifically their fig. 19.4]. If this were the case, the organization would conform to all other species examined, except for squirrels, where we believe similar errors in defining cortical fields have also occurred. Subdividing auditory cortex is more difficult than subdividing areas from other sensory modalities because of the 2-dimensional nature of the isofrequency contours versus the point-to-point mapping found in primary and secondary areas in the somatosensory and visual systems.

While all species possess belt regions of auditory cortex, variations in the relative location, nomenclature, and tonotopic organization make it very difficult to propose homologies without connectional data (fig. 13). However, all species in which responses to ultrasonic frequencies $(>20 \mathrm{kHz})$ were tested have been found to possess cortical regions representing these frequencies, although the number and location of such representations varies between species. For example, mice have a field just rostral to A1 and medial to AAF in which neurons respond to frequencies between 50 and $70 \mathrm{kHz}$ [Stiebler, 1987]. Rats have a relatively large 20 - to $55-\mathrm{kHz}$ representation in the anterior portion of A1 (fig. 12c). The shared boundary of $\mathrm{A} 1$ and $\mathrm{DC}$ in guinea pigs contains neurons responsive to $20-36 \mathrm{kHz}$, and even gerbils have a representation of 30 to $40-\mathrm{kHz}$ frequencies in small portions of both A1 and AAF.

A third feature of organization in all rodents examined is that isofrequency bands in A1 and AAF occupy variable cortical territories, and these differences appear to be related to the acoustic demands of a particular environment. For example, the most striking feature of the gerbil auditory cortex is the cortical magnification of frequencies below $5 \mathrm{kHz}$, while mice and rats have more cortical space devoted to frequencies above $15 \mathrm{kHz}$ and squirrels have a relatively large proportion of cortex devoted to middle-to-low frequencies (compare fig. 12a 
with 12d). As noted above, rodents also have a variable representation of ultrasonic frequencies.

Studies of vocal communication suggest that aspects of cortical representation are associated with many different kinds of vocalizations. These include conspecific and even heterospecific alarm calls for predator warning and identification of the sex, individual identity, and social group membership of the caller, as well as conspecific calls of separated young. Each of these categories of calls utilizes a particular frequency range. For example, comparative studies in rodents demonstrate that the calls of separated young are mostly ultrasonic, but the mean frequency and rate of calls is species specific, with mice and rats having the highest frequency calls (40-70 $\mathrm{kHz}$ and $30-50 \mathrm{kHz}$, respectively), followed by gerbils $(20-55 \mathrm{kHz})$, voles $(20-45 \mathrm{kHz})$, and hamsters [20-40 kHz; Hashimoto et al., 2004; Motomura et al., 2002]. The high frequencies of early postnatal calls made during maternal separation are not detected by predators and are due to the immature development of the lung and vocal apparatus. These calls decrease in rate very rapidly in postnatal development. The ultrasonic representations in auditory cortex mentioned above match (although not perfectly) the frequency range of calls of early postnatal young.

A remarkable amount of information can be conveyed in vocalizations. Alarm calls are an important vocalization category, and a number of rodents have a rich 'vocabulary' of calls that are urgency dependent and predator specific [Randall et al., 2005; Kiriazis and Slobodchikoff, 2006; Furrer and Manser, 2009]. In addition, differences in individuals' calls can inform the listener of the sex, social network, and even individual identity of the caller. For example, prairie dogs have different calls for different predators including humans, domestic dogs, coyotes, and hawks, which elicit appropriate reaction behaviors [Kiriazis and Slobodchikoff, 2006]. These rodents also modulate their call according to individual characteristics of the perceived predator, even distinguishing humans by the color of their clothes [Slobodchikoff et al., 2009]. Giant gerbils (close cousins of the Mongolian gerbil) have distinct calls for different predators such as dogs, humans, and lizards [Randall et al., 2005], and individuals within a population can recognize the sex and identity of a specific individual by the acoustic properties of its call. Finally, studies of Belding's ground squirrel and yellow ground squirrel vocalizations indicate that they have different calls for different predators and that individuals have signature calls that distinguish them from other squirrels within their social group [Mateo, 1996; McCowan and Hooper, 2002; Matrosova et al., 2010].

Although there is variation in the formant frequencies at which these vocalizations occur across different species, most alarm calls are of a lower frequency than the ultrasonic calls of separated young. Giant gerbil vocalizations are generally $1-2 \mathrm{kHz}$ but can be lower; Belding's ground squirrel calls range from 2 to $10 \mathrm{kHz}$, and the yellow ground squirrel calls maximum fundamental frequency is $5-6 \mathrm{kHz}$ [Matrosova et al., 2010]. The species for which call types have been well defined are often not the same species as those for which the neocortex has been well characterized in terms of tonotopic organization. However, they are often close cousins in the same family or even genus, and the match between call frequency and cortical representation is remarkable. The frequency of calls of gerbils and squirrels matches the cortical territory occupied by the representations of these frequencies in cortex (fig. 12). The adult and infant/adult vocal interactions described above indicate a high degree of sociality based on acoustic communication, and calls that distract the predator, elicit specific behaviors, warn conspecifics, and serve as acoustic identifiers of the calling individual indicate that rodents possess sophisticated social networks. Without question, these acoustic interactions are highly complex, even compared to auditory localization and orientation, and likely involve cortical processing. Taken together, the data indicate that the cortical magnification of different frequencies in different species subserves these complex acoustic interactions associated with a specific lifestyle and niche.

Other aspects of auditory cortex vary across species. The proportion of total cortex that auditory cortex assumes varies across rodents, and this is particularly notable in prairie voles (fig. 13). In recent studies in our laboratory we found that the auditory core region in prairie voles was relatively larger than in mice and other mammals with a similarly sized neocortex such as shorttailed opossums. We also found that the extent of cortex in which neurons respond to auditory stimulation was large compared to other rodents, and it overlapped other sensory areas such as V1, V2, S1, and S2 (fig. 13) [Campi et al., 2007]. The suggestion was that these normally unimodal areas were processing input from more than 1 sensory modality and that this expansion of auditory cortex was behaviorally relevant and may be due to the social system, rearing specializations, and vocal communication associated with this species [Campi et al., 2007]. 


\section{Early maps of somatosensory cortex}

a Mouse: Woolsey [1967]

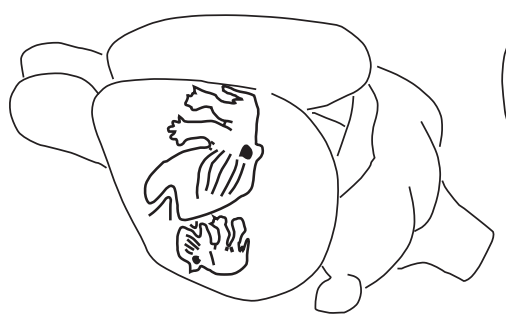

b Rat: Welker [1971]

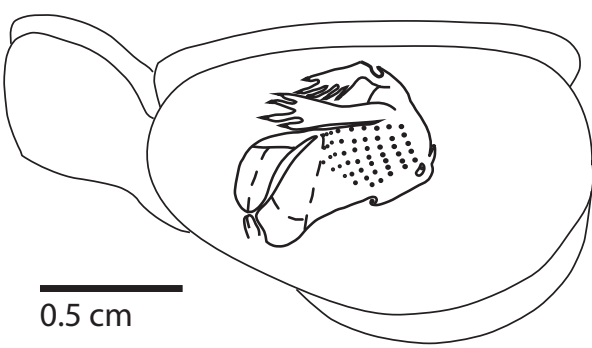

c Beaver: Carlson and Welker [1976]

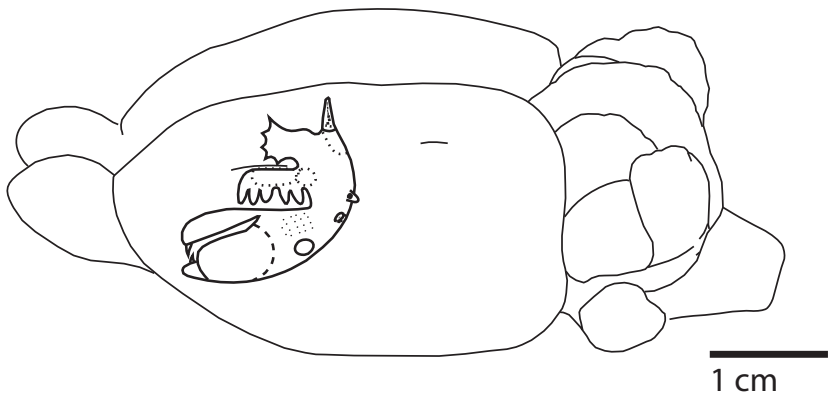

d Capybara: Campos and Welker [1976]

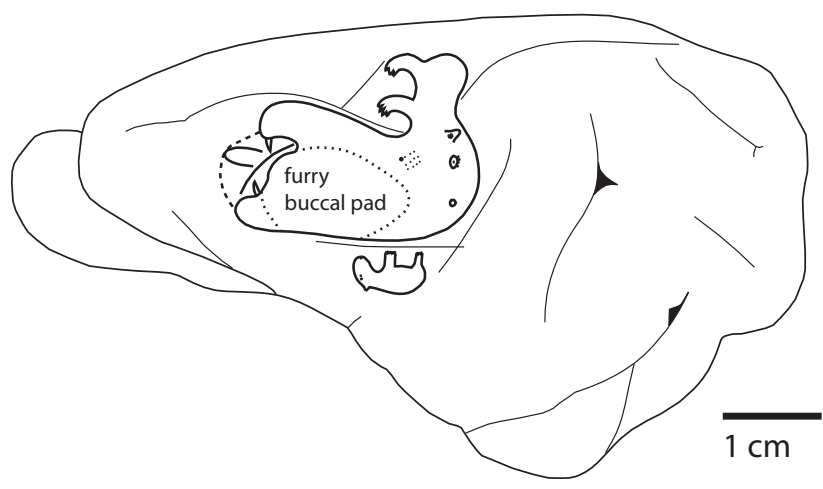

Fig. 14. Line drawings of the early maps of S1 and S2 in the mouse (a), S1 in the rat (b), S1 in the beaver (c), and S1 and S2 in the capybara (d) depicted in the form of homunculi. In all of these rodents there is a cortical magnification of portions of the face such as the whisker representation (barrel field) in mice and rats and buccal pads and lips in beavers and capybaras.

\section{Somatosensory Cortex}

Among all cortical data sets that illuminate species differences, perhaps the richest comes from studies of somatosensory cortex. The first electrophysiological recording experiments in rodents in which the topographic organization of somatosensory cortex was described were done in rats [Woolsey and Fairman, 1946; Woolsey, 1947]. More detailed maps using similar techniques were subsequently made in porcupines [Lende and Woolsey,
1956], mice [Woolsey, 1967], rats [Welker, 1971; Welker and Sinha, 1972], capybaras [Campos and Welker, 1976], and beavers [Carlson and Welker, 1976]. These studies explored the topographic organization of the primary somatosensory area, S1 (S2 was also studied), summarizing the representation of the body in cortex with 'homunculus' diagrams like that of Penfield's human homunculus [Penfield and Boldrey, 1937] (fig. 14). Early studies sometimes referred to this area as SmI or SI. As in other mammals, receptive fields of neurons in rodent $\mathrm{S} 1$ are smaller 
than receptive fields in other somatosensory fields. Also like all other mammals investigated, S1 in rodents contains a complete somatotopic representation of the contralateral body, with the tail represented most medially, the foot and trunk more laterally, the forelimb lateral to this, and the face and oral structures in the most lateral position [for review see Santiago et al., 2007]. In mice and rats, there is a huge magnification of the mystacial vibrissae representation as well as the lips and tongue. Closer examination of this expanded vibrissae representation in mice and rats revealed a distinct ring of cells in layer IV which formed a 'barrel-like' structure, with each barrel corresponding precisely to the representation of an individual whisker on the face [Woolsey and Van der Loos, 1970; Woolsey et al., 1975]. This collection of isomorphic structures in S1 was termed the barrels or barrel field.

With its strict functional/morphological relationship, barrel cortex has, over the past 40 years, served as an excellent model system for studies of development and cortical plasticity [Foeller and Feldman, 2004; Frostig, 2006; Inan and Crair, 2007; Petersen, 2007]. A detailed description of this huge body of work is well beyond the scope of this review. Instead, we will touch only on the prevalence and gross organization of rodent barrels. Comparative studies by Woolsey et al. [1975] describe the organization of barrel cortex in a variety of rodent species representing several suborders and show that the distinctiveness, relative size, and organization of barrel cortex are highly variable across rodent groups (fig. 15). These studies also shed some light on the emergence of barrel cortex in different lineages and provide 3 important conclusions about barrel cortex. The first is that the pattern of barrels in $\mathrm{S} 1$ is directly and precisely related to the number and geometric pattern of whiskers on the face. Second, the presence of barrels is not directly associated with the presence of whisking since rodents that have barrels do not always whisk (e.g. guinea pig) and rodents that have indistinct barrels do whisk (e.g. porcupine). Finally, Woolsey et al. [1975] propose that barrel formation appears to be related to brain size since rodent species with larger brains such as the capybara do not have barrels, while the smaller rodent species with small brains generally have very distinct barrel cortex. The idea that modules do not form in large brains is not supported by subsequent work in larger-brained mammals such as human and non-human primates and dolphins, in which modules similar in size to those of the barrels in murine rodents have been observed in different cortical areas [for review see Manger et al., 2008]. In our recent study of tree and ground squirrels we found that ground squirrels do appear to have barrel cortex that is revealed with cytochrome oxidase [Campi and Krubitzer, 2010]. In largerbrained tree squirrels, however, we found little evidence of barrel cortex. Barrels in other members of the family Sciuiridae are at best indistinct, although several of the species examined by Woolsey et al. [1975] (e.g. chipmunks) have smaller brains than the ground squirrel. Thus, while brain size may play a role in whether barrels emerge, the relationship between barrels and phylogeny cannot be completely ruled out.

Subsequent single- and multineuron explorations of S1 in both the anesthetized and awake rats [Chapin and Lin, 1984] revealed further functional/architectonic relationships and demonstrated the heterogeneity in both cortical architecture in body part representations other than the barrel cortex, and neural response properties of neurons in different architectonic zones of S1 (fig. 16a). Based on the appearance of layer IV, S1 was divided into several subregions with different functional properties. Neurons in cortex in which layer 4 contained densely packed, darkly staining neurons, termed granular cortex, were responsive to cutaneous stimulation whereas those in cortex outside of the granular zone (GZ), in the perigranular (PGZ) and dysgranular zones (DZ) were responsive to joint and cutaneous stimulation. A narrow transitional zone (TZ) was also described just rostral to granular S1 and contained neurons responsive predominantly to stimulation of the joints. Thus, S1 had a modular organization in which submodalities were segregated and related to distinct architectonic zones. Subsequently, Dawson and Killackey [1987] demonstrated that the detailed representation of the forepaw (individual digits and pads) was directly related to morphological distinctions revealed by succinic dehydrogenase (fig. 16b). The pattern of architectonic heterogeneity within S1 is different in other rodents such as squirrels. Squirrels have a very large unmyelinated zone (UZ) that separates the hand and face representations, much like the large dysgranular zone in rats and mice, and very small, thin unmyelinated regions, continuous with UZ, that separate major body parts. Neurons in the unmyelinated zone are not responsive to somatic stimulation under anesthetic conditions. In the final portion of our review of somatosensory cortex, we will discuss the interpretation of this heterogeneity in the primary somatosensory cortex.

After the early studies of the 1950s through the mid 70 s, the detailed organization of cutaneous responses of the contralateral body was determined for $\mathrm{S} 1$ in a variety of rodents (fig. 17) including squirrels [Sur et al., 1978; Krubitzer et al., 1986], agoutis [Pimentel-Souza et al., 
Fig. 15. Photomicrographs of barrel cortex in 13 species of rodents from 3 lineages [taken from Woolsey et al., 1975, with permission]. Below is a cladogram in which the 3 lineages are color-coded. Sciuridae = Green; Muridae $=$ blue; Chinchillidae $=$ red. To the right of the phylogenetic tree is information on the presence and distinctness of barrels as well as the presence or absence of whisking behavior. Note that barrels in most Muridae are distinct while in Sciuridae they are indistinct or absent. In the largest of all rodents, the capybara, barrels are absent. Medial is up [information is also taken from Campi and Krubitzer, 2010].

\section{Comparisons of barrel cortex in rodents}
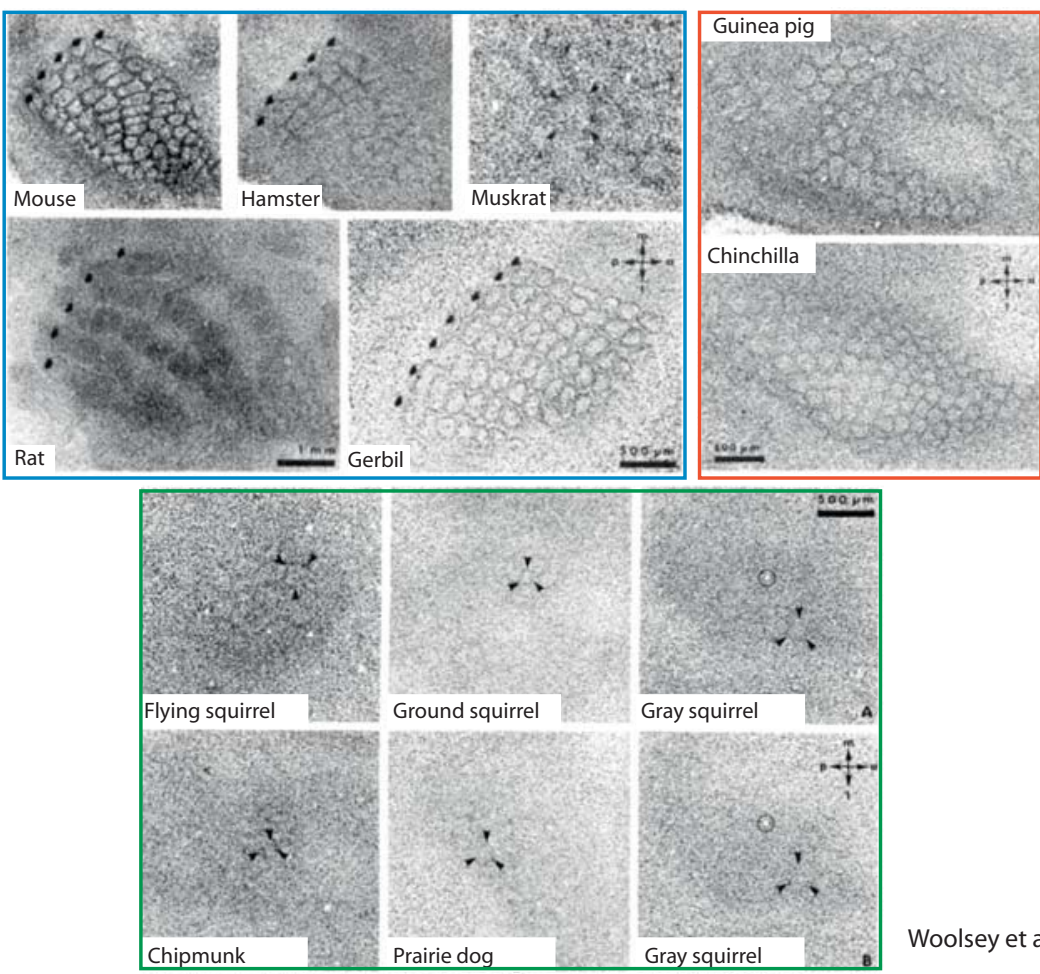

Woolsey et al. [1975

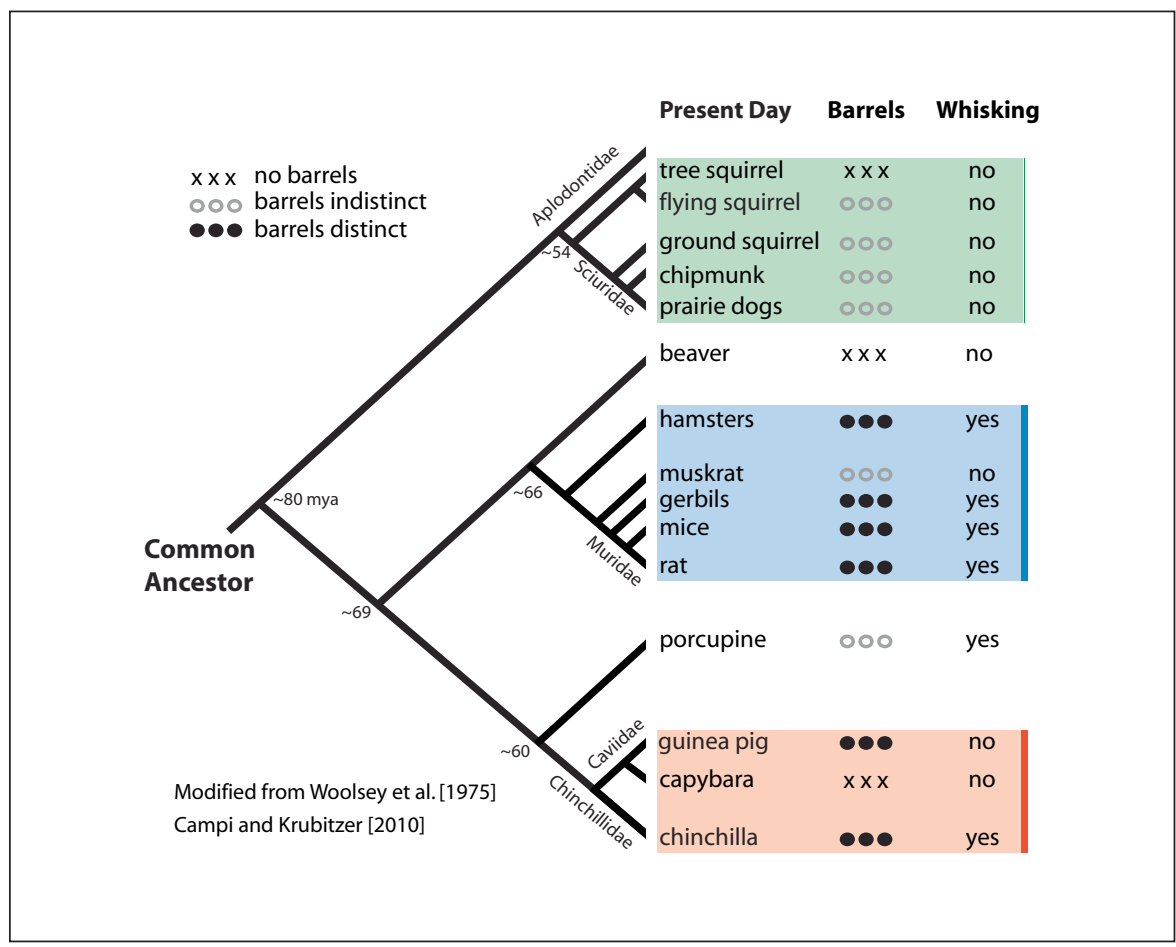


Fig. 16. Granular and dysgranular cortex in rat S1. a An illustration redrawn from Chapin and Lin [1984] of granular and dysgranular zones in rat S1 delineated by single unit electrophysiological recording and thionin staining. b Photomicrograph of a tangential section of rat tissue reacted for succinate dehydrogenase [taken from Dawson and Killackey, 1987, with permission] demonstrating the isomorphic representation of the body in rat S1. To the left of $\mathbf{b}$ is a line drawing of the representation of the hand in cortex (from another similar-looking figure); below is the corresponding portion of the rat hand colored gray (pads), black (digits labeled 1-5), and red (wrist hairs). In the printed version, colors appear as shades of gray.

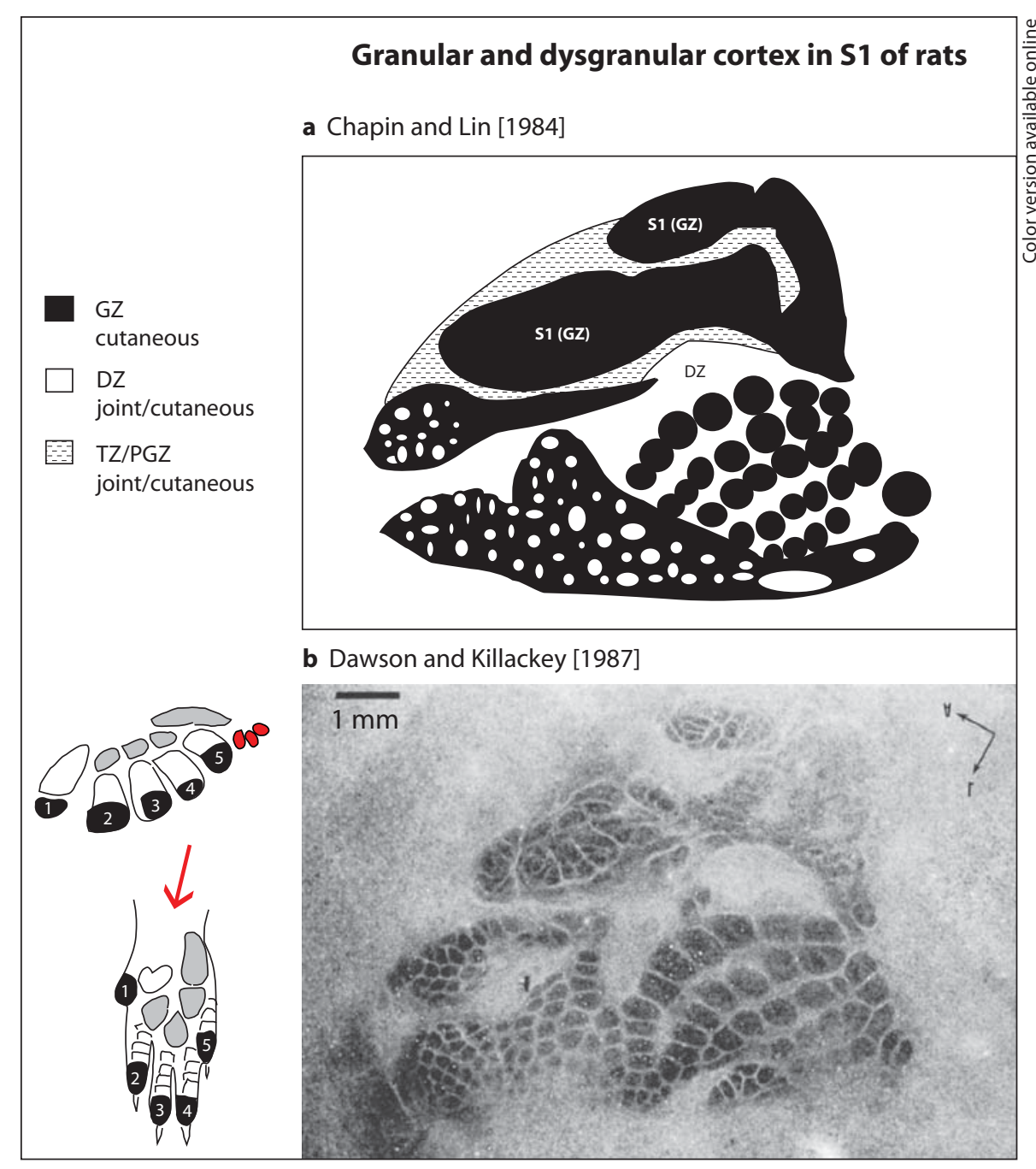

1980], naked mole rats [Henry et al., 2006], prairie voles [Campi et al., 2007], and grasshopper mice [Sarko et al., 2011]. While the gross topographic organization of the primary somatosensory area or S1 is similar in all rodents investigated and in all mammals [Woolsey, 1947; Catania and Henry, 2006; Krubitzer and Disbrow, 2010], there are several features of organization that differ between rodent species [Santiago et al., 2007]. First, while cortical magnification (the disproportionate allocation of cortical territory representing different body parts) is present in all species, the overrepresented body parts are different in different species and are not limited to the vibrissae. The magnified representations include those for the lips, buccal pads, teeth, and perioral hairs and the receptive fields for neurons in these representations are generally very small. For example, in the naked mole rat there is a cortical expansion of the incisors and other parts of the face. The receptive fields for neurons that represent the soft tissue of the face and mouth (e.g. the chin and buccal pad) are extremely small compared to other body part representations [see table 1 of Henry et al., 2006]. Likewise, the representation of the lips in squirrels is particularly large, and receptive fields for neurons in this representation are extremely small [Sur et al., 1978]. Finally, the furry buccal pad representation of the capybara is expanded, dwarfing the nearby vibrissae representation [Campos and Welker, 1976].

The cortical magnification of a particular surface of the body is associated with a specialization of the structure itself, which includes the presence of specialized receptor organs such as whiskers in rats and mice and body hairs in the naked mole rat. Cortical magnification can 
Fig. 17. Line drawings of the somatotopic organization of S1 in the prairie vole (a), rat (b), grasshopper mouse (c), naked mole rat (d), squirrel (e), and agouti (f). Body part representations have been color-coded. Note that while there are differences in the specific facial structure representation that is magnified in the cortex, cortical magnification in rodents is mostly limited to the representations of the head, face, and mouth.

\section{Organization of S1}
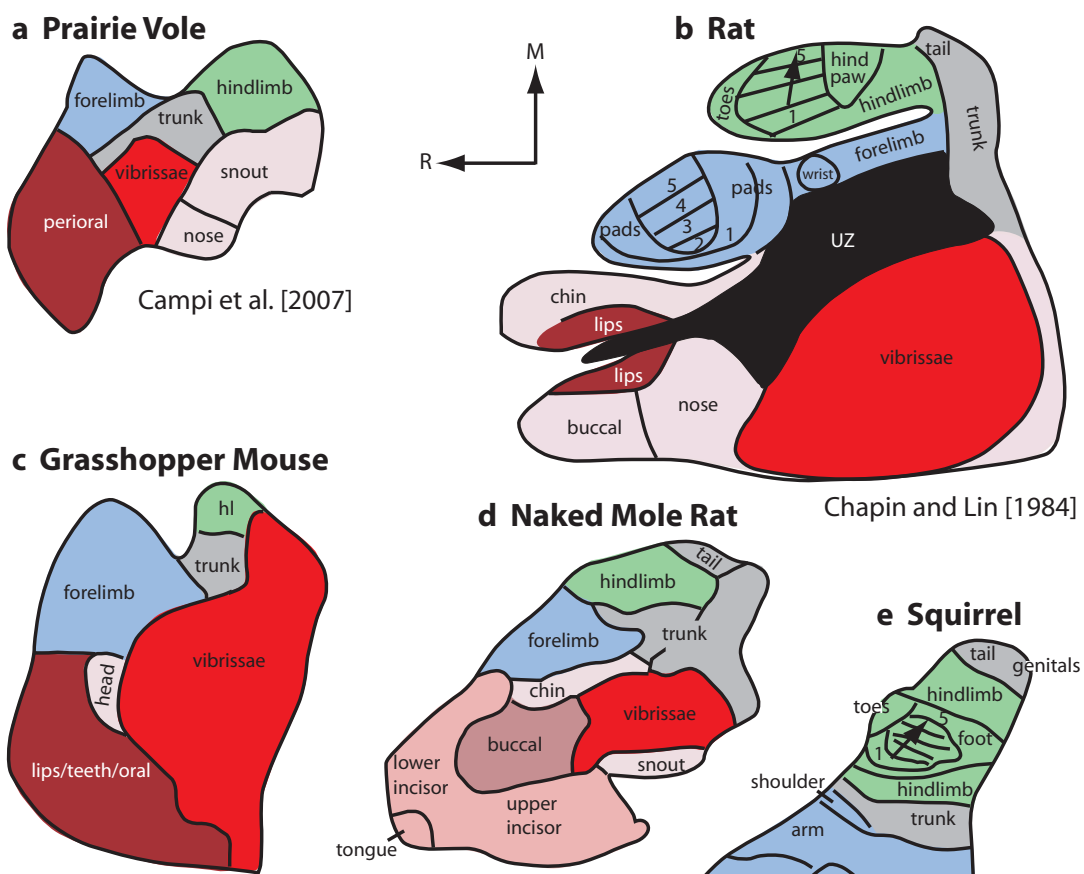

Sarko et al. [2011]

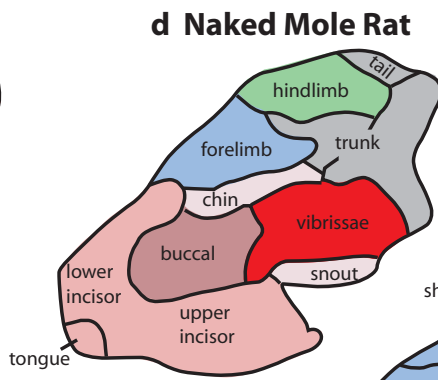

Chapin and Lin [1984]

Henry et al. [2006]
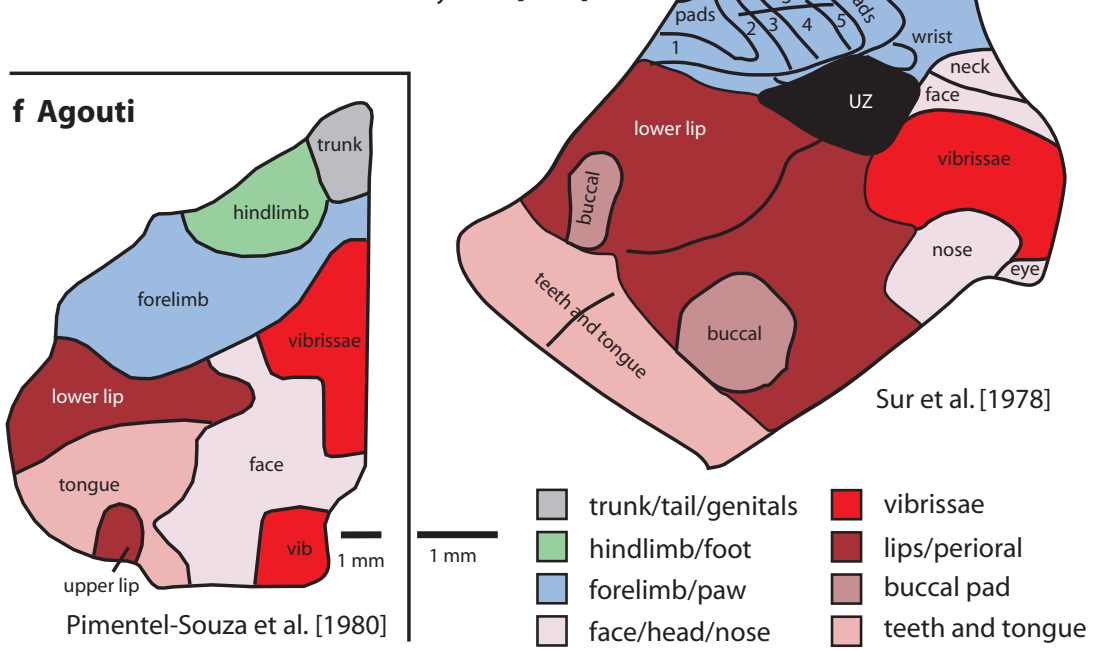

also be associated with the modification of receptor density in existing structures. Often, the structure in question has become relatively large and mobile such as the incisors of naked mole rats (which can open and close independently), the lips and buccal pads in squirrels and capybaras, and the whiskers of rats. These structures contribute to extraordinary sensory abilities, and in some cases can be used to manipulate objects (nuts, grass, rocks, and food items) in the environment. An interesting phenomenon in the rodent order that differs from the primate order is that most specializations of the somatosensory system are of the structures of the face, snout, and mouth and corresponding representations in the cortex are enlarged, although rats and squirrels do have 


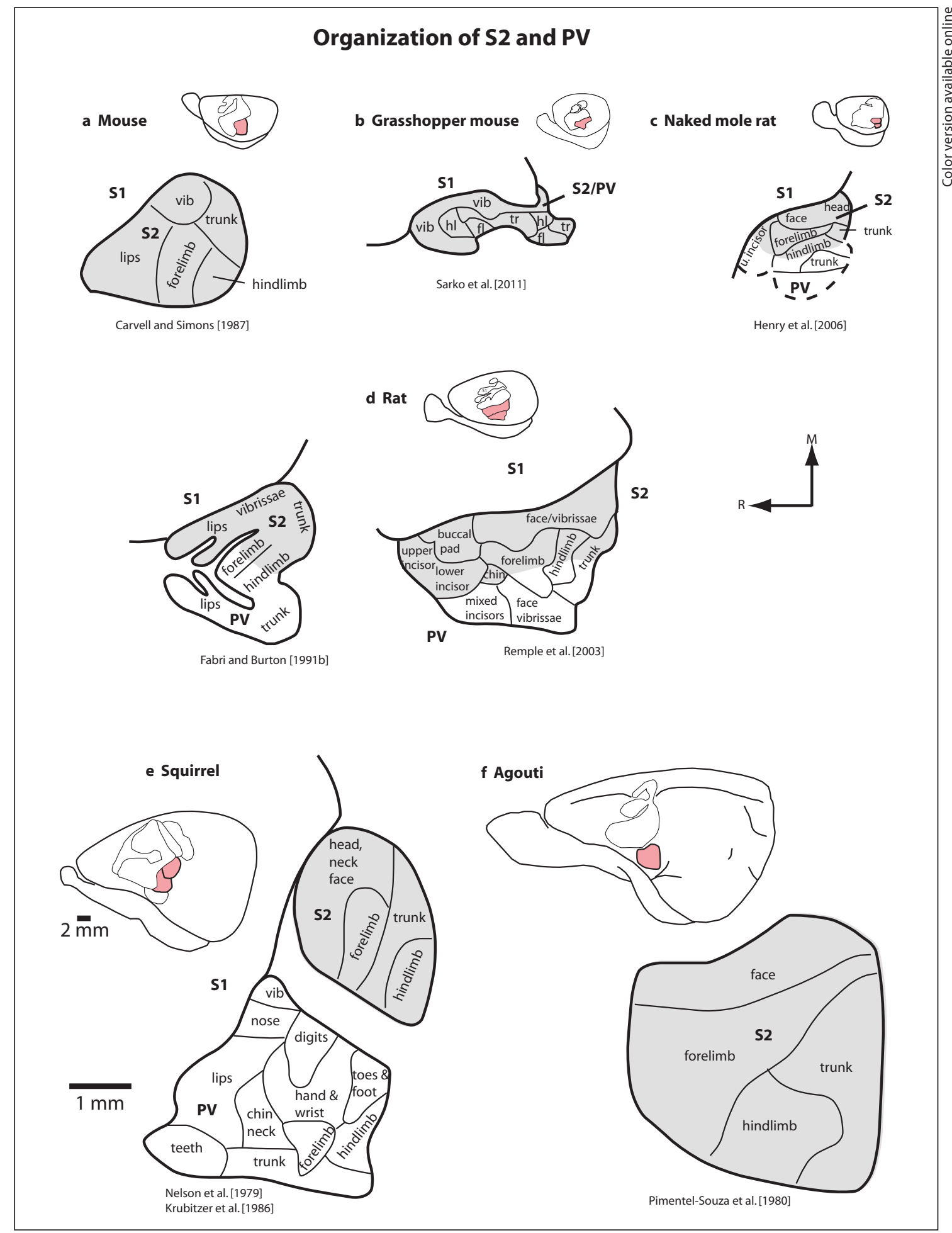

Fig. 18. Line drawings of the dorsolateral cortex showing the location of S1 in black outline and S2 and PV in dusty rose, with enlarged drawings of the S2 and PV representations in the mouse (a), grasshopper mouse (b), naked mole rat (c), rat (d), squirrel (e), and agouti (f). All rodents have at least 1 field lateral to S1, and 4 of the species shown here have a distinct second area, PV. It is difficult to determine the boundaries of PV and S2 in small-brained mammals and thus it is designated as S2/PV. All S2/PV drawings are to scale and all small brains are to scale (see separate scale bars in e). Rostral is to the left; medial is up. In the printed version, colors appear as stipple. 
Fig. 19. Line drawings of the dorsolateral cortex showing the location of S1 in black outline and $3 \mathrm{a}$ and $\mathrm{Pm}$ in dusty rose, with enlarged drawings of $\mathrm{Pm}$ representations in the rat (a) and $3 \mathrm{a}$ and $\mathrm{Pm}$ representations in the ground squirrel (b). All drawings are to scale. Rostral is to the left; medial is up. In the printed version, colors appear as stipple.

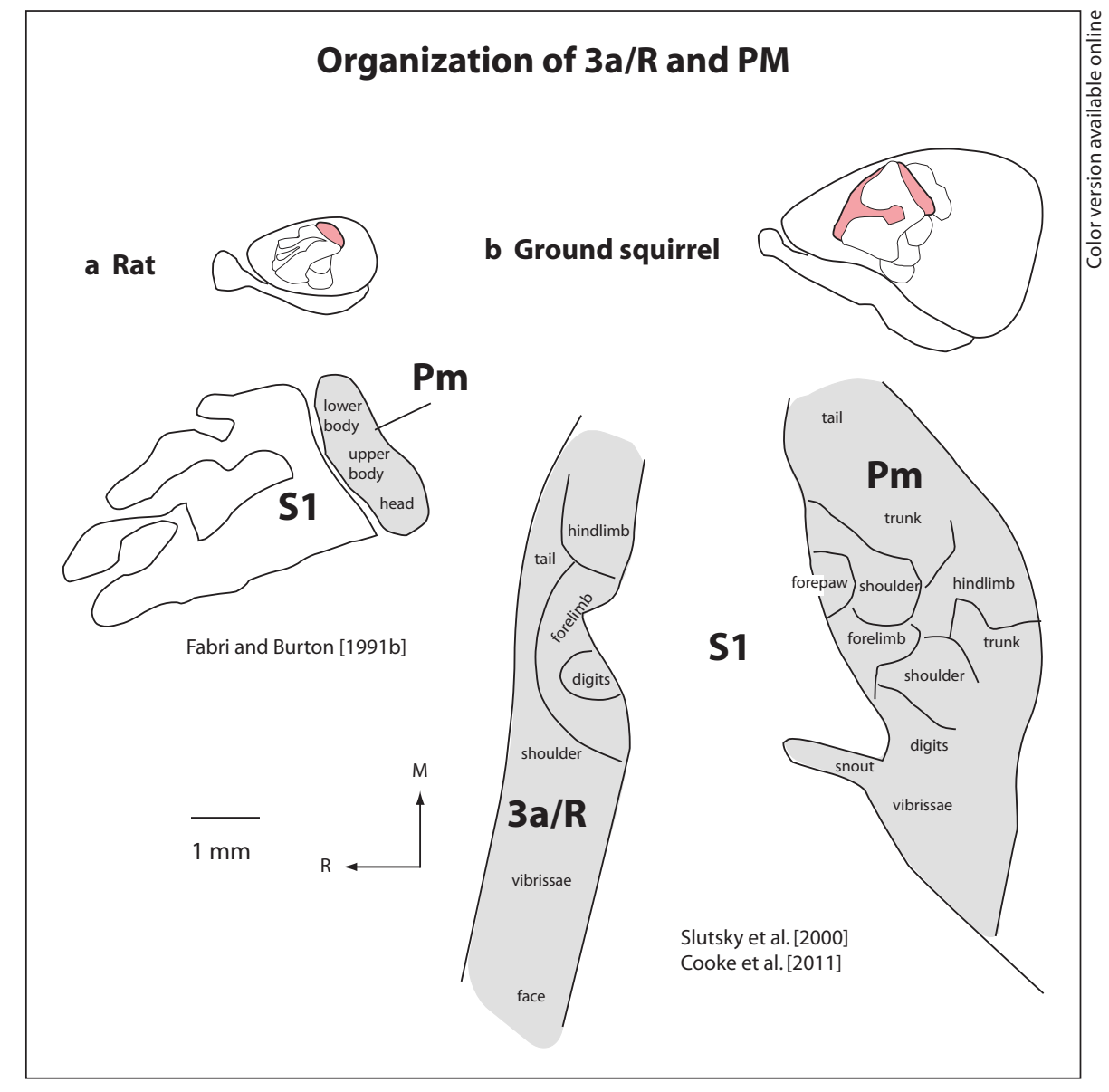

distinct representations of the digits and pads of the hand. While in primates a large portion of S1 and other sensory areas are devoted to the face and oral structures, the primary specialization, and one that probably distinguishes them from all other orders of mammals, is the specialization of the forelimb for object manipulation (rather than for locomotion as in bats, cetaceans, and ungulates). This distinction is extremely important for understanding the organization and function of higher order cortical areas, such as posterior parietal cortex, discussed below.

Among the other areas associated with somatosensory processing in rodent parietal cortex, the second somatosensory area (S2) has been described in varying degrees of detail in both electrophysiological and neuroanatomical studies in all rodents examined including porcupines [Lende and Woolsey, 1956], rats [Welker and Sinha, 1972; Fabri and Burton, 1991b; Remple et al., 2003; Brett-Green et al., 2004; Benison et al., 2007], mice [Carvell and Simons, 1987], squirrels [Nelson et al., 1979; Krubitzer et al., 1986], agoutis [Pimentel-Souza et al., 1980], prairie voles [Campi et al., 2007], naked mole rats [Henry et al., 2006], and grasshopper mice [Sarko et al., 2011]. Like S1, S2 contains a representation of the contralateral body and adjoins the caudolateral border of $\mathrm{S} 1$ at the representation of the nose and lips (fig. 18). It differs from S1 in several ways. First, receptive fields are larger and neurons are less responsive in the anesthetized preparation. Second, the representation of the body is a mirror reversal of S1 and is thus 'upright' in the brain, with the head medial and the hindlimb lateral. Finally, it is relatively small, and while cortical magnification is still seen it is not as exaggerated as in S1. In some rodents, such as prairie voles, neurons in S2 (and the caudal portion of S1) also respond to auditory stimulation (fig. 13). As noted below, in very small-brained animals such as prairie voles and grasshopper mice it is grouped together with PV.

Just lateral to $\mathrm{S} 2$ and caudolateral to $\mathrm{S} 1$ is a third small representation of the contralateral body, the parietal ventral area (PV) (fig. 18). This field was first described in 
detail in squirrels [Krubitzer et al., 1986] and was subsequently described in electrophysiological recording studies in rats [Remple et al., 2003; Brett-Green et al., 2004] and naked mole rats [Henry et al., 2006]. In rats, PV joins the representation of $S 2$ at the representation of the distal limbs, and S2, PV, and S1 share a common border at the representation of the teeth in rats and naked mole rats [Remple et al., 2003] and at the representation of the teeth and lips in squirrels [Krubitzer et al., 1986]. Areas PV and S2 are alike in their overall size and the receptive field size of their neurons, but they differ in that PV is a mirror reversal of S2 and thus contains an 'inverted' representation of the body surface like S1 (fig. 18). In squirrels, there is an auditory overlap in the caudal portion of PV in which neurons respond to both somatic and auditory stimulation [Krubitzer et al., 1986], and in rats there is an overlap of somatosensory and auditory responses in S2 in a region called the multisensory zone (MZ) [Brett-Green et al., 2003]. Responsiveness to auditory stimulation has not been tested in other animals in which dense electrophysiological maps were generated [Remple et al., 2003; Henry et al., 2006]. In small-brained animals such as the grasshopper mouse and prairie vole, $\mathrm{PV}$ has been grouped with S2 and termed S2/PV because distinguishing the 2 fields in very small brains is difficult. In fact, it is possible that only 1 of these 2 fields exists in smaller-brained animals. Studies of connections will help to resolve this issue because in rodents in which S2 and PV have been well defined each receives a separate and distinct topographic projection from S1 [Krubitzer et al., 1986; Fabri and Burton, 1991b]. Given the pervasiveness of the S2-PV somatosensory region in rodents and all other mammals examined [Krubitzer, 1996; Qi and Kaas, 2008] this field forms part of a common plan of organization in mammals and therefore was likely present in the common ancestor of all mammals.

Electrophysiological recording studies of other somatosensory areas are limited to ground squirrels [Slutsky et al., 2000]. In cortex immediately rostral and caudal to S1, neurons respond to stimulation of deep receptors of the contralateral body (fig. 19). Caudally, neurons in the region termed the parietal medial area $(\mathrm{Pm})$ are difficult to drive and have large receptive fields. The representation of body parts is very coarse but complete. Although electrophysiological recordings in this caudal cortex have not been performed in other rodents, studies of connections of S1 in squirrels [Krubitzer et al., 1986], as well as rats reveal very dense projections to this region [Akers and Killackey, 1978; Fabri and Burton, 1991a; Lee et al., 2011]. Further, in rats the dysgranular zone within

A Modern Synthesis of Cortical

Organization in Rodents
S1 projects very strongly to this region [Fabri and Burton, 1991a; Lee et al., 2011]. In rats this region is also termed posterior parietal cortex (PPC) [Reep et al., 1994] and it receives convergent sensory inputs from visual and somatosensory cortex and from nonprimary sensory nuclei of the thalamus such as LD, LP, and Po. Thus, even in the absence of electrophysiological recording data in rats, cortex caudal to $\mathrm{S} 1$ is associated with somatosensory and multisensory processing. Although further study is needed, we propose that Pm in squirrels and PPC in rats are homologous and may be a primitive homolog to portions of posterior parietal cortex (PPC) described in other mammals such as primates [Lee et al., 2011].

A number of investigators have subdivided this region and demonstrated that it is involved in generating frames of reference for navigating the environment [Nitz, 2009], and spatial attention, much like portions of posterior parietal cortex in primates [for review see Torrealba and Valdes, 2008; Bucci, 2009; Reep and Corwin, 2009]. In fact, Corwin and colleagues have developed compelling models of hemi-neglect in rats induced with lesions to PPC [King and Corwin, 1993; see Reep and Corwin, 2009, for review]. Like humans with hemineglect, these rats have contralesional neglect of visual, somatic, and auditory stimuli, as well as extinction and disorders of spatial processing.

Two questions regarding $\mathrm{PPC} / \mathrm{Pm}$ in rodents arise. First, what portions of primate posterior parietal cortex, if any, are homologous to this region? The relative size of $\mathrm{PPC} / \mathrm{Pm}$ in rats and squirrels is extremely small compared to the highly expanded posterior parietal cortex of primates. Second, do these potentially homologous regions generate similar high-level functions in rodents and monkeys given the remarkable differences in their primary effectors? For example, rats rely heavily on inputs from the whiskers whereas primates rely on visual inputs and proprioceptive inputs from the forelimb and hand. Whiskers are not just passive tactile sensors. Like the primate hand, rats' whiskers are used for active touch in which whisking movements are used like palpations made by a monkey's hand to explore objects to provide information about immediate extrapersonal space. Indeed, rats' whiskers are used to estimate the shape and location of the objects [Kleinfeld et al., 2006; Diamond et al., 2008]. The sensorimotor integration necessary to precisely control the vibrissae occurs at all levels of processing, but the process of identifying an object and how to interact with it and then directing movements based on that information occurs in the neocortex [Diamond et al., 2008] such as divisions of PPC. One might expect that 
$\mathrm{PPC} / \mathrm{Pm}$ in squirrels is somewhat differently organized than in rats since squirrels rely more heavily on vision compared to rats.

Just rostral to $\mathrm{S} 1$ and extending into $\mathrm{S} 1$ is a representation of deep receptors of the contralateral body, initially termed the rostral field in squirrels [Slutsky et al., 2000]. Neurons here have large receptive fields, and the somatotopy of the field is coarse (fig. 18). While the entire body is represented in squirrels, there appears to be a magnification of the forelimb and face representation. In recent studies in ground squirrels in our laboratory, intracortical microstimulation combined with electrophysiological recording revealed that movements of the body could be evoked from this rostral region (fig. 22) [Cooke et al., 2011]. We therefore proposed that this field plus the unresponsive zone (UZ) is homologous to area $3 \mathrm{a}$ in primates and other species [fig. 20, Wong and Kaas, 2008; Cooke et al., 2011]. In rats, there appears to be no field in the precise location of area $3 \mathrm{a}$ except for the small transitional zone (TZ) described in previous studies. We have recently suggested that, collectively, this TZ plus dysgranular cortex (DZ, located within S1) in rats is homologous to area $3 \mathrm{a}$ in squirrels. This of course rests on the supposition that most or all of the nongranular cortex in S1, sometimes proposed as separate regions, is really a single field (e.g. DZ, TZ, and perhaps the septal space surrounding barrels) [see Fabri and Burton, 1991a].

The proposed homologies between squirrel $\mathrm{R} / 3 \mathrm{a}$ and rat $\mathrm{TZ}+\mathrm{DZ}$ are supported by several observations. First, the appearance and response properties of $\mathrm{DZ}$ in rats [Chapin and Lin, 1984] and 3a in squirrels [Slutsky et al., 2000; Cooke et al., 2011] are similar. Second, the connections of the granular zone (GZ) and DZ within S1 are substantially different. Specifically, rat GZ and squirrel $S 1$ receive inputs from the ventral posterior nucleus (VP) of the thalamus while rat $\mathrm{DZ}$ and squirrel 3 a receive input from Pom. In addition, Alloway [2008] proposes that the septal regions are more strongly related to motor pathways and involved in whisking behaviors than are granular regions [for review see Krubitzer and Kaas, 1987; Cooke et al., 2007; Alloway, 2008]. Moreover, DZ in rats and $3 \mathrm{a} / \mathrm{UZ}$ in squirrels receive strong callosal input, whereas GZ in rats and most of the myelinated regions in squirrel S1 are acallosal [Akers and Killackey, 1978; Wise and Jones, 1978; Gould, 1984]. Third, both DZ/septa in rats and $3 \mathrm{a}$ in squirrels have dense projections to motor cortex and cortex immediately caudal to $\mathrm{S} 1$ in $\mathrm{PPC} / \mathrm{Pm}$.

Our studies of motor cortex in squirrels suggest that area $3 \mathrm{a}$ is involved in motor processing [Cooke et al., 2011] (see below). As noted above, Alloway [2008] pro-

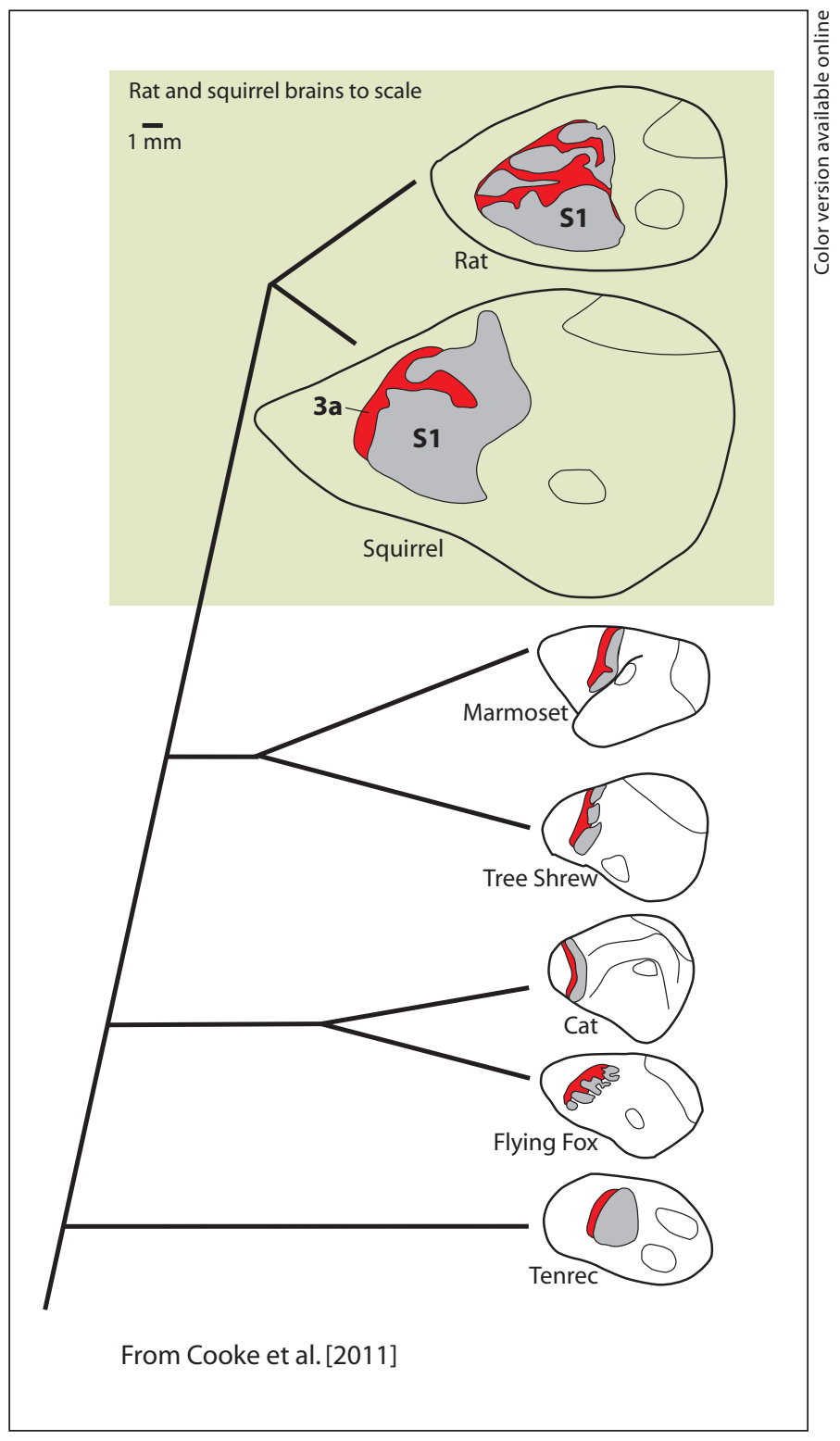

Fig. 20. Evolutionary relationship of some mammals with an identified (or in the case of the rat, proposed) area 3a. Branch lengths of the cladogram are not to scale. Each species is represented by a lateral view of a schematic brain showing $3 a$ (red) or the proposed $3 \mathrm{a} / \mathrm{DZ}$ in rats, $\mathrm{S} 1$ (gray), and the primary auditory and visual fields outlined in black. Adapted from Felleman et al. [1983] for the cat, from Chapin and Lin [1984] for the rat, from Krubitzer et al. [1997] for the tenrec, from Krubitzer et al. [1992] for the flying fox, from Huffman and Krubitzer [2001] for the marmoset, and from Wong and Kaas [2009] for the tree shrew. All brains except those of the rat and squirrel are not to scale. Area 3a is widespread in the mammalian lineage; this fact and shared properties suggest that rat dysgranular cortex is homologous with $3 a$ in squirrels in other mammals. In the printed version, red appears as dark gray. 
poses a sensory role for granular barrels and motor control function for septa. Further evidence for a motor role for a traditionally 'sensory' field comes from a recent study that found that whisker movements could be evoked by electrical stimulation in mouse S1 [Matyas et al., 2010]. Interestingly, chemical inactivation of S1 prevented the mouse from making normal sensory-evoked whisker retractions, while inactivation of a whisker retraction site in M1 had no effect on this behavior. Furthermore, M1 control of whisker retraction appeared to occur via S1, while protraction occurred more directly from M1 to subcortical structures. Whether this provocative finding of motor control in $\mathrm{S} 1$ is related to a possible 3a homolog in mice is not yet known.

In other rodent species, such as prairie voles, naked mole rats, and grasshopper mice, discontinuities in myelin/CO staining in S1 have been observed, but these thin zones have not been mapped in detail. If area $3 \mathrm{a} / \mathrm{UZ}$ and $\mathrm{DZ} /$ septa are homologous in rats and squirrels, and if this region is homologous to area $3 \mathrm{a}$ in other mammals, this suggests that the ancestor of all rodents and all eutherians had a full or partially embedded area 3a that in some lineages segregated fully (primates) or partially (flying foxes and some families of rodents such as squirrels) from S1 (fig. 20).

Taken together, the data indicate that all rodents have at least 2 somatosensory areas: S1 and 1-2 lateral fields, S2 and PV (fig. 21). A fourth field, 3a/DZ, is also observed in all rodents, although the geometric relationship of this field with $\mathrm{S} 1$ is different in different animals. In some species, such as squirrels, the field is located rostrally and is only partially embedded in S1. In rats and mice (and possibly in other small-brained rodents) this field is fully embedded in S1. This difference in geometric relationships is likely due to the variety of selective pressures found in different rodent lineages. In some species there may be selection to conserve discrete receptive fields created from thalamic inputs from the ventral posterior nucleus (VP) that are uninterrupted by inputs from other thalamic nuclei (e.g. Po) or callosal afferents (DZ/3a). This allows for short intra-areal connections and increased speed of processing from immediately adjacent body part representations [Krubitzer et al., 1992]. In this scenario, S1 would be relatively homogeneous (as in squirrels), with few interruptions in representation. On the other hand, selection for fully embedded fields, as in rats and mice, would allow rapid communication between zones receiving different but complementary thalamic inputs necessary for making rapid alterations in the movement of the effector ensemble, such as vibrissae. Finally, some species of rodents such as rats and squirrels have an area of cortex caudal to S1, PPC/Pm, that appears to carry out higherlevel functions often studied in primates. These include integration of inputs from different modalities, spatial navigation, attention, and monitoring of objects in immediate extrapersonal space. $\mathrm{PPC} / \mathrm{Pm}$ in rodents may be homologous to portions of posterior parietal cortex described in other mammals.

\section{Motor Cortex}

Several studies have examined the architecture and connectivity of motor cortex in rats and mice [Donoghue and Parham, 1983; Porter and White, 1983; Cicirata et al., 1986; Alloway et al., 2009; Colechio and Alloway, 2009] (see above for studies of cortical architecture). In some studies, cortex immediately rostral to $\mathrm{S} 1$ is reported to contain a small transitional zone with a reduced layer 4 compared to S1 and moderate myelination [Chapin and Lin, 1984; Wong and Kaas, 2008; Campi and Krubitzer, 2010; Cooke et al., 2011]. This field has been termed TZ in some studies of rats, and area $3 \mathrm{a}$ in studies of squirrels, and has been described in detail in the previous section of this review. Other studies [e.g. Donoghue and Wise, 1982; Neafsey et al., 1986] propose a slightly different scheme in rats encompassing a larger region rostral to $\mathrm{S} 1$ termed agranular cortex. Agranular cortex contains 2 architectonic divisions termed the agranular lateral division (AGl) and the agranular medial division (AGm). It is thought that $\mathrm{AGl}$ is immediately rostral and even overlapping slightly with S1. This scheme is not too different from the first scheme of organization since AGl may include all of $\mathrm{TZ}$ and portions of $\mathrm{DZ}$ as discussed previously (as well as cortex rostral to this). AGl contains a reduced layer 4 (granular layer), reduced myelin, and a thicker pyramidal cell layer (layer 5), much like area 3a of squirrels. This region has been termed Prc1 and Prc2 by Zilles et al. [1980] (fig. 4) and matches the appearance and location of AGl. AGm is rostromedial to AGl and wraps onto the medial wall of cortex with a smaller portion also bordering AGl rostrolaterally [Donoghue and Wise, 1982]. AGm is described by Donoghue and Wise [1982] as equivalent to the Prcm and Prc 3 of Zilles et al. [1980].

Studies examining the functional organization of the motor cortex have been limited mainly to rats [Hall and Lindholm, 1974; Donoghue and Wise, 1982; Gioanni and Lamarche, 1985; Neafsey et al., 1986; Kleim et al., 1998; Brecht et al., 2004; Haiss and Schwarz, 2005; Ramana- 


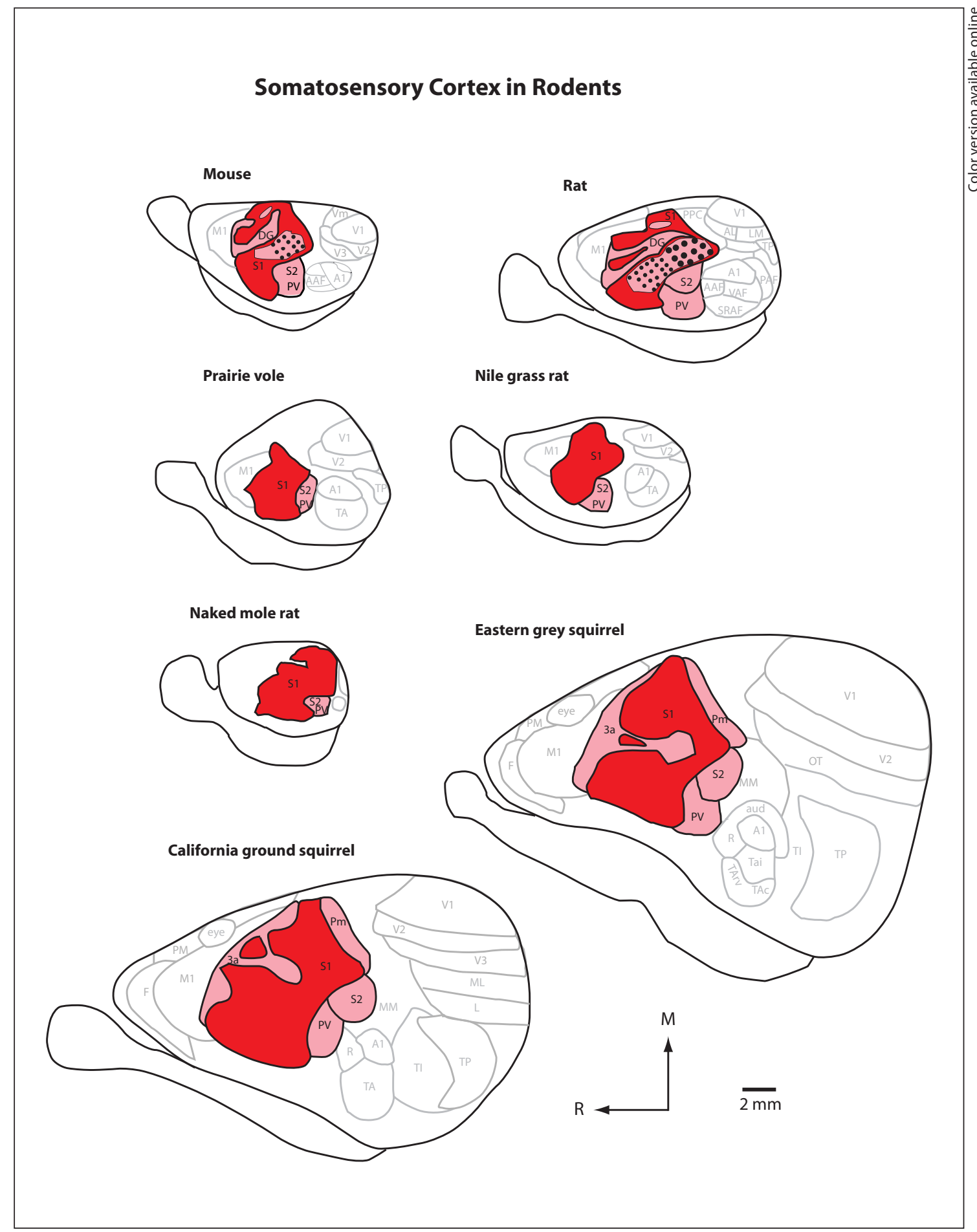

Fig. 21. Line drawings of flattened cortical hemispheres depicting the location of S1 and other somatosensory areas in somatosensory cortex in the mouse, rat, prairie vole, Nile grass rat, naked mole rat, California ground squirrel, and eastern gray squirrel. S1: Primary somatosensory area (dark red), all other delineated somatosensory areas are depicted in pink. All drawings are to scale. Rostral is to the left; medial is up. In the printed version, colors appear as shades of gray. 
Fig. 22. Line drawings of the topographic organization of M1 (AGl) as described in different studies in rats (a-e), mice (f), and squirrels (g). Despite the differences in stimulation parameters and anesthetic, the maps in rats generated in different laboratories are remarkably similar. Some of these drawings were generated by combining multiple maps from a single publication (such as in c). Some drawings are from maps chosen from one of several that were generated based on a particular current threshold (d). The squirrel motor map looks fractured compared to other maps, but the general organization is similar. Note that a second representation of the forelimb located rostrally is observed in some studies in rats $(\mathbf{c}, \mathbf{d})$, mice (f), and squirrels (g). Body part representations have been color-coded. All drawings are to scale (scale bar at lower left) except for the mouse, which is presented at twice the scale of other maps (scale bar below f). Conventions are as in previous figures.

\section{The Organization of Motor Cortex in Rodents}

a Rat: Hall and Lindholm [1974]

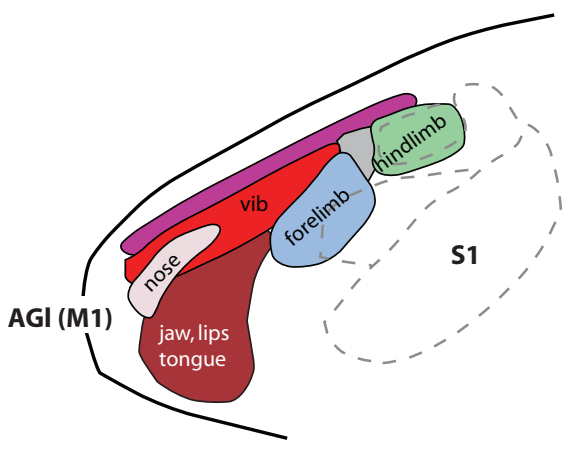

c Rat: Neafsey et al. [1986]

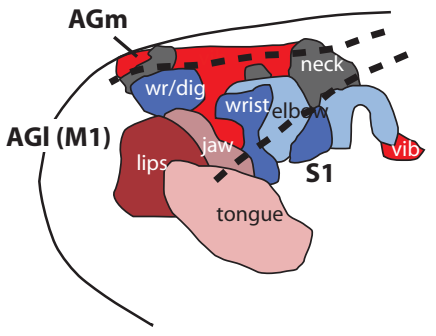

e Rat: Brecht et al. [2004]

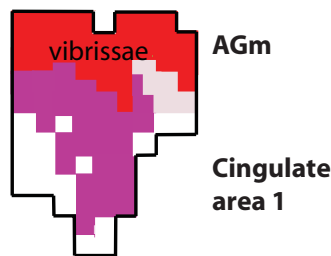

Area mapped on
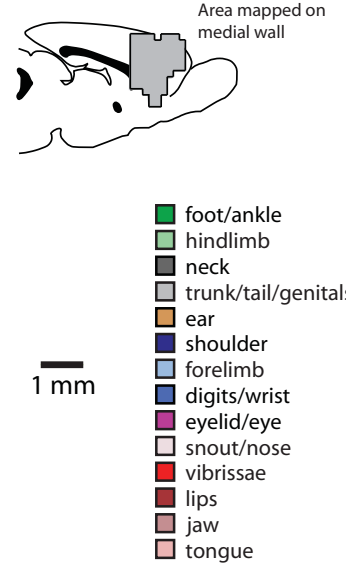

b Rat: Donoghue and Wise [1982]

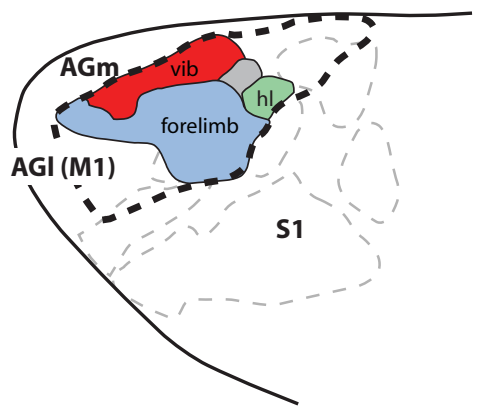

d Rat: Tandon et al. [2008]

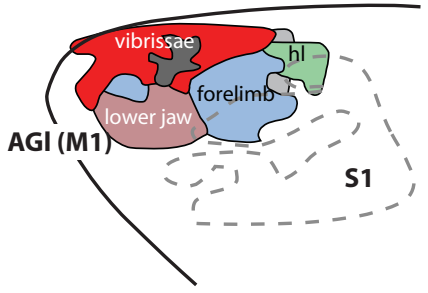

f Mouse: Tennant et al. [2010]

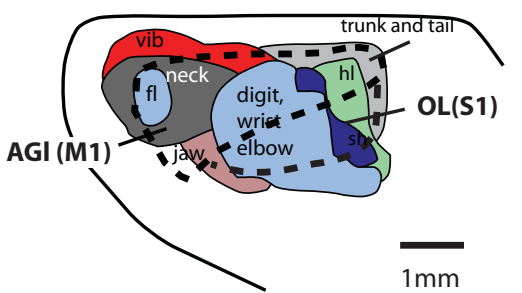

g Eastern grey squirrel: Cooke et al. [2011]

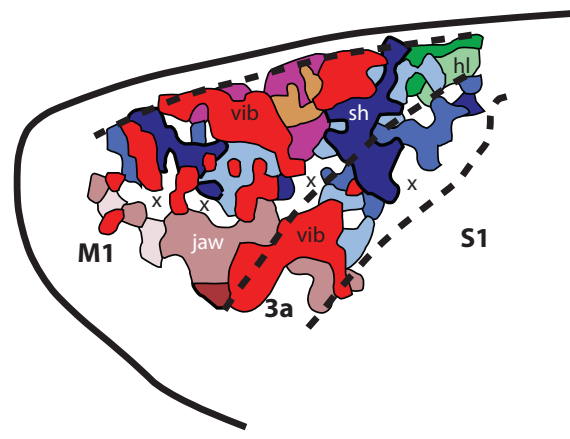


than et al., 2006; Tandon et al., 2008]. The functional organization of motor cortex in the mouse [Li and Waters, 1991; Pronichev and Lenkov, 1998; Tennant et al., 2010], and squirrel [Cooke et al., 2008, 2011] are limited and only within the last year have full functional maps for mice been generated [Tennant et al., 2010]. Earlier studies of mouse motor cortex do exist but are problematic. One study used a mouse strain characterized by muscle degeneration [Li and Waters, 1991]. Another yielded a relatively small responsive area possibly as a result of the anesthetic used [Pronichev and Lenkov, 1998]. The paucity of studies on rodent motor cortex is surprising given the diversity in lifestyle of different species of this order, the variability in terrain niche, locomotion, and navigation, and the specialization of effectors used to explore the environment. For the most part, studies in which intracortical microstimulation was used to explore functional organization are in good agreement regarding the number of motor fields in rodents, although the details of organization can be different. In fact, describing and illustrating the general organization of motor cortex in rats and other rodents is difficult for several very important reasons. First, several aspects are affected by the stimulation parameters used, even in the hands of the same team of investigators. Varying the stimulation frequency and duration, Hall and Lindholm [1974; Young et al., 2011] reported that the size of body part representations and even whole motor fields differ depending on the characteristics of the stimulation waveform [compare fig. 1 of Hall and Lindholm, 1974, with their fig. 6]. In another study, in which stimulation duration was varied, Ramanathan et al. [2006] found that short-duration trains of current pulses evoke simple muscle twitches while longer trains of stimulation evoke more elaborate multi-body-part movements such as reaching and grasping [see fig. 3 of Ramanathan et al., 2006]. Second, the type and level of anesthetic used can generate different motor maps that are more or less inclusive in terms of body part representations [see fig. 4 of Tandon et al., 2008]. Third, when movements generated at suprathreshold currents are considered, the locations and sizes of body part representations shift [see fig. 5 of Tandon et al., 2008]. Fourth, how an investigator groups their stimulation sites can generate different-looking maps. For instance, summaries of data in which general body part movements are grouped can look different from the more fractured maps that are generated when very specific movements are segregated [see fig. 2 of Tennant et al., 2010] (fig. 22). Finally, even when all of the parameters described above are held constant, there appears to be a good deal of variability in individual cortical maps within a population [see fig. 3 of Tandon et al., 2008; see fig. 2 of Tennant et al., 2010].

Considering these challenges of interpreting data from motor mapping, there is relatively good agreement between studies of the same species (fig. 22a-d) and between species (fig. 22). All studies define a large field, termed M1, which is coextensive with AGl in rats and thus partially overlaps with S1. Thresholds necessary to evoke movements in this field are low $(5-50 \mu \mathrm{A})$. In squirrels, a large field has been identified that is coextensive with the lightly-to-moderately myelinated cortex rostral to area $3 \mathrm{a}$, but it is difficult to determine a functional boundary between areas $3 \mathrm{a}$ and M1 based solely on microstimulation. In rats, M1 has a very gross somatotopic organization that roughly mirrors the mediolateral organization of S1 (fig. 22). The oral structures, including the tongue, lips, and jaw, are represented rostrolaterally in rat M1, and portions of the forelimb are represented medial to this. Just rostral to the forelimb is the representation of the vibrissae, and medial to the forelimb is the representation of the hind limb. Eye movements and eye blinks can be evoked from a rostromedial location in this field. The overall organization of M1 in mice and squirrels is similar, but the maps in these rodents appear to be fractured, with splits in body part representations and multiple representations of the same body part (fig. 22g) [see fig. 2C-H of Tennant et al., 2010]. However, as noted above, this may be due to a number of factors.

Rostral and medial to M1/AGl in rats (or perhaps inside the rostral portion of M1, depending on which organizational scheme is used) is a second representation of the forelimb or rostral forelimb area (RFA) [Neafsey and Sievert, 1982; Kleim et al., 1998; Brecht et al., 2004]. Compared to movement representations of the caudal forelimb area, which tend to involve the elbow and shoulder, the RFA is associated more closely with movements of the digits [Neafsey and Sievert, 1982]. However, this trend is reversed in the mouse [Tennant et al., 2010]. Neafsey and Sievert [1982] argued that because there is no 'rostral hind limb area' and because the RFA has similar stimulation current thresholds to the rest of M1, it is not a separate motor area but rather a part of M1 proper. Under this interpretation, the RFA is part of a fractured M1 organization. Subsequent studies in rats [e.g. Tandon et al., 2008], mice [Tennant et al., 2010], and squirrels [Cooke et al., 2011] have identified a rostral forelimb representation. It should be noted, however, that the exact rostral boundary of M1 and its relationship to the RFA and other motor fields is not well established since these regions have usu- 


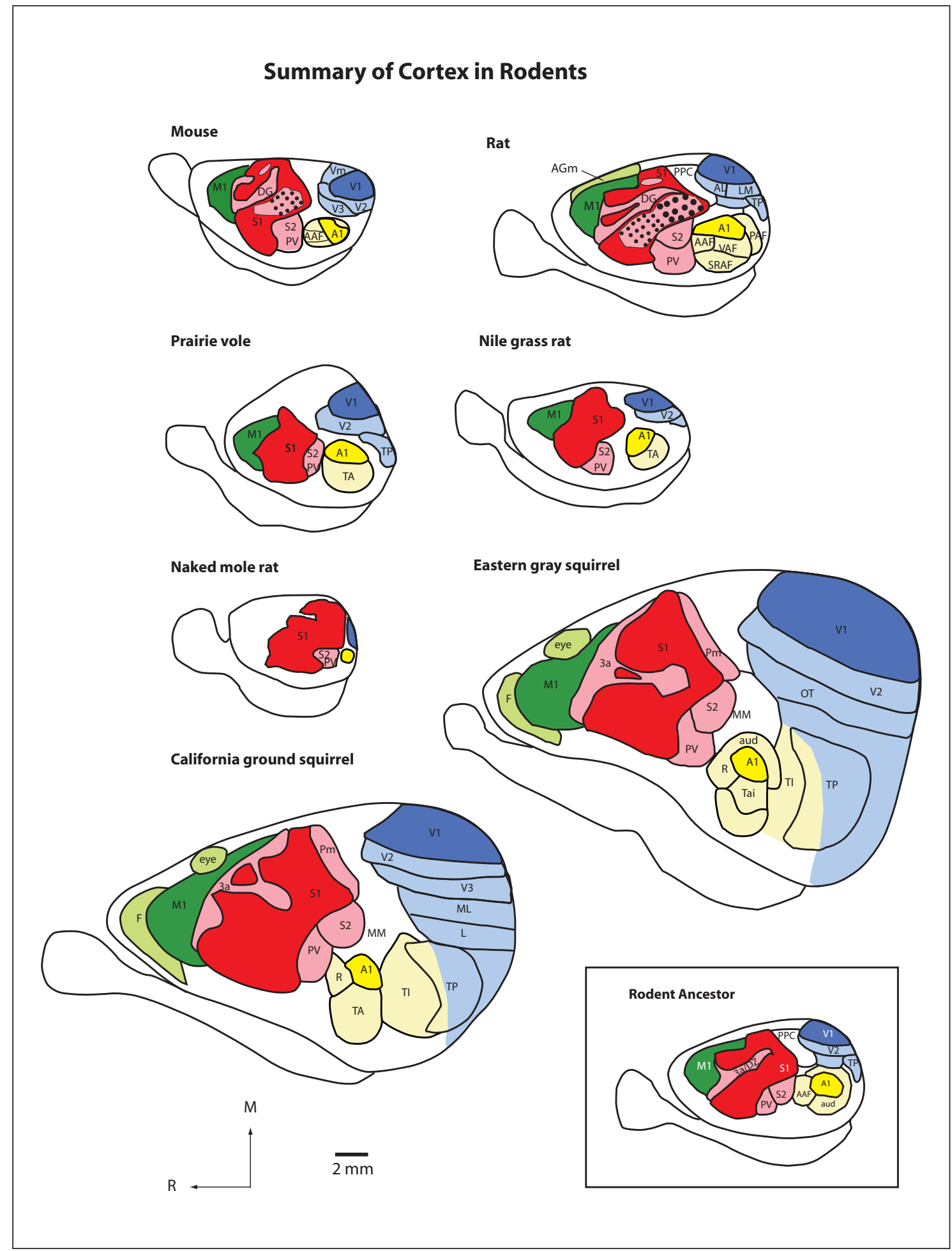

Fig. 23. Line drawings of flattened cortical hemispheres depicting the location of sensory and motor cortex in the mouse, rat, prairie vole, Nile grass rat, naked mole rat, California ground squirrel, and eastern gray squirrel. There are dramatic differences in the amount of cortex devoted to different sensory domains, the relative size of cortical fields, and the number of cortical fields in different animals. However, the similarities in organization indicate that these fields were present in the common ancestor of all rodents (inset). All drawings are to scale. Rostral is to the left; medial is up. 
ally been explored in separate studies. An alternate hypothesis is that the rostral forelimb movement region in M1 is actually part of a second field, M2/SMA, that wraps around the dorsal cortex and continues on the medial wall to include representations of the vibrissae snout and eye (fig. 22). A small hind limb representation (as in M1) may not be present or may not have been observed in previous studies.

Since both AGl and AGm project to the spinal cord [Wise et al., 1979], it is clear that both are involved in motor processing. However, some studies using 1 set of stimulation parameters and anesthesia found stimulationevoked movements for all body parts at sites in AGl but not AGm [Donoghue and Wise, 1982] and therefore argued that AGm is not part of M1 but instead might be similar to SMA in other animals. In contrast, Neafsey et al. [1986] did not find a complete muscle representation in AGl but were able to evoke vibrissae and eye movements from sites in AGm, which they likened to a rodent frontal eye field. Brecht et al. [2004] present yet another scheme in which M1 comprises AGl, AGm, and the cingulate area 1 on the medial wall, which together represent an entire set of movements of the body, with AGl representing most of the body, AGm the vibrissae, and cingulate area 1 eye and nose movements (fig. 22e). This last paper proposes that some differences in the relative sizes and borders of these fields may be due to the problem of activating the excitable layer $\mathrm{V}$ and then resolving the geometry of the electrode angle with the steeply curving cortex near the medial wall.

Taken together, studies in rats, mice, and squirrels have revealed a large representation of movements of the body, M1, which in many but not all reckonings is coextensive with the architectonic region AGl. It is not clear whether this functional field overlaps S1 in rats or if there are actually 2 fields, one that is coextensive with area $3 \mathrm{a} /$ TZ cortex (which is also distinct from S1) and one that is M1 proper. Support for the latter proposition is provided above in the section on somatosensory cortex. It is possible that a second field rostromedial to M1 and wrapping onto the medial wall is present as well and corresponds to architectonic area AGm. Interestingly, in rats this field appears to be dominated by the representation of the head, including the main somatosensory effectors of rats, the whiskers. If it is not, in fact, part of M1, this field may be homologous to the supplementary motor area (SMA) described in other mammals such as primates based on its location [Penfield and Welch, 1949; Woolsey et al., 1952].

\section{Conclusions}

There is a common plan of cortical organization that rodents share that includes V1, V2, V3, S1, 3a (DZ+TZ), S2, PV, A1, AAF (R), TP, and M1. Given the ubiquity of these fields in most rodents, and their presence in a number of other mammals [Krubitzer et al., 1995; Krubitzer, 2009], it is likely that the common ancestor of all rodents had a cortical organization that included these fields (fig. 23). In some species of rodents, additional visual fields have evolved. In other species, such as the smallbrained subterranean naked mole rat, visual fields appear to be reduced. Auditory cortex has also undergone similar expansions and contractions in different lineages. Since most rodents have a relatively homogeneous S1, the status of $S 1$ in the common ancestor may have been more like a squirrel with a partially embedded 3a/DZ; in murine rodents in particular, an elaborate integration of these 2 fields occurred, likely for swift and precise control of the whiskers. As in all rodents examined, it is likely that the facial morphology of the rodent common ancestor had an expanded representation.

Within the rodent order, there is considerable variability in the amount of cortex devoted to different sensory domains and to each area. When comparing homologous fields, the details of representation are also highly variable, the modular organization or extent of homogeneity of representation is different, and neuron number and density varies even within a species reared in different conditions. Finally, the total number of cortical fields is variable. These differences in sensory domain allocation, cortical field size, cortical field number, and magnification of representation are related to the morphological and behavioral specializations of each species. Because all behavior is mediated by the brain, and since the neocortex subserves complex behaviors, it is not surprising that differences at multiple levels of cortical organization are observed. Such differences are likely to be present at cellular and molecular levels as well.

When considering rodent models, it is critical to fully appreciate the extent of variability that rodents exhibit both in brain organization and behavior. In our quest for a ubiquitous animal model we sometimes ignore or forget the remarkable diversity of animals that evolution has produced. The push for translational studies in the neurosciences has moved us ever further from the importance of describing and understanding the possible. Of course, most current studies are driven by the extraordinary molecular manipulations that can be performed in mice, and we sometimes generate models 
of human behavior very far removed from the behavior of the animal that serves as that model. This leads to mouse models of higher-level function and dysfunction such as schizophrenia and even language. Despite the ease of performing molecular manipulations on 1 or 2 species of rodents, we should not settle for these models alone since in many instances mice may not necessarily be good models for other rodents, let alone humans. Moreover, laboratory-reared animals may not be accurate representatives of the species itself. Thus, when choosing an animal model for any given question, it is important to keep in mind the wonderful diversity that evolution has wrought and, of course, that all rodents are not the same.

\section{Acknowledgement}

Leah Krubitzer is support by NINDS (2 R01-NS035103, 2 R21NS07122502, and IOS-0743924); Katherine Campi has been supported by NEI (T 32 EYO15387) and NRSA (NS62633); Dylan Cooke is supported by NRSA (NS59262).

\section{References}

Akers RM, Killackey HP (1978): Organization of corticocortical connections in the parietal cortex of the rat. J Comp Neurol 181:513-537.

-Alloway KD (2008): Information processing streams in rodent barrel cortex: the differential functions of barrel and septal circuits. Cereb Cortex 18:979-989.

-Alloway KD, Smith J, Beauchemin K, Olson M (2009): Bilateral projections from rat M1 whisker cortex to the neostriatum, thalamus, and claustrum: forebrain circuits for modulating whisking behavior. J Comp Neurol 515:548-564.

Anderson B, Harvey T (1996): Alterations in cortical thickness and neuronal density in the frontal cortex of Albert Einstein. Neurosci Lett 210:161-164.

- Benison AM, Rector DM, Barth DS (2007): Hemispheric mapping of secondary somatosensory cortex in the rat. J Neurophysiol 97: 200-207.

Bravo H, Olavarria J, Torrealba F (1990): Comparative study of visual inter and intrahemispheric cortico-cortical connections in five native Chilean rodents. Anat Embryol (Berl) 181:67-73.

-Brecht M, Krauss A, Muhammad S, Sinai-Esfahani L, Bellanca S, Margrie TW (2004): Organization of rat vibrissa motor cortex and adjacent areas according to cytoarchitectonics, microstimulation, and intracellular stimulation of identified cells. J Comp Neurol 479:360-373.

-Brett-Green B, Fifkova E, Larue DT, Winer JA, Barth DS (2003): A multisensory zone in rat parietotemporal cortex: intra- and extracellular physiology and thalamocortical connections. J Comp Neurol 460:223-237.

-Brett-Green B, Paulsen M, Staba RJ, Fifkova E, Barth DS (2004): Two distinct regions of secondary somatosensory cortex in the rat: topographical organization and multisensory responses. J Neurophysiol 91:1327-1336.
Brodmann K (1909): Vergleichende Lokalisationslehre der Grosshirnrinde in ihren Prinzipien dargestellt auf Grund des Zellenbaues. Leipzig, Barth.

Bucci DJ (2009): Posterior parietal cortex: an interface between attention and learning? Neurobiol Learn Mem 91:114-120.

Budinger E, Heil P, Scheich H (2000): Functional organization of auditory cortex in the mongolian gerbil (Meriones unguiculatus). 3 . Anatomical subdivisions and corticocortical connections. Eur J Neurosci 12:2425-2451.

Campi KL, Collins CE, Todd WD, Kaas JL (2011): Comparison of area 17 cellular composition in laboratory and wild-caught rats including diurnal and nocturnal species. Brain Behav Evol, in press.

Campi KL, Karlen SJ, Bales KL, Krubitzer L (2007): Organization of sensory neocortex in prairie voles (Microtus ochrogaster). J Comp Neurol 502:414-426.

Campi KL, Krubitzer L (2010): Comparative studies of diurnal and nocturnal rodents: differences in lifestyle result in alterations in cortical field size and number. J Comp Neurol 518:4491-4512.

Campos GB, Welker WI (1976): Comparisons between brains of a large and a small hystricomorph rodent: capybara, Hydrochoerus and guinea pig, Cavia - neocortical projection regions and measurements of brain subdivisions. Brain Behav Evol 13:243-266.

Cang J, Renteria RC, Kaneko M, Liu X, Copenhagen DR, Stryker MP (2005): Development of precise maps in visual cortex requires patterned spontaneous activity in the retina. Neuron 48:797-809.

Carlson M, Welker WI (1976): Some morphological, physiological and behavioral specializations in North American beavers (Castor canadensis). Brain Behav Evol 13:302-326.

Carvell GE, Simons DJ (1987): Thalamic and corticocortical connections of the second somatic sensory area of the mouse. J Comp Neurol 265:409-427.
Catania KC, Henry EC (2006): Touching on somatosensory specializations in mammals. Curr Opin Neurobiol 16:467-473.

Caviness VS Jr (1975): Architectonic map of neocortex of the normal mouse. J Comp Neurol 164:247-263.

-Changizi MA (2001): Principles underlying mammalian neocortical scaling. Biol Cybern 84:207-215.

Chapin JK, Lin CS (1984): Mapping the body representation in the SI cortex of anesthetized and awake rats. J Comp Neurol 229:199-213.

Cicirata F, Angaut P, Cioni M, Serapide MF, Papale A (1986): Functional organization of thalamic projections to the motor cortex: an anatomical and electrophysiological study in the rat. Neuroscience 19:81-99.

Colechio EM, Alloway KD (2009): Differential topography of the bilateral cortical projections to the whisker and forepaw regions in rat motor cortex. Brain Struct Funct 213: 423-439.

Cooke DF, Padberg J, Zahner T, Grunewald BLK (2008): Complex movements evoked by microstimulation of motor cortex in the California ground squirrel (Spermophilus beecheyi) (abstract). Soc Neurosci p 27718.

Cooke DF, Padberg J, Zahner T, Krubitzer L (2007): Thalamocortical connections of motor and sensorimotor cortical fields in California ground squirrel (Spermophilus beecheyi) (abstract). Soc Neurosci 13:37493772.

Cooke DF, Padberg J, Zahner T, Krubitzer L (2011): The functional organization and cortical connections of motor cortex in squirrels. Submitted.

Dawson DR, Killackey HP (1987): The organization and mutability of the forepaw and hindpaw representations in the somatosensory cortex of the neonatal rat. J Comp Neurol 256:246-256. 
Diamond ME, von Heimendahl M, Knutsen PM, Gioanni Y, Lamarche M (1985): A reappraisal of Kleinfeld D, Ahissar E (2008): 'Where' and 'what' in the whisker sensorimotor system. Nat Rev Neurosci 9:601-612.

$\checkmark$ Donoghue JP, Parham C (1983): Afferent connections of the lateral agranular field of the rat motor cortex. J Comp Neurol 217:390-404.

Donoghue JP, Wise SP (1982): The motor cortex of the rat: cytoarchitecture and microstimulation mapping. J Comp Neurol 212:76-88.

$\checkmark$ Doron NN, Ledoux JE, Semple MN (2002): Redefining the tonotopic core of rat auditory cortex: physiological evidence for a posterior field. J Comp Neurol 453:345-360.

$\checkmark$ Drager UC (1975): Receptive fields of single cells and topography in mouse visual cortex. J Comp Neurol 160:269-290.

-Espinoza SG, Thomas HC (1983): Retinotopic organization of striate and extrastriate visual cortex in the hooded rat. Brain Res 272: 137-144.

Fabri M, Burton H (1991a): Topography of connections between primary somatosensory cortex and posterior complex in rat: a multiple fluorescent tracer study. Brain Res 538: 351-357.

Fabri M, Burton H (1991b): Ipsilateral cortical connections of primary somatic sensory cortex in rats. J Comp Neurol 311:405-424.

Faherty CJ, Kerley D, Smeyne RJ (2003): A GolgiCox morphological analysis of neuronal changes induced by environmental enrichment. Brain Res Dev Brain Res 141:55-61.

-Felleman DJ, Wall JT, Cusick CG, Kaas JH (1983): The representation of the body surface in S-I of cats. J Neurosci 3:1648-1669.

-Foeller E, Feldman DE (2004): Synaptic basis for developmental plasticity in somatosensory cortex. Curr Opin Neurobiol 14:89-95.

Frostig RD (2006): Functional organization and plasticity in the adult rat barrel cortex: moving out-of-the-box. Curr Opin Neurobiol 16: 445-450.

- Furrer RD, Manser MB (2009): The evolution of urgency-based and functionally referential alarm calls in ground-dwelling species. Am Nat 173:400-410.

-Gaillard F, Bonfield S, Gilmour GS, Kuny S, Mema SC, Martin BT, Smale L, Crowder N, Stell WK, Sauve Y (2008): Retinal anatomy and visual performance in a diurnal conerich laboratory rodent, the Nile grass rat (Arvicanthis niloticus). J Comp Neurol 510:525538.

Gaillard F, Kuny S, Sauve Y (2009): Topographic arrangement of S-cone photoreceptors in the retina of the diurnal Nile grass rat (Arvicanthis niloticus). Invest Ophthalmol Vis Sci 50: 5426-5434.

-Gelfo F, De Bartolo P, Giovine A, Petrosini L, Leggio MG (2009): Layer and regional effects of environmental enrichment on the pyramidal neuron morphology of the rat. Neurobiol Learn Mem 91:353-365. rat motor cortex organization by intracortical microstimulation. Brain Res 344:49-61.

- Girman SV, Sauve Y, Lund RD (1999): Receptive field properties of single neurons in rat primary visual cortex. J Neurophysiol 82:301311.

Gould HJ 3rd (1984): Interhemispheric connections of the visual cortex in the grey squirrel (Sciurus carolinensis). J Comp Neurol 223: 259-301.

Haiss F, Schwarz C (2005): Spatial segregation of different modes of movement control in the whisker representation of rat primary motor cortex. J Neurosci 25:1579-1587.

Hall RD, Lindholm EP (1974): Organization of motor and somatosensory neocortex in the albino rat. Brain Res 66:23-38.

Hall WC, Kaas JH, Killackey H, Diamond IT (1971): Cortical visual areas in the grey squirrel (Sciurus carolinesis): a correlation between cortical evoked potential maps and architectonic subdivisions. J Neurophysiol 34:437-452.

Harel N, Mori N, Sawada S, Mount RJ, Harrison RV (2000): Three distinct auditory areas of cortex (AI, AII, and AAF) defined by optical imaging of intrinsic signals. Neuroimage 11: 302-312.

- Harrison RV, Kakigi A, Hirakawa H, Harel N, Mount RJ (1996): Tonotopic mapping in auditory cortex of the chinchilla. Hear Res 100: 157-163.

Hashimoto H, Moritani N, Aoki-Komori S, Tanaka M, Saito TR (2004): Comparison of ultrasonic vocalizations emitted by rodent pups. Exp Anim 53:409-416.

Heimel JA, Van Hooser SD, Nelson SB (2005): Laminar organization of response properties in primary visual cortex of the gray squirrel (Sciurus carolinensis). J Neurophysiol 94: 3538-3554.

-Henry EC, Remple MS, O’Riain MJ, Catania KC (2006): Organization of somatosensory cortical areas in the naked mole-rat (Heterocephalus glaber). J Comp Neurol 495:434452.

Herculano-Houzel S (2007): Encephalization, neuronal excess, and neuronal index in rodents. Anat Rec (Hoboken) 290:1280-1287.

Herculano-Houzel S (2011): Not all brains are made the same: new views on brain scaling in evolution. Brain Behav Evol 78:22-36.

-Herculano-Houzel S, Mota B, Lent R (2006): Cellular scaling rules for rodent brains. Proc Natl Acad Sci USA 103:12138-12143.

- Horikawa J, Hess A, Nasu M, Hosokawa Y, Scheich H, Taniguchi I (2001): Optical imaging of neural activity in multiple auditory cortical fields of guinea pigs. Neuroreport 12:3335-3339.

Hosokawa Y, Sugimoto S, Kubota M, Taniguchi I, Horikawa J (2004): Optical imaging of binaural interaction in multiple fields of the guinea pig auditory cortex. Neuroreport 15:1093-1097.
Huchon D, Chevret P, Jordan U, Kilpatrick CW, Ranwez V, Jenkins PD, Brosius J, Schmitz J (2007): Multiple molecular evidences for a living mammalian fossil. Proc Natl Acad Sci USA 104:7495-7499.

-Huchon D, Madsen O, Sibbald MJ, Ament K, Stanhope MJ, Catzeflis F, de Jong WW, Douzery EJ (2002): Rodent phylogeny and a timescale for the evolution of Glires: evidence from an extensive taxon sampling using three nuclear genes. Mol Biol Evol 19: 1053-1065.

Huffman KJ, Krubitzer LA (2001): Area 3a: topographic organization and connections in marmoset monkeys. Cerebral Cortex 11: 849-867.

-Husson TR, Mallik AK, Zhang JX, Issa NP (2007): Functional imaging of primary visual cortex using flavoprotein autofluorescence. J Neurosci 27:8665-8675.

Inan M, Crair MC (2007): Development of cortical maps: perspectives from the barrel cortex. Neuroscientist 13:49-61.

Innocenti GM, Fiore L (1976): Morphological correlates of visual field transformation in the corpus callosum. Neurosci Lett 2:245-252.

Jacobs GH, Birch DG, Blakeslee B (1982): Visual acuity and spatial contrast sensitivity in tree squirrels. Behav Processes 7:367-375.

Jameie SB, Abdolrahmani M, Nobakht M (2010): Effects of total light deprivation on dorsal lateral geniculate nucleus of male neonate rats. Oman Med J 25:179-183.

Jones EG, Burton H (1976): Areal differences in the laminar distribution of thalamic afferents in cortical fields of the insular, parietal and temporal regions of primates. J Comp Neurol 168:197-247.

Kaas JH (2008): The evolution of the complex sensory and motor systems of the human brain. Brain Res Bull 75:384-390.

Kaas JH (2010): The evolution of auditory cortex: the core areas; in Weiner JA, Schreiner CE (eds): The Auditory Cortex. New York, Springer Science+Business Media LLC.

Kaas JH, Hall WC, Diamond IT (1972): Visual cortex of the grey squirrel (Sciurus carolinensis): architectonic subdivisions and connections from the visual thalamus. J Comp Neurol 145:273-305.

Kaas JH, Krubitzer LA, Johanson KL (1989): Cortical connections of areas 17 (V-I) and 18 (V-II) of squirrels. J Comp Neurol 281:426446

Kalatsky VA, Polley DB, Merzenich MM, Schreiner CE, Stryker MP (2005): Fine functional organization of auditory cortex revealed by Fourier optical imaging. Proc Natl Acad Sci USA 102:13325-13330.

Kalatsky VA, Stryker MP (2003): New paradigm for optical imaging: temporally encoded maps of intrinsic signal. Neuron 38:529-545.

Karlen SJ, Krubitzer L (2006): Phenotypic diversity is the cornerstone of evolution: variation in cortical field size within short-tailed opossums. J Comp Neurol 499:990-999. 
-Kaskan PM, Franco EC, Yamada ES, Silveira LC, Darlington RB, Finlay BL (2005): Peripheral variability and central constancy in mammalian visual system evolution. Proc Biol Sci 272:91-100.

- Keller J, Strasburger H, Cerutti DT, Sabel BA (2000): Assessing spatial vision - automated measurement of the contrast-sensitivity function in the hooded rat. J Neurosci Methods 97:103-110.

Kennedy H, Dehay C, Bullier J (1986): Organization of the callosal connections of visual areas V1 and V2 in the macaque monkey. J Comp Neurol 247:398-415.

-King VR, Corwin JV (1993): Comparisons of hemi-inattention produced by unilateral lesions of the posterior parietal cortex or medial agranular prefrontal cortex in rats: neglect, extinction, and the role of stimulus distance. Behav Brain Res 54:117-131.

Kiriazis J, Slobodchikoff CN (2006): Perceptual specificity in the alarm calls of Gunnison's prairie dogs. Behav Processes 73:29-35.

Kleinfeld D, Ahissar E, Diamond ME (2006): Active sensation: insights from the rodent vibrissa sensorimotor system. Curr Opin Neurobiol 16:435-444.

-Kleim JA, Barbay S, Nudo RJ (1998): Functional reorganization of the rat motor cortex following motor skill learning. J Neurophysiol 80:3321-3325.

Kolb B, Gibb R, Gorny G (2003): Experience-dependent changes in dendritic arbor and spine density in neocortex vary qualitatively with age and sex. Neurobiol Learn Mem 79:1-10.

Komitova M, Mattsson B, Johansson BB, Eriksson PS (2005): Enriched environment increases neural stem/progenitor cell proliferation and neurogenesis in the subventricular zone of stroke-lesioned adult rats. Stroke 36: $1278-1282$.

Koprowski JL (1994): Sciurus carolinensis. Lawrence, Allen Press.

Krubitzer L (2009): In search of a unifying theory of complex brain evolution. Ann NY Acad Sci 1156:44-67.

Krubitzer L, Disbrow E (2010): The evolution of parietal areas involved in hand use in primates; in Dolins EL, Mitchell RW (eds): Spatial Cognition, Spatial Perception. Cambridge, Cambridge University Press, pp 365-421.

Krubitzer L, Manger P, Pettigrew J, Calford M (1995): Organization of somatosensory cortex in monotremes: in search of the prototypical plan. J Comp Neurol 351:261-306.

Krubitzer LA (1996): The organization of lateral somatosensory areas in primates and other mammals; in Franzen O, Johanson R, Terenius L (eds): Somethesis and the Neurobiology of the Somatosensory Cortex, International Symposium Series. Boston, Birkhäuser, pp 173-185.

Krubitzer LA, Kaas JH (1987): Thalamic connections of three representations of the body surface in somatosensory cortex of gray squirrels. J Comp Neurol 265:549-580.
Krubitzer LA, Kaas JH (1989): Cortical integration of parallel pathways in the visual system of primates. Brain Res 478:161-165.

-Krubitzer LA, Kaas JH (1990): Cortical connections of MT in four species of primates: areal, modular, and retinotopic patterns. Vis Neurosci 5:165-204.

Krubitzer L, Künzle H, Kaas J (1997): Organization of sensory cortex in a madagascan insectivore, the tenrec (Echinops telfairi). J Comp Neurol 379:399-414.

Krubitzer LA, Sesma MA, Kaas JH (1986): Microelectrode maps, myeloarchitecture, and cortical connections of three somatotopically organized representations of the body surface in the parietal cortex of squirrels. J Comp Neurol 250:403-430.

Krubitzer LA, Tweedale R, Clarey JC, Calford M (1992): Interhemispheric connections of somatosensory cortex in the flying fox (Pteropus poliocephalus) (abstract). Soc Neurosci 18:1544.

Lee T, Alloway KD, Kim U (2011): Interconnected cortical networks between primary somatosensory cortex septal columns and posterior parietal cortex in rat. J Comp Neurol 519:405-419.

Lende RA, Woolsey CN (1956): Sensory and motor localization in cerebral cortex of porcupine (Erethizon dorsatum). J Neurophysiol 19:544-563.

Li CX, Waters RS (1991): Organization of the mouse motor cortex studied by retrograde tracing and intracortical microstimulation (ICMS) mapping. Can J Neurol Sci 18:28-38.

Lin CS, Weller RE, Kaas JH (1982): Cortical connections of striate cortex in the owl monkey. J Comp Neurol 211:165-176.

Luethke LE, Krubitzer LA, Kaas JH (1988): Cortical connections of electrophysiologically and architectonically defined subdivisions of auditory cortex in squirrels. J Comp Neurol 268:181-203.

Lyon DC, Kaas JH (2002): Evidence from V1 connections for both dorsal and ventral subdivisions of $\mathrm{V} 3$ in three species of New World monkeys. J Comp Neurol 449:281-297.

Malach R (1989): Patterns of connections in rat visual cortex. J Neurosci 9:3741-3752.

-Manger PR, Cort J, Ebrahim N, Goodman A, Henning J, Karolia M, Rodrigues SL, Strkalj G (2008): Is 21st century neuroscience too focussed on the rat/mouse model of brain function and dysfunction? Front Neuroanat 2:5.

Mateo JM (1996): Early auditory experience and the ontogeny of alarm-call discrimination in Belding's ground squirrels (Spermophilus beldingi). J Comp Psychol 110:115-124.

-Matrosova VA, Volodin IA, Volodina EV, Vasilieva NA (2010): Stability of acoustic individuality in the alarm calls of wild yellow ground squirrels Spermophilus fulvus and contrasting calls from trapped and freeranging callers. Naturwissenschaften 97: 707-715.
Matyas F, Sreenivasan V, Marbach F, Wacongne C, Barsy B, Mateo C, Aronoff R, Petersen CC (2010): Motor control by sensory cortex. Science 330:1240-1243.

McCowan B, Hooper SL (2002): Individual acoustic variation in Belding's ground squirrel alarm chirps in the High Sierra Nevada. J Acoust Soc Am 111:1157-1160.

Merzenich MM, Kaas JH, Roth GL (1976): Auditory cortex in the grey squirrel: tonotopic organization and architectonic fields. J Comp Neurol 166:387-401.

Metin C, Godement P, Imbert M (1988): The primary visual cortex in the mouse: receptive field properties and functional organization. Exp Brain Res 69:594-612.

Mohammed AH, Zhu SW, Darmopil S, HjerlingLeffler J, Ernfors P, Winblad B, Diamond MC, Eriksson PS, Bogdanovic N (2002): Environmental enrichment and the brain. Prog Brain Res 138:109-133.

Montero VM (1973): Evoked responses in the rat's visual cortex to contralateral, ipsilateral and restricted photic stimulation. Brain Res 53:192-196.

-Montero VM, Bravo H, Fernandez V (1973b): Striate-peristriate cortico-cortical connections in the albino and gray rat. Brain Res 53: 202-207.

Montero VM, Rojas A, Torrealba F (1973a): Retinotopic organization of striate and peristriate visual cortex in the albino rat. Brain Res 53:197-201.

Motomura N, Shimizu K, Shimizu M, Aoki-Komori S, Taniguchi K, Serizawa I, Saito TR (2002): A comparative study of isolation-induced ultrasonic vocalization in rodent pups. Exp Anim 51:187-190.

Neafsey EJ, Bold EL, Haas G, Hurley-Gius KM, Quirk G, Sievert CF, Terreberry RR (1986): The organization of the rat motor cortex: a microstimulation mapping study. Brain Res 396:77-96.

Neafsey EJ, Sievert C (1982): A second forelimb motor area exists in rat frontal cortex. Brain Res 232:151-156.

Nelson RJ, Sur M, Kaas JH (1979): The organization of the second somatosensory area (SmII) of the grey squirrel. J Comp Neurol 184:473489.

Niell CM, Stryker MP (2008): Highly selective receptive fields in mouse visual cortex. J Neurosci 28:7520-7536.

Nitz D (2009): Parietal cortex, navigation, and the construction of arbitrary reference frames for spatial information. Neurobiol Learn Mem 91:179-185.

-Olavarria J, Mignano LR, Van Sluyters RC (1982): Pattern of extrastriate visual areas connecting reciprocally with striate cortex in the mouse. Exp Neurol 78:775-779.

Olavarria J, Montero VM (1981): Reciprocal connections between the striate cortex and extrastriate cortical visual areas in the rat. Brain Res 217:358-363. 
- Olavarria J, Montero VM (1984): Relation of callosal and striate-extrastriate cortical connections in the rat: morphological definition of extrastriate visual areas. Exp Brain Res 54: 240-252.

-Olavarria J, Montero VM (1989): Organization of visual cortex in the mouse revealed by correlating callosal and striate-extrastriate connections. Vis Neurosci 3:59-69.

-Olavarria J, Montero V (1990): Elaborate organization of visual cortex in the hamster. Neurosci Res 8:40-47.

-Paolini M, Sereno MI (1998): Direction selectivity in the middle lateral and lateral (ML and L) visual areas in the California ground squirrel. Cereb Cortex 8:362-371.

- Papadopoulos GC, Michaloudi HC (1999): Apoptosis in the visual system of normal and dark-reared rats. Brain Res 838:214-217.

$\checkmark$ Penfield W, Boldrey E (1937): Somatic motor and sensory representation in the cerebral cortex of man as studied by electrical stimulation. Brain 60:389-443.

Penfield W, Welch K (1949): The supplementary motor area in the cerebral cortex of man. Trans Am Neurol Assoc 74:179-184.

- Peters A, Kara DA, Harriman KM (1985): The neuronal composition of area 17 of rat visual cortex. 3. Numerical considerations. J Comp Neurol 238:263-274.

- Petersen CC (2007): The functional organization of the barrel cortex. Neuron 56:339-355.

-Pimentel-Souza F, Cosenza RM, Campos GB, Johnson JI (1980): Somatic sensory cortical regions of the agouti, Dasyprocta aguti. Brain Behav Evol 17:218-240.

- Polley DB, Read HL, Storace DA, Merzenich MM (2007): Multiparametric auditory receptive field organization across five cortical fields in the albino rat. J Neurophysiol 97: 3621-3638.

Porter LL, White EL (1983): Afferent and efferent pathways of the vibrissal region of primary motor cortex in the mouse. J Comp Neurol 214:279-289.

- Pronichev IV, Lenkov DN (1998): Functional mapping of the motor cortex of the white mouse by a microstimulation method. Neurosci Behav Physiol 28:80-85.

- Prusky GT, Alam NM, Beekman S, Douglas RM (2004): Rapid quantification of adult and developing mouse spatial vision using a virtual optomotor system. Invest Ophthalmol Vis Sci 45:4611-4616.

Qi H-X, Kaas JH (2008): Somatosensory areas of the cerebral cortex: architectonic characteristics and modular organization; in Kaas JH, Gardner E (eds): The Senses: A Comprehensive Reference. London, Elsevier, vol 6, p 143.

-Ramanathan D, Conner JM, Tuszynski MH (2006): A form of motor cortical plasticity that correlates with recovery of function after brain injury. Proc Natl Acad Sci USA 103: 11370-11375.
Randall JA, McCowan B, Collins KC, Hooper SL, Rogovin K (2005): Alarm signals of the great gerbil: acoustic variation by predator context, sex, age, individual, and family group. J Acoust Soc Am 118:2706-2714.

Reep RL, Chandler HC, King V, Corwin JV (1994): Rat posterior parietal cortex: topography of corticocortical and thalamic connections. Exp Brain Res 100:67-84.

Reep RL, Corwin JV (2009): Posterior parietal cortex as part of a neural network for directed attention in rats. Neurobiol Learn Mem 91:104-113.

Remple MS, Henry EC, Catania KC (2003): Organization of somatosensory cortex in the laboratory rat (Rattus norvegicus): evidence for two lateral areas joined at the representation of the teeth. J Comp Neurol 467:105118.

Ringo JL (1991): Neuronal interconnection as a function of brain size. Brain Behav Evol 38: $1-6$.

-Ringo JL, Doty RW, Demeter S, Simard PY (1994): Time is of the essence: a conjecture that hemispheric specialization arises from interhemispheric conduction delay. Cereb Cortex 4:331-343.

Rocha FA, Ahnelt PK, Peichl L, Saito CA, Silveira LC, De Lima SM (2009): The topography of cone photoreceptors in the retina of a diurnal rodent, the agouti (Dasyprocta aguti). Vis Neurosci 26:167-175.

Rosa MG, Krubitzer LA (1999): The evolution of visual cortex: where is V2? Trends Neurosci 22:242-248.

Roth G, Dicke U (2005): Evolution of the brain and intelligence. Trends Cogn Sci 9:250-257.

Rumberger A, Tyler CJ, Lund JS (2001): Intraand inter-areal connections between the primary visual cortex $\mathrm{V} 1$ and the area immediately surrounding V1 in the rat. Neuroscience 102:35-52.

Santiago LF, Rocha EG, Freire MA, Dias IA, Lent R, Houzel JC, Picanco-Diniz CW, Pereira A Jr, Franca JG (2007): The organizational variability of the rodent somatosensory cortex. Rev Neurosci 18:283-294.

-Sarko DK, Leitch DB, Girard I, Sikes RS, Catania KC (2011): Organization of somatosensory cortex in the northern grasshopper mouse (Onychomys leucogaster), a predatory rodent. J Comp Neurol 519:64-74.

-Schuett S, Bonhoeffer T, Hubener M (2002): Mapping retinotopic structure in mouse visual cortex with optical imaging. J Neurosci 22:6549-6559.

Segraves MA, Rosenquist AC (1982): The distribution of the cells of origin of callosal projections in cat visual cortex. J Neurosci 2:1079-1089.

Sereno MI, Rodman HR, Karten HJ (1991): Organization of visual cortex in the California ground squirrel (abstract). Soc Neurosci 17: 844.
Sesma MA, Casagrande VA, Kaas JH (1984): Cortical connections of area 17 in tree shrews. J Comp Neurol 230:337-351.

-Slobodchikoff CN, Paseka A, Verdolin JL (2009): Prairie dog alarm calls encode labels about predator colors. Anim Cogn 12:435-439.

-Slutsky DA, Manger PR, Krubitzer L (2000): Multiple somatosensory areas in the anterior parietal cortex of the California ground squirrel (Spermophilus beecheyii). J Comp Neurol 416:521-539.

- Solovei I, Kreysing M, Lanctot C, Kosem S, Peichl L, Cremer T, Guck J, Joffe B (2009): Nuclear architecture of rod photoreceptor cells adapts to vision in mammalian evolution. Cell 137:356-368.

-Steiner B, Winter C, Hosman K, Siebert E, Kempermann G, Petrus DS, Kupsch A (2006): Enriched environment induces cellular plasticity in the adult substantia nigra and improves motor behavior function in the 6-OHDA rat model of Parkinson's disease. Exp Neurol 199:291-300.

-Steppan SJ, Storz BL, Hoffmann RS (2004): Nuclear DNA phylogeny of the squirrels (Mammalia: Rodentia) and the evolution of arboreality from c-myc and RAG1. Mol Phylogenet Evol 30:703-719.

Stiebler I (1987): A distinct ultrasound-processing area in the auditory cortex of the mouse. Naturwissenschaften 74:96-97.

Stiebler I, Neulist R, Fichtel I, Ehret G (1997): The auditory cortex of the house mouse: leftright differences, tonotopic organization and quantitative analysis of frequency representation. J Comp Physiol A 181:559-571.

-Sur M, Nelson RJ, Kaas JH (1978): The representation of the body surface in somatosensory area I of the grey squirrel. J Comp Neurol 179:425-449.

Tandon S, Kambi N, Jain N (2008): Overlapping representations of the neck and whiskers in the rat motor cortex revealed by mapping at different anaesthetic depths. Eur J Neurosci 27:228-237.

- Taniguchi I, Horikawa J, Moriyama T, Nasu M (1992): Spatio-temporal pattern of frequency representation in the auditory cortex of guinea pigs. Neurosci Lett 146:37-40.

Tennant KA, Adkins DL, Donlan NA, Asay AL, Thomas N, Kleim JA, Jones TA (2010): The organization of the forelimb representation of the C57BL/6 mouse motor cortex as defined by intracortical microstimulation and cytoarchitecture. Cereb Cortex 21:865-876.

Thomas H, Tillein J (1997): Functional organization of the auditory cortex in a native Chilean rodent (Octodon degus). Biol Res 30:137148.

Thomas H, Tillein J, Heil P, Scheich H (1993): Functional organization of auditory cortex in the mongolian gerbil (meriones unguiculatus). 1. Electrophysiological mapping of frequency representation and distinction of fields. Eur J Neurosci 5:882-897. 
Thomas HC, Espinoza SG (1987): Relationships between interhemispheric cortical connections and visual areas in hooded rats. Brain Res 417:214-224.

Tiao YC, Blakemore C (1976): Functional organization in the visual cortex of the golden hamster. J Comp Neurol 168:459-481.

Torrealba F, Valdes JL (2008): The parietal association cortex of the rat. Biol Res 41:369377.

Turner AM, Greenough WT (1985): Differential rearing effects on rat visual cortex synapses. 1. Synaptic and neuronal density and synapses per neuron. Brain Res 329:195-203.

-Van der Gucht E, Hof PR, Van Brussel L, Burna K, Arckens L (2007): Neurofilament protein and neuronal activity markers define regional architectonic parcellation in the mouse visual cortex. Cereb Cortex 17:2805-2819.

-Van Hooser SD (2007): Similarity and diversity in visual cortex: is there a unifying theory of cortical computation? Neuroscientist 13 . 639-656.

-Van Hooser SD, Heimel JA, Chung S, Nelson SB Toth LJ (2005): Orientation selectivity without orientation maps in visual cortex of a highly visual mammal. J Neurosci 25:19-28.

-Van Hooser SD, Nelson SB (2006): The squirrel as a rodent model of the human visual system. Vis Neurosci 23:765-778.

-Wagor E, Mangini NJ, Pearlman AL (1980): Retinotopic organization of striate and extrastriate visual cortex in the mouse. J Comp Neurol 193:187-202.

-Wallace MN, Rutkowski RG, Palmer AR (2000): Identification and localisation of auditory areas in guinea pig cortex. Exp Brain Res 132 445-456.

-Wang Q, Burkhalter A (2007): Area map of mouse visual cortex. J Comp Neurol 502: 339-357.
Wang Q, Gao E, Burkhalter A (2011): Gateways of ventral and dorsal streams in mouse visual cortex. J Neurosci 31:1905-1918.

-Welker C (1971): Microelectrode delineation of fine grain somatotopic organization of (SmI) cerebral neocortex in albino rat. Brain Res 26:259-275.

Welker C, Sinha MM (1972): Somatotopic organization of SmII cerebral neocortex in albino rat. Brain Res 37:132-136.

Wise SP, Jones EG (1978): Developmental studies of thalamocortical and commissural connections in the rat somatic sensory cortex. J Comp Neurol 178:187-208.

Wise SP, Murray EA, Coulter JD (1979): Somatotopic organization of corticospinal and corticotrigeminal neurons in the rat. Neuroscience 4:65-78.

Wong P, Gharbawie OA, Luethke LE, Kaas JH (2008): Thalamic connections of architectonic subdivisions of temporal cortex in grey squirrels (Sciurus carolinensis). J Comp Neurol 510:440-461.

Wong P, Kaas JH (2008): Architectonic subdivisions of neocortex in the gray squirrel ( $\mathrm{Sci}$ urus carolinensis). Anat Rec (Hoboken) 291: 1301-1333.

Woolsey CN (1947): Patterns of sensory representation in the cerebral cortex. Fed Proc 6: 437-441.

Woolsey CN, Fairman D (1946): Contralateral, ipsilateral, and bilateral representation of cutaneous receptors in somatic areas I and II of the cerebral cortex of pig, sheep, and other mammals. Surgery 19:684-702.

Woolsey CN, Settlage PH, Meyer DR, Sencer W, Pinto Hamuy T, Travis AM (1952): Patterns of localization in precentral and 'supplementary' motor areas and their relation to the concept of a premotor area. Res Publ Assoc Res Nerv Ment Dis 30:238-264.
Woolsey TA (1967): Somatosensory, auditory and visual cortical areas of the mouse. Johns Hopkins Med J 121:91-112.

Woolsey TA, Van der Loos H (1970): The structural organization of layer IV in the somatosensory region (SI) of mouse cerebral cortex: the description of a cortical field composed of discrete cytoarchitectonic units. Brain Res 17:205-242.

Woolsey TA, Welker C, Schwartz RH (1975): Comparative anatomical studies of the $\mathrm{SmL}$ face cortex with special reference to the occurrence of 'barrels' in layer IV. J Comp Neurol 164:79-94.

Wree A, Zilles K, Schleicher A (1981): A quantitative approach to cytoarchitectonics. 7. The areal pattern of the cortex of the guinea pig. Anat Embryol (Berl) 162:81-103.

Wree A, Zilles K, Schleicher A (1983): A quantitative approach to cytoarchitectonics. 7 . The areal pattern of the cortex of the albino mouse. Anat Embryol (Berl) 166:333-353.

Young NA, Vuong J, Flynn C, Teskey GC (2011): Optimal parameters for microstimulation derived forelimb movement thresholds and motor maps in rats and mice. J Neurosci Methods 196:60-69.

Zhang K, Sejnowski TJ (2000): A universal scaling law between gray matter and white matter of cerebral cortex. Proc Natl Acad Sci USA 97:5621-5626.

Zilles K, Zilles B, Scheicher A (1980): A quantitative approach to cytoarchitectonics. 6 . The areal pattern of the cortex of the albino rat. Anat Embryol (Berl) 159:335-360. 